\title{
3 Direktes und offenes Polemisieren bei Melchior Hoffman
}

\subsection{Der Streit mit Nikolaus von Amsdorf I: Die Hintergründe}

I 526 formulierte Melchior Hoffman in seiner Auslegung des I 2 . Kapitels des Buches Daniel35r erstmals schriftlich seine apokalyptische Lehre. Die Welt schien für Hoffman an einem Punkt angelangt, an dem nur noch eine apokalyptische Reinigung, ein Trennen der ,Spreu vom Weizen ${ }^{6352}$ durch den Schöpfer, die Weltordnung wieder herstellen könnte. ${ }^{353}$ Hoffman war nicht allein mit seinen apokalyptischen Visionen. Die im I6. Jahrhundert üblichen Endzeitvorstellungen lassen sich aus einer intensiven Sehnsucht nach einer neuen, besseren Welt und der endzeitlichen Stimmung dieser Zeit erklären: Vermehrte Naturkatastrophen, Dürreperioden, Epidemien (z. B. die Pest) sowie die ,Enthüllung' des Antichristen unter dem Papstgewand wurden vor dem

${ }^{351}$ Hoffman, Melchior (I 526): Das xij Capitel des prophetē Danielis außgelegt / und das ewangelion des andern sondages / gefallendt im Aduent / vnd von den zeychenn des iüngsten gerichtes / auch vom sacrament / beicht vnd absolucion / eyn schöne vnterweisung an die in Lieflandt / vnd eym yden christen nutzlich zu wissen. M dxxvj. [Stockholm: Königliche Druckerei]. Kurztitel: Das xij Capitel [...] Danielis oder Daniel-Auslegung.

352 Vgl. zum Beispiel: „Dat ander wert sick all sůluest finden vnde begeuen mit der tydt / dat de důuel vnde dat kaff [die Spreu] / vnde de valsche buecknecht [Bauchknechte] wert geapenbaret werden. "Hoffman ( 1528 ): Dat Nicolaus Amsdorff, A4r.

353 Die Reform der evangelischen Bewegung Luthers, insbesondere nach dem Bauernkrieg I 525 , schienen ihm nicht die gewünschten Effekte erreicht zu haben. Die angestrebten Veränderungen versprachen ihm wohl nicht, die elementaren sozialen Missstände auszumerzen, die er als Handwerker zu spüren bekam, den Menschen zu einem besseren zu machen und die Weltordnung herzustellen, die ihm vorschwebte.

How to cite this book chapter:

Lundström, Kerstin. 2015. Direktes und offenes Polemisieren bei Melchior Hoffman. In: Lundström, Kerstin. Polemik in den Schriften Melchior Hoffmans: Inszenierungen rhetorischer Streitkultur in der Reformationszeit, Pp. 118-205. Stockholm: Stockholm University Press. DOI: http://dx.doi.org/10.16993/bae.c. License: CC-BY 
Hintergrund des religiösen Weltbilds als apokalyptische Vorzeichen interpretiert. ${ }^{354}$ Hoffmans Lehre vom Jüngsten Tag ging in ihrer Intensität und Konkretheit jedoch weiter als die meisten eschatologischen Anschauungen seiner Zeit, denn er glaubte, einen Zeitpunkt in naher Zukunft errechnen zu können. Er behauptete - und dies sah er mit dem I2. Kapitel des Buches Daniel und der Offenbarung des Johannes belegt -, dass die Rechnung zum Jüngsten Tag bereits begonnen hätte und sich binnen der kommenden sieben Jahre, also bis zum Jahre I 533 , erfüllen würde. Über diese Berechnung des Jüngsten Tages geriet er in den einzig erhaltenen Schriftwechsel seiner Laufbahn. ${ }^{355}$ Erstmals geriet er in einen persönlichen Streit mit einem lutherischen Reformator, dem Magdeburger Superintendenten Nikolaus von Amsdorf, der in mehreren polemischen Schriften und Gegenschriften ausgetragen wurde. Insgesamt dauerte der Streitschriftenwechsel mit Amsdorf von Herbst I 527 bis Spätsommer I 528 an. Im Rahmen dieses Schriftwechsels wurden zwischen den beiden beteiligten Schreibern fünf Schriften ausgetauscht: Drei stammen aus der Feder Amsdorfs, die anderen zwei verfasste Hoffman.

In den folgenden Ausführungen sollen im Besonderen diese zwei Schriften Hoffmans im Zentrum der Untersuchungen stehen. Bevor die einzelnen Schriften erörtert werden, wird zunächst Hoffmans Wirken in Holstein beleuchtet und die Entstehung des Streits skizziert. Ziel ist es, eine kontextuelle Basis der Ereignisse zu schaffen, in die der Schriftwechsel eingebettet ist. Daran anschließend wird diskutiert, unter welchen Bedingungen die Drucke von Amsdorf und Hoffman entstanden sind. Da Hoffman nicht nur als Verfasser, sondern auch als Drucker seiner Texte fungierte, bedarf es einer näheren Betrachtung der jeweiligen Umstände der Drucklegung. Auf die Erläuterungen der Hintergründe folgen eingehende Untersuchungen der Polemik Hoffmans: Unter Berücksichtigung von Amsdorfs Schriften, der chronologischen Abfolge und der kausalen Zusammenhänge des Schriftwechsels werden

354 Vgl. Aertsen, Jan A. (2002): „Ende und Vollendung: Eschatologische Perspektiven im Mittelalter. Einleitung “. In: Ders. \& Martin Pickavé (Hg.): Ende und Vollendung: Eschatologische Perspektiven im Mittelalter. Berlin \& New York: De Gruyter, S. 69-75.

355 Es ist zwar aus den Quellen bekannt, dass Hoffman noch einen Schriftwechsel mit Marquard Schuldorp geführt hat, aber da die Überlieferung sehr spärlich ist und die meisten Schriften nicht erhalten geblieben sind, kann hier nur der Schriftwechsel zwischen Hoffman und Amsdorf untersucht werden. Weitere Schriftwechsel zu einem späteren Zeitpunkt sind der Forschung jedoch nicht bekannt. 
Hoffmans Schriften auf die Formen des Polemisierens und die einzelnen polemischen Strategien hin analysiert.

\subsubsection{Melchior Hoffman in Schleswig-Holstein (1527-1529)}

Anfang des Jahres 527 zog Melchior Hoffman von Stockholm mit einem kurzen Zwischenhalt in Lübeck nach Kiel im zu der Zeit dänischen Holstein. König Friedrich I. von Dänemark rief Hoffman laut dessen eigener Beschreibung im Dialogus zu sich,

nam jn [...] an für seinen diener / vnd gab jm brieff vnnd sigel im gantzen land zů Holstē das wort gots zů predigen / wo es jm geliebet / vnd befestiget in fürnemlich zum Kyll / zů einem prediger / nam all sein hab vnd gůt in seinen schutz / weib / kind / vnd all die seinen / zů handthaben / schützen / vnd beschirmē / in allen rechtfertigen Christlichen Sachen. ${ }^{356}$

Hoffman kam demnach als Laienprediger an die Nikolaikirche in Kiel, wo sich ebenfalls der altgläubige Kirchenvorsteher Wilhelm Pravest sowie der Diakon und Luther-Schüler Marquard Schuldorp befanden. Das Zusammentreffen dreier voneinander divergierender Parteien des christlichen Glaubens versprach Auseinandersetzungen, die nicht lange auf sich warten ließen. Hoffman beschuldigte den Rat der Stadt, Kirchengut veruntreut zu haben, was ihm den Zorn der Obrigkeiten einbrachte. Schuldorp missbilligte Hoffmans aufrührerische Predigten, die den Obrigkeiten gegenüber kritisch waren, und meinte, Hoffmans Anhänger wären weniger an religiösen Fragen als an einem Aufstand interessiert. ${ }^{357}$ Zudem kritisierte Schuldorp, dass Hoffman die Aufgabe eines Predigers, nämlich die Unterstützung der weltlichen Obrigkeit, nicht wahrgenommen hätte. Mit Hinblick auf den Bauernkrieg ( I 525 ) gab es für den evangelischen Diakon durchaus Anlass zur Unruhe, nicht zuletzt weil Hoffman bereits mit mehreren Bilderstürmen in Livland in Verbindung gebracht worden war (obgleich jener nie selbst involviert war). Ein Aufstand war aufgrund der allgemeinen Unzufriedenheit der Handwerker und Bauern zudem nicht ganz auszuschließen..$^{3{ }^{8}}$ Hoffmans apokalyptische Predigten waren ein weiterer Grund für Schuldorp, den aufsässigen Laienprediger mäßigen zu wollen. Da Hoffman sich vor Ort scheinbar nicht überzeugen ließ, sein Verhalten zu ändern, suchte

\footnotetext{
356 Anonymus [i. e. Hoffman und Karlstadt] (I 529), Dialogus, A2v.

357 Deppermann (I979), S. 89 f.

$35^{8}$ Ebd., S. 9I-94.
} 
Schuldorp in dem bisher mündlich verlaufenen Streit mit Hoffman ${ }^{359}$ Hilfe von außerhalb und beschwerte sich brieflich bei Martin Luther und Nikolaus von Amsdorf über Hoffman. ${ }^{360}$ Die beiden Theologen standen in freundschaftlichem Verhältnis zu Schuldorp, der ebenfalls einige Jahre in Wittenberg studiert hatte. In seinem Beschwerdebrief an Amsdorf schickte er zudem auch Hoffmans Daniel-Auslegung von I 526 mit, woraufhin Amsdorf seine Geringschätzung der Auslegung in seiner Antwort mitteilte. Dies sprach sich anscheinend in Kiel herum. ${ }^{36 \mathrm{I}}$ Schließlich kam es auch Hoffman zu Ohren, der daraufhin den Versuch unternahm, das Wittenberger Lager auf seine Seite zu ziehen. Er reiste in Begleitung eines königlichen Kaplans über Magdeburg nach Wittenberg, um die Sache persönlich mit Amsdorf und Luther zu besprechen. Es ist davon auszugehen, dass Hoffman sich zu diesem Zeitpunkt noch zum Lager Luthers zählte und aufgrund eines früheren Empfehlungsschreibens,

359 Aus der Zeit sind keine Schriften zwischen den beiden überliefert oder erwähnt worden. Vgl. dazu auch Deppermann (I979) und Krohn (I758). In seiner Schrift Nasen geist ruft Hoffman Schuldorp auf, seine Positionen in schriftlicher Form zu äußern. Dabei klingt an, dass dies bis zu dem Zeitpunkt (I 528 ) nicht geschehen war. Vgl. Hoffman ( 1528 ): Nasen geist, $\mathrm{C}_{4} \mathrm{r}$.

${ }_{360}$ Mark A. Noll behauptet fälschlicherweise: [B]efore Hofmann settled in SchleswigHolstein, he felt constrained to make a second journey to Wittenberg in order to seek once again, justification for his ministry and to convince the stalwarts of the Reformation that his teaching was correct and profitable. "Noll, Mark A. (I973): „Luther Defends Melchior Hoffman“. The Sixteenth Century Journal 4: 2, S. 476o, hier S. 52. Da Luther sich jedoch in seinem Brief an Amsdorf auf den Brief von Schuldorp bezieht, muss der Konflikt zwischen Hoffman und Schuldorp auch schon vor Hoffmans Reise nach Wittenberg bestanden haben. Demnach muss Hoffman schon eine Weile in Schleswig-Holstein tätig gewesen sein, als er seine zweite Reise nach Wittenberg antrat. Der Brief von Luther an Amsdorf vom I7.05.I 527 ist zu finden in: Luther, Martin (I933): D. Martin Luthers Werke. Kritische Gesamtausgabe. Briefwechsel. Bd. 4. Briefe I 526-I 528. Weimar: Hermann Böhlaus Nachfolger, S. 202f. (Originalwortlaut siehe Anmerkung 363). Luthers Werkausgabe wird im Folgenden mit dem Standardkürzel WA (Weimarer Ausgabe) wiedergegeben. Vgl. dazu auch Marquard Schuldorps Breef an die gelövighen der Stadt Kyll (BIv) von I 529, in der Schuldorp bestätigt, dass Hoffman erst nach seinem Kielaufenthalt in Richtung Magdeburg und Wittenberg reist. Der hier angegebene Titel ist lediglich eine nachträgliche Namensgebung der Forschung, da die ersten Seiten der Schrift fehlen. Auf Bir beginnt die Schrift mit der salutatio: „Marquardus Schuldorp gheeschet vnd geordenth tho Schleßwick tho predighen dat wort Gades / van Jhesu Christo dem Sóne Gades / wunsche allen gelouyghen der Stadt Kyle Gnade vnd frede van Gade vnsem vader / vnd vnsem Herren Jhesu Christo." Sie wird oftmals auch als Titel angegeben.

${ }^{361}$ Ilgner, Christoph (2008): „Nikolaus von Amsdorf, wider den rotten vnnd secten gaist"“. In: Dingel, Irene (Hg.): Nikolaus von Amsdorf (1483-I565) zwischen Reformation und Politik. Leipzig: Evang. Verlagsanstalt, S. 25 I-279. 
das ihm Luther und Bugenhagen im Sommer I 525 ausgestellt hatten, ${ }^{362}$ weiterhin darauf vertraute, bei jenem Unterstützung zu finden. Seit dem Empfehlungsschreiben hatte sich Luthers vormalig positive Einstellung zu Hoffman allerdings geändert und war einer geringschätzigen, ablehnenden Haltung gewichen. Da Hoffman seinen Besuch in Wittenberg, samt seinem Zwischenstopp in Magdeburg, brieflich angekündigt hatte, warnte Luther Amsdorf in einem Brief vom 17.05.I 527 vor dem „livländischen Propheten “ und riet ihm, Hoffman unfreundlich zu empfangen sowie ihn auf seinen Berufsstand zu verweisen. ${ }^{363}$ Diesen Fingerzeig auf den Handwerkerstand kann man auf einen Gesinnungswandel Luthers zurückführen. Seine I 523 aufgestellte Forderung, „[d]as eyn Christliche versamlūg odder gemeyne: recht $v \bar{n}$ macht habe: alle lere tzu vrteylen: vnd lerer zu beruffen: eyn vnd abzusetzen: Grund vnd

${ }^{362}$ Luther, Martin, Johannes Bugenhagen \& Melchior Hoffman (I525): Eyne Christliche vormanung von eusserlichem Gottis dienst vnde eyntracht / an die yn lieffland / durch D Martinum Luther vnde andere. Wittenberg: [o. Dr.] Luther und Bugenhagen hatten in diesem Schreiben jeweils einen Sendbrief an die Livländer verfasst, Hoffman durfte seinen eigenen Sendbrief mit dem Titel Jhesus hinzufügen. Aufgrund mehrerer Tumulte und Bilderstürme durch Hoffmans Anhänger (Hoffman selbst hatte weder dazu aufgerufen, noch war er daran aktiv beteiligt gewesen) wurde Hoffman von der Dorpater Obrigkeit aufgefordert, ein Zeugnis Luthers einzuholen, in dem Hoffmans Lehre begutachtet werden sollte. Ohne ein solches Schreiben war ihm das Predigen fortan verboten. Auf einer Reise nach Wittenberg gelang es Hoffman zwar, ein solches Empfehlungssschreiben zu erhalten, bei seiner Rückkehr hatte sich die Lage jedoch weiter zugespitzt, so dass ihm die Approbation auch weiterhin verwehrt blieb. Nach der öffentlichen Beleidigung des Bürgermeisters wurde Hoffman schließlich aus Dorpat vertrieben. Nach kurzem Aufenthalt in Reval (wo er ebenfalls vertrieben wurde) zog er I 526 weiter nach Stockholm.

363 Deppermann (I979), S. 97. Deppermann bezieht sich hier auf den Brief Luthers an Amsdorf vom I7.05.I 527. WA. Briefwechsel 4, S. 202f: „Melchiorem illum prophetam Livoniensem si venerit, ne suscipias amice, neque familiariter. Passus sum serias litteras ob meum testimonium, quod illi stultus et deceptus dedi. Nam hoc fretus coepit illic ipsos praedicatores contemnere et superbire. Prorsus mihi displicet homo et spiritus eius, qui iniussus et non vocatus insanit ambulans in mirabilibus supra se. Si venerit, iube eum suae vocationi h.e. pellificio vacare et a prophetando vacare cessare que, donec in ecclesiam admissus fuerit, auditus et iudicatus.“ Vgl. dazu auch Ilgner (2008), S. 265. Eine englische Übersetzung der lateinischen Textstelle legt Noll vor: „Do not receive Melchior, the famous Livonian prophet, with kindness or intimacy if he comes. I have received a serious letter on account of my testimony which I (simple-minded and deluded) gave to him. For, making use of that, he began to censure and lord it over the preachers there. In sum, I am displeased with this man and his spirit who, unbidden and without a call, goes around dealing in marvelous things beyond himself. If he comes, order him to return to his vocation, the making of furs, and tell him to stop prophesying until he is admitted into the church after having been heard and judged." Noll (I973), S. 53. 
vrsach aus der schrifft" ${ }^{364}$ hatte er selbst nach 1525 wieder abgeschwächt. ${ }^{365}$ Die Einsetzung der Priester durch die Obersten einer Gemeinde wurde anstelle der Wahl durch alle Gemeindemitglieder gesetzt. Dies ist vermutlich einerseits auf die Ereignisse des Bauernkrieges zurückzuführen, ${ }^{366}$ andererseits aber auch darauf, dass immer mehr Laienprediger in das aktuelle Kirchengeschehen eingriffen und Luther seine eigenen Reformversuche durch deren radikale Forderungen sowie die daraus resultierende aufrührerische Stimmung in Gefahr sah. Hoffman war bereits in Livland und Stockholm mit Bilderstürmen und Massenaufruhr in Verbindung gebracht worden (obgleich er nie dazu aufgerufen hatte) und war infolge seiner obrigkeitskritischen Haltung bereits aus fünf Städten vertrieben worden. Luther war nun - zwei Jahre nach seinem Rekommandationsschreiben für Hoffman - darauf bedacht, den selbsternannten Laienprediger zu mäßigen bzw. ihn gänzlich vom Reformationsgeschehen auszuschließen.

In Magdeburg angekommen suchte Hoffman Amsdorf wie angekündigt für ein persönliches Gespräch auf. Der Empfehlung Luthers nachkommend verwies Amsdorf den Kürschner bei dem Zusammentreffen aber auf sein Handwerk und lehnte ein Gespräch über theologische Themen mit ihm ab. Nach dieser Zurückweisung zog Hoffman verärgert weiter nach Wittenberg, bekam dort jedoch ebenfalls nur Martin Luthers und Johannes Bugenhagens abschätzige Kritik für seine allegorische Auslegung des ersten Matthäus-Kapitels zu hören. ${ }^{367} \mathrm{Nach}$

${ }^{664}$ Luther, Martin (I 523): Das eyn Christliche versamlūg odder gemeyne: recht $v \bar{n}$ macht habe: alle lere tzu vrteylen: vnd lerer zu beruffen: eyn vnd abzusetzen: Grund vnd vrsach aus der schrifft. Wittenberg: [o. Dr.]. Digitalisat: Münchener Digitalisierungszentrum Digitale Bibliothek (MDZ), URL: http://www.mdz-nbnresolving.de/urn/resolver.pl?urn=urn:nbn:de:bvb:I2-bsb IоI62529-2 (I8.I0.20I 5). Siehe auch Luther, Martin (I900): D. Martin Luthers Werke. Kritische Gesamtausgabe. Schriften. Bd. I I. Predigten und Schriften I523. Weimar: Hermann Böhlaus Nachfolger, S. 408-4I6.

365 Fagerberg, Holsten (I978): „Amt / Ämter / Amtsverständnis VI“. In: Krause, Gerhard \& Gerhard Müller (Hg.): Theologische Realenzyklopädie. Bd. 2. AgendeAnselm von Canterbury. Berlin \& New York: De Gruyter, S. 552-574, hier S. $560 f$.

${ }_{366}^{6 g}$ Vgl. Deppermann (I979), S. 6If.

367 Hoffman selbst berichtet von den negativen Erfahrungen, die er I 528 in Wittenberg machen musste, in der Vorrede des Drucks jener Schrift: „Do ick mynen Lereren tho Wittemberch solck eine Grundt an den Dach stellede, unde der Schrifft klar nach wolde, do moste ick armes Wörmeken ein grotter Sủnder wesen, vnde vor einen Drömer geholden werden, vnde also schentlick geschendet, gelastert vnde voracht [...]“. Hoffman, Melchior ( I 529): [Das] Erste Capitel des Evangelisten St. Mattheus. Das Original dieser Schrift ist verschollen. Lediglich der Titel und die Vorrede sind erhalten und zu finden in: Krafft, Johannes Melchior (I723): Ein Zweyfaches 
diesen beiden Niederlagen begab sich Hoffman unverrichteter Dinge über Magdeburg zurück nach Kiel. Auf dem Rückweg wurde er jedoch in Magdeburg vom Rat der Stadt festgenommen und seine Besitztümer beschlagnahmt. ${ }^{36}$ Mittellos zog er nach der baldigen Freilassung weiter nach Hamburg, wo er vom Pfarrer der Nikolaikirche, Johannes Ziegenhagen, einen Zehrpfennig zur Weiterreise nach Kiel erhielt. ${ }^{669}$ Dort angekommen, erfuhr er von Amsdorfs Schreiben Ein vormanung an die von Magdeburg / das sie sich fur falschen Propheten zu büten wissen, ${ }^{370}$ das dieser unterdessen zur Warnung vor Hoffman in Magdeburg veröffentlicht hatte.

Im Rückblick kann Amsdorfs Flugschrift als Beginn des Schriftwechsels mit Hoffman betrachtet werden. Ob Amsdorf eine Gegenschrift Hoffmans intendierte, ist Ein vormanung jedoch nicht ablesbar: Eine konkrete Aufforderung, eine Gegenschrift zu verfassen, gibt es trotz des Anredewechsels im letzten Abschnitt (vom Publikum zu Hoffman) nicht. Hoffmans Reaktion mag mehr die Absicht gehabt haben, das Kieler Publikum auf seine Seite zu ziehen. Wie bereits erwähnt, wurden in dem daraus resultierenden Schriftwechsel in der ersten Hälfte des Jahres I 528 vier weitere Schriften ausgetauscht.

Der Streit zwischen Amsdorf und Hoffman blieb während des gesamten Schriftwechsels insofern exklusiv zwischen den beiden Kontrahenten, als sich niemand öffentlich, durch z. B. eine eigene Schrift zu dem polemischen Thema, am Streit beteiligte. Obwohl Luther vor dem Streit seine ablehnende Haltung gegenüber Hoffman deutlich gemacht hatte, mischte er sich nicht aktiv in das Geschehen ein. Am Rande spielte Luther aber trotzdem eine wichtige Rolle für die Gesamtentwicklungen an der Kieler Nikolaikirche, beginnend mit einem Briefwechsel mit dem altgläubigen Pfarrer Wilhelm Pravest. Auf der Basis des Streits mit Amsdorf sah Pravest seine Chance, mit Hilfe Luthers den aufrührerischen Hoffman loszuwerden. In einem Brief an den namhaften

Zwey-Hundert-Jåhriges Jubel-Gedåchtnis. Hamburg: Johann Wolfgang Fickweiler, S. 440-445, hier S. 445 .

${ }^{68}$ Die Gründe für die Festnahme sind nicht nachvollziehbar. „[Hoffman] beschuldigte später Amsdorf, dass er dahinter stecke und wollte dafür sogar zwei Zeugen aufbieten; Amsdorf jedoch dementierte, mit seiner Verhaftung etwas zu tun zu haben; die Gründe des Rates blieben unklar.“ Ilgner (2008), S. 265.

369 Deppermann (I979), S. 99.

370 Amsdorf, Nikolaus von (I 527): Ein vormanung an die von Magdeburg / das sie sich fur falschen Propheten zu huten wissen. Magdeburg: Hans Bart. Kurztitel: Ein vormanung. Die Quellenangaben bei Zitaten werden mit den Initialen EV und der Folienangabe der Übersichtlichkeit halber in Klammern gestellt. 
Reformator würdigte Pravest am 2I. Februar I 528 die evangelische Lehre, beklagte aber den Verlust alter Kirchenrituale in Kiel unter ihrem Einfluss, und dass ein neuer Prediger mit Namen Melchior im Namen der evangelischen Lehre seine apokalyptische Prophetie verkünde. ${ }^{37 \mathrm{I}}$ Luther schrieb Pravest am I4. März wohlwollend zurück und bestätigte ihm, dass er diejenigen, die Verbrechen im Namen des Evangeliums begingen, mehr bekämpfe als den Papst. Melchior Hoffman sei möglichst durch die Obrigkeiten vom Predigen abzuhalten, da er unberufen unbillige Visionen verbreite - diese Empfehlung solle Pravest an die Kieler weitergeben. ${ }^{372}$ Luthers Brief diente Pravest jedoch zu anderen Zwecken als Luther im Sinn hatte. Zusammen mit einem selbstverfassten Spottgedicht auf Luther machte der Kieler Pfarrer den Brief in seiner Gemeinde publik, um den Reformator im Interesse des alten Glaubens zu diskreditieren. ${ }^{373}$ Als Luther schließlich von dem Vorgehen Pravests erfuhr, schrieb er am 9. Mai I 528 an letzteren, dass er dessen Täuschung missbillige und es nicht intendiert habe, dass Diener des Wortes angegriffen werden sollten, selbst wenn sie Unruhen stifteten. ${ }^{374}$

${ }^{371}$ „Advenit ad nos quidam, qui se fatetur euangelii promotorem Christi seque destinatum iactitat a Deo, et quicquid dixerit, pro lege, pro euangelio complectendum persuadere nititur, nec tamen latini sermonis sapit quicquam (ut dicit) homo, Melchior nomine, pellifex quondam, qui temere imo et scripto tradidit de novissimo die mundumque finiendum infra septennium. " Pravest an Luther, WA. Briefwechsel 4, S. 38I-383, hier S. 383. Übersetzungen von Teilen des Briefwechsels zwischen Pravest und Luther sowie eine Erklärung der Zusammenhänge gibt Noll (I973), S. $55-57$.

372 „Scio, mi frater in Domino, sub praetextu euangelii plurima scandala patrari, et omnia mihi imputari; sed quid ego faciam? Nemo est illorum, qui se non putet me centuplo doctiorem, nec me audiunt. Nam magis mihi cum ipsis est bellum quam cum papa, et magis ipsi nocent. Ego sane nullas ceremonias damno, nisi quae pugnant cum euangelio, caeteras omnes in ecclesia nostra servo integras. [...] Ego innocuus sum ab ipsorum furore et tumultu. Nam nos habemus, Dei gratia, Ecclesiam pacatissimam et quietissimam, templum liberum et integrum, sicut antea, nisi quantum est ante me ab Carolostadio turbatum. A Melchiore Pellifice velim cavere vos omnes, et curare apud magistratum, ne ad conciones admittat, etiamsi literas Regis ostendet. Ad docendum neque valet neque vocatus est. Haec dicito omnibus vestris nomine meo, ut ipsum vitent ac tacere cogant." Luther an Pravest, WA. Briefwechsel 4, S. 4IO-4I 2, hier S. 4IIf.

373 „Luther's reply now became fodder for anti-Lutheran propaganda. Pravest had a papal fieldday at Luther's expense: speaking out of one side of his mouth he scored Luther for dangerous liberties taken with the essentials of the faith; out of the other side of his mouth (and contradictorily) he claimed that Luther in spite of his posturing was still a Roman Catholic.“ Noll (I973), S. 56. Vgl. auch Deppermann (1979), S. I04.

374 „Esto sane, Melchiorem noluerim tumultuari, at credidi, te esse placidum et sincerum verbi doctorem, ut multo minus voluerim te in verbi ministros etiam unquam 
Am selben Tag schrieb Luther ebenfalls an den Kieler Bürger Konrad Wulf und den Bürgermeister Paul Harge. Er erklärte die Umstände des Briefs, den Pravest in Kiel für seine Zwecke missbraucht hatte und machte auf die Täuschung aufmerksam. Das in seinem zweckentfremdeten Brief gefällte Urteil über Hoffman schwächte er dieses Mal ab, indem er ihm die rechten Absichten zusprach. Seiner ungezügelten Art sei jedoch Einhalt zu gebieten. ${ }^{375}$

Die Briefe vom 9. Mai deuten an, dass Luther erst einmal keine Maßnahmen gegen Hoffman ergreifen wollte. Nicht vor dem 24. Juli sollte Luther seine Meinung gegenüber Hoffman negativ kundtun: In einem Brief an Herzog Christian, Statthalter der Herzogtümer Schleswig und Holstein und Kronprinz von Dänemark (später König Christian III.), warnte er diesen vor Hoffman, da das, was er von ihm gehört und gelesen habe, „gar nichts zur Sachen dient vnd vergebliche Tichterei ist“. ${ }^{376}$ Luther bat Herzog Christian, „die Einträchtigkeit der Lehre zu foddern vnd solchen Steigergeistern nicht zu viel Raum [zu] lassen“..377 Gegen Hoffman persönlich zur Feder zu greifen, erachtete Luther wohl nicht als wichtig genug. ${ }^{378}$

Dass Luther mit dem Brief an den Herzog Christian im Juli schließlich doch Maßnahmen gegen Hoffman ergriff, mag auch daran liegen, dass sich der Streit im weiteren Verlauf des Jahres I 528 einerseits thematisch von der Apokalyptik auf die für die Wittenberger Reformatoren wesentlich wichtigere Abendmahlsfrage ${ }^{379}$ und andererseits personell

inquietiores debacchantem et fuerentem concitare et animare, sed potius admonere et retinere, si scivissem hostem esse te." Luther an Pravest, WA. Briefwechsel 4 , S. 453 f., hier S. 454 . „To be sure, I did not want Melchior to cause an uproar; moreover, I believed you were a peaceful and genuine teacher of the Word. Much less, however, did I want to incite you and stir you up against ministers of the Word, even one who stirs around madly causing disturbances; rather, I would have admonished and restrained you if I had known you were an enemy. "Übersetzung von Noll (I973), S. 57.

375 Luther an Paul Harge, WA. Briefwechsel 4, S. 454f. Luther an Konrad Wulf, WA. Briefwechsel 4, S. 456.

${ }^{376}$ Luther an Herzog Christian, WA. Briefwechsel 4, S. 503-505, hier S. 504.

377 Ebd., S. 505 .

${ }_{378}$ In einem Brief an Amsdorf schrieb Luther am 25.I I.I 528, dass er nicht direkt an Melchior Hoffman schreibe, weil er zu beschäftigt sei: „Vellem Melchiorem istum, tuum hostem, petere stylo, si vacaret, mi Amsdorfi; sed modo sum certe occupatior." Luther an Amsdorf, WA. Briefwechsel 4, S. 6Io.

379 Hoffmans Auffassung des Abendmahls steht insbesondere der Auffassung Karlstadts nahe, mit der sich Luther bereits I 525 schriftlich auseinandersetzte: Da Karlstadt das Abendmahl lediglich als Zeichen wertete und insbesondere die guten Werke ins Zentrum für den rechtmäßigen Empfang des Abendmahls stellte, sah Luther 
von Nikolaus von Amsdorf wieder auf Marquard Schuldorp verlagert hatte. Dieser befand sich zu diesem Zeitpunkt zwar an seiner neuen Wirkungsstätte, am Laurentius-Altar des Domes in Schleswig, kehrte aber immer wieder nach Kiel zurück, um sich über die Geschehnisse an der Kieler Nikolaikirche und die Arbeit seiner Kollegen zu informieren. ${ }^{380}$ So muss es sich ereignet haben, dass Schuldorp sowohl von den fortschreitenden Streitigkeiten Hoffmans mit den Lutheranern als auch von Hoffmans Abendmahlsauffassung ${ }^{38}$ erfahren hatte und daraufhin zur Feder gegen Hoffman griff und ein Traktat mit dem Titel Inhalt vom Sacramente und Testamente des Leibes und Blutes JEsu Christi verfasste..$^{32}$ Nach Barthold Nikolaus Krohn, der sich wiederum auf die Überlieferung Johannes Mollers bezieht, führte dies zu zwei Gegenschriften Hoffmans: ${ }^{383}$ I. Inhalt und Bekenntnisse vom Sakrament

seine zentrale Lehre von der Rechtfertigung durch den Glauben allein in Gefahr: „Weyl deñ nu Doctor Carlstad [...] nit ain mal leeret / was glaube vñ liebe sey [...] sonder auf eusserliche werck dringet vnd treybt / sey ain yeglicher vor jm gewarnet“. Luther, Martin ( 1525 ): wider die himelischen Propheten / Vō den bildern und Sacrament [et]c. [o. O: o. Dr.], A3r-v. Der Abendmahlsstreit mit Zwingli bestätigt zudem die Brisanz des Themas für Luther.

${ }^{380}$ Deppermann führt weiter aus: „An die Stelle Schuldorps trat als Diakon Herrmann Biestermann, der im Anfang ein zuverlässiger Parteigänger Luthers zu sein schien, sich dann aber Melchior Hoffman anschloß.“ Deppermann (I979), S. 89.

${ }^{381}$ Hoffman lehnte die Auffassung der Realpräsenz Jesu Christi im Brot und Wein des Abendmahls ab und bestritt sowohl die Transsubstantiationslehre der römischen Kirche als auch die lutherische Auffassung der Konsubstantiation. Das Abendmahl sei eine Gedächtnisfeier und fände lediglich im Geiste des Gläubigen statt. Hoffman teilte seine spiritualistische Auffassung des Abendmahls unter anderem mit Andreas Rudolf Bodenstein von Karlstadt und Ulrich Zwingli. Mit beiden stritt Luther um die Abendmahlsfrage (besonders heftig war der Abendmahlsstreit mit Zwingli, der seinen Höhepunkt im Marburger Religionsgespräch I 529 fand). Zu der Rolle Melchior Hoffmans im Abendmahlsstreit der Reformation siehe Deppermann (I979), S. II9-I32.

${ }^{882}$ Im Dialogus wird auf eine Schrift Hoffmans Bezug genommen, wobei es sich vermutlich um die hier erwähnte Schrift handelt: „Zum letsten / hat er da selbst vß getruckt vnd bekandt den warē grundt / vō dem nachtmal des herren Jesu Christi / da haben sich die / welche Luthers vnd Pomeranus meinung seind / gantz hart wider jn gelegt / vnd ein groß geschrey über den kürßner gemacht [...]. “ Anonymus [i. e. Hoffman und Karlstadt] (I 529), Dialogus, A2v.

${ }^{383}$ Krohn schreibt: „Ich habe die Titel dieser drey Schriften (hier gemeint sind die erste Schrift Schuldorps und die zwei Schriften Hoffmans) so in hochdeutscher Sprache hieher gesetzt, wie ich sie beym Moller, am angef. Orte T.I S. 604. und T.II. S. 353. und andern angetroffen habe. Ich vermuthe, daß Moller die Urschriften so wenig gesehen hat, als ich. Aber es ist wahrscheinlich, daß sie plattdeutsch verfertiget sind. Wenn Hofmann für die Holsteiner schrieb, so bediente er sich dieser Sprache [...]. “ Krohn (I758), S. I 40. Krohn bezieht sich auf Moller, Johannes (I744): Cimbria literata, sive scriptorum ducatus utriusque Slesvicensis et Holsatici. Havniae [= Kopenhagen]. 
und Testament des Leibes und Blutes JEsu Christi und 2. Beweis das Marquard Schuldorp in seinem Inhalt vom Sakrament und Testament ketzerisch und verführerisch geschrieben. Aus dem Schriftwechsel zwischen Schuldorp und Hoffman ist lediglich Schuldorps letzte Schrift (ohne Titelblatt) erhalten. Sie wird in der Forschung oftmals als Breef an die gelöuighen der Stadt Kyll betitelt. ${ }^{38}$ Dieser Umstand macht eine eingehende Untersuchung von Hoffmans Polemik hier unmöglich, es kann lediglich auf Schuldorps Redewiedergaben referiert werden, die etwas über Hoffmans Argumentation und Polemik verraten.

Nachdem die Streitigkeiten mit Hoffman bis Ende des Jahres I 528 wenig Aufmerksamkeit auf Seiten der Obrigkeiten erhalten hatten, nahm König Friedrich I. von Dänemark schließlich doch eine kritische Haltung gegenüber Hoffman ein, dem er noch zwei Jahre zuvor einen Schutzbrief ausgestellt hatte. Verschiedene politische Veränderungen zwangen den König dazu, eine andere Politik als vorher zu betreiben und sämtliche von der lutherischen abweichenden Reformbewegungen $\mathrm{zu}$ unterbinden. ${ }^{385}$ Vermutlich in dem Kontext sowie durch Luthers Fürsprache (vom 24. Juli I 528) unterstützt, beauftragte Herzog Christian zu Beginn des Jahres I 529 seinen Berater Eberhardt Weidensee mit einem Gutachten über Hoffmans Abendmahlslehre. ${ }^{386}$ Dieser hatte mit Amsdorf die Reformation in Magdeburg durchgeführt und stand immer noch in freundschaftlichem Verhältnis zu ihm. ${ }^{387}$ Weidensees

Deppermann gibt insgesamt drei Schriften an und nennt als weiteren Titel die Schrift, auf die Eberhardt Weidensee antwortet: Sendebreef dat he nich bekennen konne dat een stuck lyvlikes brods syn god sy. Jedoch ist der Wortlaut des Titels aus dem Titel von Eberhardt Weidensees Schrift gegen Hoffman von I 529 entnommen: Eyn vnderricht vth der hillighen schryfft / Dem Dorchlichtygen Hochgebarnen Forsten und Hernn / Hernn Christiarnn / Erffgenomem tho Norwegenn / Hertoghenn tho Schleßwigk Holsten etc. Dorch Eberhardt Wydenßehe gedan / Melchior Hoffmans sendebreff I darynne hee schryfft I dat he nycht bekennen köne dat eyn stucke lijvlikes brodes syn Godt sy / belangende [Haderslev: o. Dr.]. Der Wortlaut des Titels kann jedoch allein aufgrund des Personalpronomens „he“ (er) nicht aus Hoffmans Feder stammen. Die Annahme, dass es sich um eine dritte Schrift handelt, bleibt daher eine vage Vermutung. Weidensee kann ebenso auf eine der beiden von Krohn genannten Schriften Hoffmans Bezug genommen haben. Es kann dennoch nicht völlig ausgeschlossen werden, dass Hoffman noch einen weiteren Sendbrief an Weidensee verfasste, dessen Titel aber nicht bekannt ist.

${ }^{384}$ Deppermann gibt folgende Informationen über den Titel dieser Schrift: „Vermuteter Titel, da Titelblatt und A-A4b fehlen." Deppermann (1979), S. 353. Die Grußworte, die oftmals als Titel angegeben werden, sind bei Anmerkung $360 \mathrm{zu}$ finden.

${ }_{385}$ Vgl. ebd., S. I06f.

386 Ebd., S. I07.

${ }_{387}$ Ebd., S. Io6. 
Traktat Eyn vnderricht vth der hillighen schryfft bezieht sich auf den bereits genannten Breef an die gelöuighen der Stadt Kyll. Die Schrift war verfasst worden, um Hoffmans Abendmahlsauffassung zu entkräften. Kronprinz Christian sah sich daraufhin gezwungen, Hoffmans Wirken ein Ende zu setzen und ordnete eine Disputation für den 8. April I 529 an, bei der Hoffman seine Lehre verteidigen bzw. zurücknehmen sollte. Hoffman weigerte sich jedoch vehement, seine Auffassungen zu revidieren. Die Folge der Widerrufsverweigerung war ein Landesverweis, den König Friedrich I. dem u. a. vorgeschlagenen Todesurteil vorzog.

Die Disputation stellte einen großen Einschnitt in Hoffmans Leben dar - nicht nur weil er ein weiteres Mal vertrieben wurde, sondern auch weil sie den endgültigen Bruch Hoffmans mit den Lutheranern zur Folge hatte. ${ }^{88}$ Die Streitigkeiten, die der Kürschner bis zu diesem Zeitpunkt immer nur mit einzelnen Vertretern der Gruppe der Lutheraner hatte, weiteten sich nun in seinen folgenden Schriften auf „des Luthers hauff“ 389 aus, den er seitdem als homogene Gruppe verwarf. Für Hoffman war mit dem für ihn unglücklichen Ausgang der Disputation die bis dahin noch bestehende Bindung an Luther und seine Glaubensgenossen gelöst. Hoffman besiegelte die vollzogene Ablösung noch im selben Jahr ( I 529) mit dem von ihm und Karlstadt verfassten Dialogus, einem als Reformationsdialog konzipierten Bericht über die Flensburger Disputation.

\subsubsection{Unzensierte Polemik? Die Entstehungs- und Druckbedingungen des polemischen Schriftwechsels}

Reformationspolemische Schriften waren oftmals von den lokalen, (religions-)politischen und ideologischen Umständen, in denen sie produziert wurden, bestimmt. Wie waren die Bedingungen, die der Magistrat einer Stadt den Druckern setzte, welche Überzeugung hatten

${ }^{388}$ Inwiefern der Bruch mit den Lutheranern in Hoffmans Schriften, die nach der Disputation in Flensburg entstanden sind, ablesbar ist, kann nachgelesen werden in: Lundström, Kerstin (20II): „Der Freund wird zum Feind. Selbst- und Fremdzuschreibungen als Mittel zur Abgrenzung von den Lutheranern in Melchior Hoffmans Schriften der Straßburger Zeit“. In: Unzeitig, Monika (Hg.): Grenzen überschreiten - transitorische Identitäten. Beiträge zu Phänomenen räumlicher, kultureller und ästhetischer Grenzüberschreitung in Texten vom Mittelalter bis zur Moderne. Bremen: edition lumière, S. $22 \mathrm{I}-232$.

${ }^{389}$ Hoffman (I 529/30): WEissagung vsz heiliger gôtlicher geschrifft, B $3 \mathrm{v}$ (vollständige Angabe bei Anmerkung 643). Dies ist nur ein Beispiel, das repräsentativ für einige weitere Schriften Hoffmans ab I 529 steht, die auf die Lutheraner in ähnlicher Weise - immer in Form einer Gruppenbeschreibung - referieren. 
die Drucker, waren sie einem Risiko durch den Druck bestimmter Schriften ausgesetzt und waren sie in solch einem Falle bereit, dieses Risiko zu tragen? Die Zensur war zwar gängiges Mittel zur Kontrolle des Reformationsschrifttums, aber eine Vielzahl der Autoren und Drucker setzte sich über diese hinweg und veröffentlichte und druckte anonym oder unter Pseudonym. Eine Untersuchung des unmittelbaren Entstehungskontextes ist insofern als wichtige Ergänzung zur Textanalyse zu betrachten.

Nikolaus von Amsdorf brachte seine drei Schriften gegen Hoffman bei dem Drucker Hans Bart in Magdeburg heraus. ${ }^{390}$ Aufgrund der dort schon seit mehreren Jahren vorangetriebenen Reformation kann davon ausgegangen werden, dass das Publikum ebenfalls mehrheitlich evangelisch war. Es ist weiterhin anzunehmen, dass Amsdorfs Ziel die Aufrechterhaltung der noch relativ neuen evangelischen Ordnung war, als er sowohl I 525 gegen Wolfgang Cyclop als auch I 527/28 gegen Melchior Hoffman zur Feder griff. Da Amsdorf eine machtvolle Stellung in Magdeburg besetzte und die wenigen ansässigen Drucker zumeist reformatorische Schriften druckten, sind Schwierigkeiten beim Druck oder Einschränkungen durch den Drucker eher auszuschließen. Amsdorf hatte schon vorher mehrfach bei Hans Bart, aber auch bei Heinrich Öttinger drucken lassen, deshalb ist es höchstwahrscheinlich, dass er seine Schriften ohne Probleme und ohne Zensur publizieren konnte. Nicht zuletzt kann der doch überwiegend sachliche Ton von Amsdorfs Schriften dazu beigetragen haben, dass der Druckprozess problemlos ablief. Auflagen oder Verbreitungskreis sind allerdings nicht übermittelt.

Hoffman hingegen hatte eine andere Position. Als Handwerker und Laienprediger besaß er keine hohe gesellschaftliche Stellung. Er hatte jedoch durch sein Gewerbe und/oder durch die Hilfe seiner Schwiegereltern ${ }^{391}$ die finanziellen Mittel und besaß in Kiel sogar eine eigene Druckerpresse, ${ }^{392}$ die bei der Verbreitung seiner

390 In Magdeburg gab es in den Jahren I 524 bis I 530 nur vier Drucker: Hans Knappe der Jüngere (I 524-I 525 ), Heinrich Öttinger (I 525 -I 53 I), Hans Bart (I $527-$ I 528 ) und Michael Lotter (I528/29-1530). Kapp, Friedrich (I 886): Geschichte des Deutschen Buchhandels. Bd I. Leipzig: Verlag des Börsenvereins der Deutschen Buchhändler, S. I 66.

${ }^{391}$ Vgl. Bailey, Richard G. (I 990): „Melchior Hoffman: Proto-Anabaptist and Printer in Kiel, I 527-I 529“. Church History 59: 2, S. I75-I90, hier S. I 86.

392 „Er [Hoffman] hat das Verdienst, die erste Druckerpresse nach Kiel gebracht zu haben." Ficker (I926), S. I des Nachwortes zu Hoffmans Nasen geist. Bailey gibt Informationen zur Größe und zum Inventar der Druckerpresse Hoffmans: „A 
theologischen Auffassungen und beim Schriftwechsel mit Amsdorf förderlich war. Mit dem Besitz der Druckerpresse nahm Hoffman große Kosten auf sich, verfolgte aber keine kommerziellen Zwecke mit dem Verkauf seiner Druckerzeugnisse. ${ }^{393}$ Der Besitz der Druckerpresse lässt zum einen seine gute finanzielle Lage und zum anderen Hoffmans Zielstrebigkeit bei seiner theologischen und publizistischen Tätigkeit erahnen: „Hoffman's fory into printing was occasioned by his characteristic need to propagate his teaching and defend himself against his opponents. “394 Die Druckerpresse ermöglichte ihm die Unabhängigkeit von Machtstrukturen und -instanzen, die eine Publikation hätten verhindern oder einschränken können. ${ }^{395}$ Eine Beeinträchtigung seiner Veröffentlichungen wäre nicht gänzlich auszuschließen gewesen, erstens weil Hoffman keine einflussreiche Stellung besaß und von einigen Lutheranern bereits gemieden wurde, zweitens weil es keine Drucker in der Region gab ${ }^{396}$ und drittens weil Kiel sowie ganz Holstein religionspolitisch einen unklaren Status hatten. Hoffman entging diesen möglicherweise hinderlichen Faktoren durch den eigenen Druck.

Die religionspolitisch uneindeutige Lage hatte für Hoffman so keine Nachteile, sondern nur Vorteile, denn die Kirchenpolitik, die in Schlewig-Holstein betrieben wurde, kam ihm eher zur Hilfe, als dass sie ihn in seinem Wirken einschränkte. Klaus Deppermann erklärt die Umstände Holsteins mit der verzwickten politischen und finanziellen

survey of Hoffman's inventory, provided by Volbehr, reveals a moderate-sized printery. It consisted of two presses [...]. “ Weiterhin macht er die Annahme, dass die Presse sehr alt, vielleicht sogar eine der frühesten Pressen war. Hoffman hatte sie von dem Lübecker Drucker Steffan Arndes erworben. „Arndes is known to have had five presses, so Hoffman purchased only part of the Arndes inventory. “ Bailey (I990), S. I 85.

393 „Vellum and paper was expensive to buy, and it would have been financially prudent for Hoffman to keep his pamphlets short and his editions small. [...] To recoup some of the costs Hoffman may have sold some of his pamphlets at fairs and book markets, but it was not a capitalist venture. He probably covered his own costs with help from friends." Ebd., S. I 86.

394 Ebd., S. I 87.

395 Vgl. dazu Paintner, die folgende Begrenzungen der Publizistik aufzählt, die zwar die zweite Hälfte des I6. Jahrhunderts betreffen, aber auch in der ersten Hälfte ebenso vorhanden waren: „Zum einen begrenzt der Zugang zur Druckerpresse die Möglichkeiten zur Diskussionsbeteiligung, Sowohl eine finanzielle Basis als auch Beziehungen sind nötig, um den eigenen Text auf den Markt zu bringen." In Paintner (20I0), S. I44. Hoffman konnte beide Grundvoraussetzungen erfüllen und so am Diskurs teilnehmen.

396 Bailey (I990), S. I 87. 
Lage Friedrichs I. von Dänemark, der sich „[i]n der Religionsfrage [...] durch die bestehenden Machtverhältnisse zu einer zwiespältigen Politik veranlaßt [sah]." “397 Teils war er gezwungen, den alten Glauben offiziell weiterhin zu vertreten, teils galten seine persönlichen und finanziellen Interessen dem neuen evangelischen Glauben. Er forderte auf der einen Seite Geld von den Prälaten ein und versprach mit der Zahlung, den alten katholischen Glauben zu schützen, gab aber auf der anderen Seite Wanderpredigern die Möglichkeit, unter seinem Schutz auf seinem Territorium das „,reine Gotteswort“ (eine Umschreibung für Luthers Lehre) zu verkünden “. ${ }^{398}$ Da diese Prediger nicht mit Pfründen ausgestattet werden mussten, war der König nicht gezwungen, den altgläubigen Priestern ihre Pfründe wegzunehmen oder zu kürzen. ${ }^{399}$ Die Situation in Kiel während Hoffmans Aufenthalt beruhte auf einer ambivalenten Kirchenpolitik, denn mit Melchior Hoffman hatte der König einen weiteren Vertreter des neuen Glaubens an die Kieler Nikolaikirche geholt (Hoffman zählte sich in den Jahren I 523-I 529 selbst zum Lager Luthers und wurde scheinbar auch trotz seiner bereits in wichtigen Punkten divergierenden Auffassungen von anderen dazu gezählt). ${ }^{400}$ Erst nach einiger Zeit wurde klar, dass Hoffmans Auffassungen und Predigten sich von denen der Lutheraner zu weit entfernt hatten, um noch als lutherisch gelten zu können - vor allem auch in Anbetracht des Kurswechsels Luthers nach dem Bauernkrieg I 525.

Der Schriftwechsel mit Nikolaus von Amsdorf macht diese Differenzen schließlich sehr deutlich, obgleich Hoffman seinerseits noch nicht auf eine Abspaltung vom Wittenberger Lager zielte. Ungeachtet der Tatsache, dass Hoffmans zwei polemische Schriften bereits die unvermeidliche Separation von protestantischen Theologen und Laienpredigern stellenweise erahnen lassen, inszenieren sie vorwiegend nur einen Streit zwischen zwei Individuen anstatt zwischen Gruppen - das persönliche Zwiegespräch, das dialogische Wortgefecht zweier einzelner Kontrahenten, bildet dementsprechend das polemische Programm.

\footnotetext{
397 Deppermann (I979), S. 85.

${ }^{398}$ Ebd., S. 87.

399 Ebd.

${ }^{400}$ „König und Adel hatten nichts dagegen, wenn der altgläubige Klerus auch von unten her unter Druck gesetzt wurde. “ Ebd.
} 


\subsection{Der Streit mit Nikolaus von Amsdorf II: Die Schriften}

Seid ich vernym das es yo nicht anders sein mag / sondern mit gro̊blichen sachen zu schreiben gedrungen werde / wil ich der verantwortung vberbůtig sein.

(Melchior Hoffman) ${ }^{40 r}$

Amsdorfs Schreiben Ein vormanung, das er I 527 in Magdeburg drucken ließ, kann - wie bereits erläutert - als Initiationsschrift des Streits zwischen ihm und Hoffman betrachtet werden. Wie der Titel verrät, sollte es die Bewohner Magdeburgs vor dem kurz zuvor durchgereisten Melchior Hoffman warnen bzw. diesen in Misskredit bringen, um die Reformation in Magdeburg nicht zu gefährden. Vermutlich fühlte sich Amsdorf durch seine bisherigen Erfahrungen mit sogenannten ,Schwarmgeistern', ${ }^{402}$ Irrlehrern aus der Sicht der Reformatoren, dazu gezwungen, in Magdeburg Präventivmaßnahmen für eine eventuelle Rückkehr Hoffmans zu ergreifen. Amsdorf bekleidete seit September I 524 das Amt des Pfarrers von St. Ulrich in Magdeburg und man hatte ihn mit der Aufgabe betraut, die schon begonnene Reformation in Magdeburg voranzutreiben. ${ }^{003}$ Noch I 52I hatte Amsdorf eine große Unsicherheit gegenüber ,Schwarmgeistern' bewiesen, als er in Wittenberg in Kontakt mit den „Zwickauer Propheten“ kam. Er hatte Probleme,

${ }^{40 \mathrm{r}}$ Hoffman ( 1528 ), Nasen geist, A2r. Vollständige Angabe bei Anmerkung 36.

${ }^{402}$ Das Schlag- bzw. - die pejorative Komponente exakter erfassend - das Stigmawort Schwarmgeist ist synonym mit dem Schlag-/Stigmawort Schwärmer, das nach Hans-Joachim Diekmannshenke eines „[...] der Lieblingsworte Luthers im Kampfe gegen die Radikalen ist, [...] entstanden aus der Terminologie der Bienenzüchter, dann ,im I6. jahrh. und später gern in religiösem sinne auf irrgläubigkeit zielend“ [Grimm Bd. 9, Sp. 2288]. In diesem Sinne eine Neuprägung Luthers, bezeichnet es anfangs nicht nur Radikale, sondern Abweichende aller Art, d. h. auch im reformatorischen Lager selbst. Im Gegensatz zum Ketzer assoziiert Schwärmer eine spöttische Komponente, die im summenden, schwirrenden Flug der jungen Bienen ein Zeichen von Unreife und Übermut erblickt. Schwärmen als Fehlen von ,Ruhe und Besonnenheit' charakterisiert aus der Sicht Luthers jugendliches Ungestüm, welches leicht zu religiöser Verworrenheit führt. [...] Die spöttische Titulierung von Abirrenden als Schwärmer wird bald zur spezifisch Lutherschen Gesamtbezeichnung der Radikalen. [...] Schwärmer wird als Schlagwort ausschließlich gegen religiöse Irrlehren verwendet [...].“ Diekmannshenke (I990), S. 337-340. Das Stigmawort wurde jedoch nicht allein auf lutherischer Seite angewandt, sondern u. a. auch von den Radikalen selbst, um die Lehre der Lutheraner oder anderer religiöser Gruppierungen als unfundierte und demnach schwärmerische Irrlehre darzustellen. Auch Hoffman verwendet das Stigmawort Schwärmer bzw. Schwarmgeist zu diesem Zweck in seinen polemischen Schriften.

${ }_{403}$ Ilgner (2008), S. $255 \mathrm{f}$. 
die Situation und die "wundersame[n] vnd vnerhorte[n] ding[e]“ einzuordnen, und erbat sich die Hilfe von Melanchthon und Spalatin, da er selbst glaubte, dass der Auftritt der "Zwickauer Propheten“ das Weltende ankündigen würde. ${ }^{404}$ Nachdem Amsdorf jedoch I 525 ein weiteres Mal mit einem so genannten ,Schwarmgeist', dem Mediziner Wolfgang Cyclop, in Kontakt gekommen war und sich mit diesem schon in einem Streitschriftenwechsel über das Abendmahl auseinandergesetzt hatte, ${ }^{405}$ war er zum Zeitpunkt des Zusammentreffens mit Hoffman im Jahr I 527 nicht mehr zu verunsichern, zumal Luther ihm geraten hatte, Hoffman unfreundlich zu empfangen. Ein vormanung ist demzufolge nicht die erste Warnung, die Amsdorf an das Magdeburger Publikum richtete.

Ihrer unterrichtenden, pastoral warnenden und mahnenden Funktion folgend, ist die kleine Schrift Ein vormanung als Dialog mit „lieben Freunde[n]" 406 angelegt, bricht aber am Ende mit dieser Konzeption der Anrede, denn die Schlussworte richten sich plötzlich direkt an Hoffman. ${ }^{407}$ Als Anlass des Schreibens nennt Amsdorf die Unklarheit von Melchior Hoffmans Errechnung der Apokalypse. Hoffmans Lehre vom Jüngsten Tag sei „tunckel vorgebliche vnd vnnütze rede“,408 die Angaben nicht genau genug. Amsdorf wirft Hoffman also einerseits vor, eine zu ungenaue Datierung gemacht zu haben und damit unklar zu

404 Ilgner (2008), S. 253.

${ }^{405}$ Ilgner gibt eine Darstellung der Streitigkeiten zwischen Amsdorf und Wolfgang Cyclop in seinem Aufsatz. Der Streit hatte sich über Cyclops Predigten entfacht, in denen er behauptet hatte, dass das Brot und der Wein beim Abendmahl nicht Christi Leib und Blut wären, sondern diese nur bedeuteten. Daraufhin sah Amsdorf sich gezwungen, Cyclop schriftlich entgegenzutreten und das Publikum in Magdeburg zu warnen: Vermanung Nicolai von Amsdorff an die von Magdeburg wider den rotten unnd secten gaist D. Ciclops. M. D. XXV. Ebd., S. 252-263. Das vorliegende Exemplar wurde I 525 in Augsburg gedruckt.

${ }^{406}$ Amsdorf beginnt seine vier Textseiten lange Schrift mit den groß- und fettgedruckten Begrüßungsworten: „Mein lieben Freunde“ (EV, A2r).

${ }^{407}$ „O du schwarzter Teuffel ich ken dich wol / ich hab dich noch bey einem ergriffen / do ich mit dir redte / das wil ich sparen bis du kompst / vnd dich (wils Gott) aller welt zeigen / vnd offenbar machen wer du bist / Der Teuffel kan auch schleichen vnd sich demütig machen / gleube mir.“ (EV, A3v)

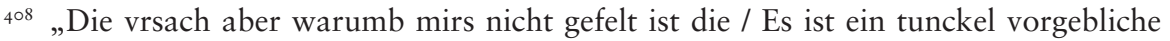
vnd vnnütze rede / ynn dem das er die zween Propheten nicht anzeiget wer sie sein / vnd auch nicht die zeit wenn sie angefangen haben zu weissagen / das man kundt rechen wenn die sieben jar vmb weren / Der heilige geist redet nicht so tunckel vnd vnuerstendig / sondern klar / hell vnd verstendig / vnd zeigt an gewisse zal / der iar den anfang vnd das ende / wie der Engel die zeit von Christo dem Daniel klerlich anzeigt." (EV, A2r) 
sein, kritisiert aber gleichzeitig, dass Hoffman überhaupt eine Datierung vornimmt, da man aus seiner Sicht jederzeit auf die Wiederkunft Christi warten solle. Als Untermauerung diskreditiert er Hoffman als selbsternannten Propheten, der infolge seiner Selbsternennung nur vom Teufel geschickt sein könne anstatt von Gott.

Bevor Hoffman jedoch zur Feder gegen die Denunzierungen Amsdorfs griff, schickte er trotz seines zuvor missglückten Besuchs in Wittenberg (I 527) Amsdorfs Ein vormanung mit eigenen kritischen Kommentaren versehen an Luther. Luther schrieb daraufhin am 3O.I 2.I 527 an Amsdorf:

Melchior ille Hofman ad me misit quaternionem a te editum, cum scholiis in te. Sed Marquardus [Schuldorp] sic testimonium de eo scribit, ut mihi totus sit suspectus multis modis, vanus, vix quieturus, nisi malum sibi conciliet. Monebo, ubi potero, ut sibi caveant ab illo. ${ }^{409}$

Da die von Hoffman gewünschte Reaktion Luthers ausblieb, verfasste Hoffman dann schließlich, vermutlich Anfang des Jahres I 528, auf Niederdeutsch seine erste polemische Schrift gegen Amsdorf mit dem Titel Dat Nicolaus Amsdorff der Meydeborger Pastor / nicht weth / wat he setten / schriuen edder swetzen schal / darmede he syne logen bestedigen moge / unde synen gruweliken anlop.410 Mit der Nennung Amsdorfs im Titel wird bereits deutlich die personalisierte Polemik hervorgehoben und die Funktion der Schrift angekündigt.

\subsubsection{Direktes Polemisieren und Ironisieren als Mittel der Streitkonstruktion in Dat Nicolaus Amsdorff [...] nicht weth / wat he setten / schriuen edder swetzen schal}

Hoffmans erste polemische Schrift gegen Amsdorf ist einer der ersten Kieler Drucke. ${ }^{4 I}$ Die Auflagenzahl ist unbekannt. Der spärliche

409 „Melchior Hofmann hat mir einen von Dir herausgegebenen Bogen geschickt mit Bemerkungen wider Dich. [sic: Auslassung in der Originalübersetzung] Aber Marquard Schuldorp charakterisiert mir ihn so, daß ich vor ihm warnen werde, wo ich kann. " Lateinischer Originalwortlaut und Übersetzung in WA. Briefwechsel 4 , S. 3 II.

410 Vollständige Angabe siehe Anmerkung 36. Die Quellenangaben bei Zitaten werden mit den Initialen DNA und der Folienangabe der Übersichtlichkeit halber in Klammern gestellt. Übersetzung des Titels: „Dass Nikolaus Amsdorf, der Magdeburger Pastor, nicht weiß, was er setzen, schreiben oder schwätzen soll, damit er seine Lügen bestätigen möge und seinen grauenvollen Angriff.“

${ }^{41}$ Siehe die nachgestellten Anmerkungen Gerhard Fickers (eine Seite) zur Faksimileausgabe von Dat Nicolaus Amsdorff in: Ficker (I928). 
Erhalt der Schrift lässt zwar auf keine große Auflage schließen, diese Schlussfolgerung bleibt jedoch eine Vermutung. Dat Nicolaus Amsdorff kann als Replik auf Amsdorfs Schrift betrachtet werden, denn Hoffman orientiert sich inhaltlich sehr an Amsdorfs Initiationsschrift: Amsdorfs Argumente gegen Hoffman werden zumeist genannt und entkräftet. Es werden u. a. die Forderungen Amsdorfs wiedergegeben, dass Hoffman seine Prophezeiung mit Bibelstellen untermauern müsse und die zwei Zeugen, die laut diesem zugegen seien, benennen solle. Hoffman aber begegnet diesen Forderungen in seiner Schrift lediglich mit Ironie und schreibt Amsdorf ein naives Verständnis des Sachverhalts zu. Er verweist einerseits auf seine Daniel-Auslegung - Amsdorf solle diese doch richtig lesen - und bestreitet andererseits, den Beginn der prophezeiten sieben Jahre verkündet zu haben. Amsdorfs Argument, dass man den Jüngsten Tag stets erwarten solle, entkräftet Hoffman mit einem Gegenbeweis aus der Bibel (2 Thess 2). Dat Nicolaus Amsdorff gibt direkte Repliken auf die meisten Argumente Amsdorfs, doch der Vorwurf, aufgrund einer fehlenden Priesterberufung ein Gesandter des Teufels zu sein, wird in Hoffmans erster Schrift nicht direkt kommentiert. ${ }^{42}$ Nach der polemischen Bearbeitung der ausgewählten gegnerischen Argumente richtet sich Hoffman im letzten Abschnitt an die Leser und bringt seine peroratio an, dass sie trotz des Streits zwischen den Gelehrten keinen christlichen Lehrer um eines solche Schreibens willen verachten sollen (A4r).

\section{Zur Sprache und Struktur von Dat Nicolaus Amsdorff}

Dat Nicolaus Amsdorff ist mit insgesamt sechs Seiten Text ${ }^{4 \mathrm{I} 3}$ eine recht kurze Flugschrift. Trotzdem ist sie zwei Textseiten länger als Amsdorfs Ein vormanung. Sie besteht aus dem Titelblatt (AIr), ${ }^{414}$ das ein Bild des Weltenrichters im herzförmigen Inneren der fünfblättrigen Lutherrose trägt (siehe Abb. I), sechs Textseiten (AIv-A4r) und der unbedruckten Rückseite. Die Struktur des Textlayouts ist durchgehend gleichförmig (Fließtext, Abschnitte mit Einzug), heraus sticht nur die typographische Abtrennung des letzten Abschnitts mit einer ganzen Leerzeile Abstand. Bereits die sich optisch abhebende Trennung der Abschnitte weist in Hinsicht auf die sonst gebrauchten Abschnittstrennungen

${ }^{1 \mathrm{I} 2}$ In seiner zweiten Schrift gegen Amsdorf (Nasen geist) macht Hoffman dieses Thema hingegen zu einem zentralen Punkt. Siehe Kapitel 3.2.2 Imagekonstruktion und die Integration inter- und kontextueller Bezüge durch offenes Polemisieren in Das Niclas Amsdorff [...] ein lugenhafftiger falscher nasen geist sey.

${ }^{413}$ Insgesamt umfasst die Schrift acht Seiten: Titelblatt Arr-A4v (letzte Seite leer).

${ }^{414}$ Die Angabe der Folien für Dat Nicolaus Amsdorff erfolgt aufgrund des zentralen Stellenwerts dieser Schrift in diesem Kapitel in Klammern im Fließtext. 


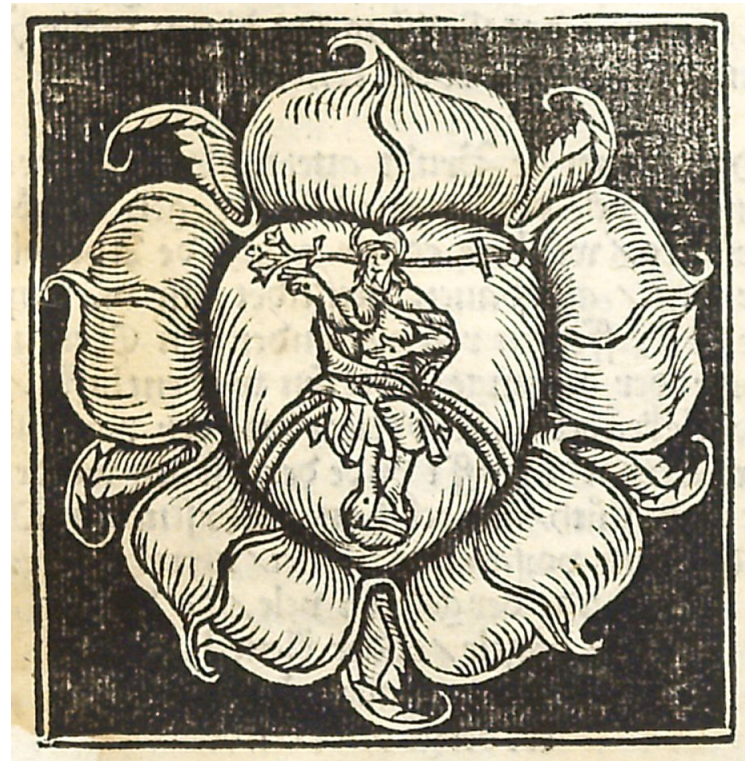

Abbildung 1. In den drei Kieler Drucken verwendete Hoffman dieses Bild des Welternrichters in der Lutherrose. Es handelt sich um eine typische Abbildung des Weltenrichters: Jesus sitzt auf dem Himmelsbogen, die Erde zu seinen Füssen. Aus seinem Mund kommen eine Lilie zu seiner rechten Seite und ein Schwert zu seiner linken Seite heraus. Ein Heiligenschein in Form eines Nimbus hinter dem Kopf ist angedeutet, die volle Rundung wird aber am oberen Ende durch die obere mittlere Einbuchtung der Herzform, die das Blüteninnere der Lutherrose darstellt, unterbrochen. Jesus trägt ein typisches umhangartiges Gewand, die linke Hand auf der davon unbedeckten Brust, eine Geste, die das Bedecken der tödlichen Seitenwunde - und somit das Leid Christi mit der Hand andeutet. Der rechte Arm ist in die Höhe, in Richtung der Lilie gestreckt, was darauf hinweisen könnte, dass Hoffmans Weltenrichter die Erlösung (Lilie) eher als die Verdammnis (Schwert) verspricht. Gerade in der Stellung der Hände variieren viele Darstellungen des Weltenrichters: Oftmals zeigen beide Hände schräg nach oben zu den beiden Gegenständen. Manchmal zeigt die Rechte schräg nach oben, die Linke schräg nach unten, welches man als Andeuten des Himmels auf der rechten Seite und der Hölle auf der linken interpretieren könnte. Auch die Händestellung bei Hoffmans Weltenrichter kommt öfter vor, deswegen soll hier keine Überinterpretation vorgenommen werden. Diese Abbildung ist aufgrund der besseren Qualität nicht aus der besprochenen Schrift, sondern der letzten Seite (Q3v) von Hoffmans I 529 erschienenen Schrift Dat Boeck Cantica Canticorum: edder dat hoge leedt Salomonis: vthgelecht dorch Melchior Hoffman Köninckliker maiestat tho Dennemarcken gesetter Prediger thom Kyll: ym lande tho Holsten entnommen. 
durch Einzug der ersten Zeile auf eine strukturelle Distanz hin. Sie korrespondiert auf textueller Ebene mit einer expliziten Änderung der Kommunikationssituation: Hoffman spricht in dem Abschnitt ausschließlich seine Leserschaft an und wechselt damit den auf Textebene markierten Hauptadressaten von Amsdorf zum Publikum.

Abgesehen von dem letzten hervorgehobenen Abschnitt sind die anderen I3 Abschnitte inhaltlich nach kleineren Themen eingeteilt, es geht, wie oben erwähnt, um Amsdorfs einzelne Aussagen und Argumentationen. Die Schrift ist nicht nach einer dispositio der Rhetoriklehre durchstrukturiert. ${ }^{45}$ Eine beinahe einzeilige salutatio („De gnade sy allen gelouigen in Christo Amen“ [AIv]) ist zwar noch klar zu erkennen, dann aber fließen die in der Rhetorik unterschiedenen Teile der Rede oder des Briefs ineinander, so dass narratio und argumentatio nicht als einzelne Einheiten nacheinander ausfindig zu machen sind. Vielmehr sind die Redeteile jeweils in den einzelnen Abschnitten nebeneinander vorhanden. Hoffman berichtet oftmals erst über bisherige Geschehnisse, um zu zeigen, wie schlecht er in der Vergangenheit behandelt wurde, und/oder gibt das Argument Amsdorfs wieder, um es dann mit einem Gegenargument oder einer Schimpftirade auf Amsdorfs lügnerischen Charakter zu entkräften. Diesem Muster folgend, steigt Hoffman, nach der kurzen salutatio, in medias res in die polemische Auseinandersetzung mit Amsdorf ein, ohne die Leserschaft aktiv ins Geschehen einzuführen (exordium) oder deren Wohlwollen zu erheischen (captatio benevolentiae). Schon im zweiten Satz danach wird Amsdorf mit „Ey du fyner dreper“ (AIv) ${ }^{416}$ direkt angesprochen, die sarkastisch verhöhnende Grundstimmung des Schreibens wird - vom Titel bereits angedeutet - unmittelbar am Anfang deutlich.

Die folgenden Abschnitte werden meistens mit einer Inquit-Formel im weitesten Sinne ${ }^{417}$ eingeleitet: „Den anderen punct / den de fyne dreper schrifft $[\ldots]$ “. (AIv), „Darumme secht dat logenmuel [...]“ (AIv), „Ock schrifft de dappere stryder vnde auerwinner [...]“ (A2r), „De wyle de peltzer dat gesecht hefft [...]“ (A2r), „Ock sprickt dat schone kindt [...]“ (A2r), „Du schriffst ock [...]“ (A2v), „Ock secht dat schalcksoge [...]“

${ }^{415}$ Zum Aufbau der Rede und des Briefs sowie den rhetorischen Termini siehe u. a. Plett, Friedrich (200I): Einführung in die rhetorische Textanalyse. Hamburg: Buske. ${ }^{416}$ „Ei, du feiner Schütze“. Diese und folgende Übersetzungen aus dem Mittelniederdeutschen durch die Verfasserin.

${ }^{417}$ Inquit = lat. er sagt. Die Erweiterung bezieht sich hier ebenfalls sowohl auf das Schreiben als auch auf andere grammatische Personen, wie z. B. „Du schriffst ock $[\ldots]^{“}(\mathrm{~A} 2 \mathrm{v})$. 
(A2v), „Sindt du o̊uerst dy lest beduncken [...]“ (A3r), „Du scheldest

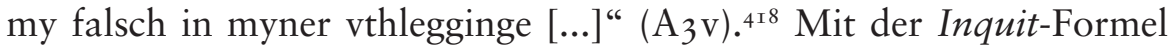
wird jeweils eine Redewiedergabe indiziert, so dass Abschnitt für Abschnitt jeweils ein Argument oder eine Aussage des Gegners vorgestellt und kommentiert wird. Nur wenige der Abschnitte beginnen ohne Inquit-Formel: „Euen ein solcker loggener ys de Amsdorff [...]“ (A3r), „Sůh Amsdorff [...]“ (A3r), „Wo du dat nicht doen kanst / so blyff men mit dynem stanck tho huss [...]“ (A3v).419 Sie tauchen erst ab der Mitte der Schrift auf, der erste Abschnitt ohne die Inquit-Formel setzt den Wendepunkt, indem festgestellt wird, dass Amsdorf ein Lügner sei (s. o.). Die Argumente sind in der ersten Hälfte des Textes bereits genannt und widerlegt worden und Hoffman betont noch einmal die Quintessenz seiner Auseinandersetzung mit Amsdorfs Argumenten: Er konstatiert, dass Amsdorf Hoffman geschändet sowie die Bibel falsch ausgelegt habe, er nun damit aufhören und anhand der von Hoffman genannten Kapitel eine richtige Auslegung vornehmen solle. Wenn dies nicht möglich sei, möge er es lieber gänzlich lassen. Er stellt also eine petitio an Amsdorf innerhalb des Rahmens, der die Leserschaft anspricht. Der letzte Abschnitt schließlich ist wieder deutlich als Briefform identifizierbar und eine petitio und peroratio sind an die „leuen vtherwelden Christen vnde Gades hylgen " (A4r $)^{420}$ gerichtet.

Sprachlich ist Hoffmans Schrift dem Kieler Raum angepasst, ${ }^{42}$ denn sie ist auf Niederdeutsch verfasst. Bereits vorher hatte Hoffman seine Texte sowohl auf Hochdeutsch (z. B. seine Daniel-Auslegung von I 526) als auch auf Niederdeutsch (z. B. An de gelöfigen vorsambling inn Liflant ein korte formaninghe von I 525) verfasst. Da Hoffman aus dem hochdeutschen Sprachraum (Schwäbisch-Hall) stammte, lässt sich anneh-

${ }_{418}{ }^{8}$ „Der andere Punkt, von dem der feine Schütze schreibt [...]“, „Darum sagt das Lügenmaul [...]“, „Auch schreibt der tapfere Streiter und Überwinder [...]“, „Als der Pelzer das gesagt hat [...]“, „Auch spricht das schöne Kind [...]“, „Du schreibst auch [...]“, „Auch sagt das Schalksauge [...]“, „Seit du dich zuoberst bedünken lässt $[\ldots]$ “, „Du beschuldigst mich, mit meiner Auslegung falsch zu liegen [...]“.

${ }^{419}$ „Eben ein solcher Lügner ist der Amsdorf [...]“, „Sieh, Amsdorf [...]“, „Wenn du das nicht tun kannst, so bleibe doch mit deinem Gestank zu Hause [...]“.

420 „lieben auserwählten Christen und Gottesheiligen/Gottes Heilige“.

${ }^{421}$ Das livländische Niederdeutsch, das Hoffman verwendete, zählt Agathe Lasch zum Nordniedersächsischen. Dieses spaltet sie wiederum in das OstfriesischOldenburgische, Nordalbingische, das im Kieler Raum gesprochen wurde, und das Ostelbische, das sowohl das Lübische als auch das livländische Niederdeutsch erfasst, auf. Demnach ist Hoffmans Schriftsprache dem Kieler Niederdeutsch ähnlich, weist aber grundsätzliche Unterschiede auf. Lasch, Agathe (I9I4): Mittelniederdeutsche Grammatik. Halle/Saale: Niemeyer, S. I6-I9. 
men, dass er das Niederdeutsche bei seinen langjährigen Aufenthalten im niederdeutschen Sprachraum (z. B. spätestens I523-I526 in Livland und I 526-I 527 in Stockholm), insbesondere auch durch sein Handwerk und Handelsbeziehungen bedingt, erlernte. Die innerdeutsche Sprachgrenze schränkte mitunter das Verstehen ein, so dass sie durchaus den Kreis der potenziellen Leser vordefinierte und begrenzte. ${ }^{422}$ Dass Hoffman seine Schrift auf Niederdeutsch verfasste, lässt insofern noch vor einer Analyse die These zu, dass das intendierte Publikum der Polemik eher die Leserschaft in Kiel war als der Gegner Nikolaus von Amsdorf selbst, denn dieser beherrschte das Niederdeutsche nicht, ${ }^{423}$ obgleich sein Hauptwirkungskreis Magdeburg zum niederdeutschen Sprachraum gehörte. Die Wahl des Niederdeutschen unterstreicht darüber hinaus die grundlegende Ausrichtung der Polemik auf die polemische Instanz und lässt eine Nebenadressierung Amsdorfs letztendlich sogar fraglich erscheinen. Die in der Schrift dominante Form des direkten Polemisierens (die Dominanz wird im Folgenden noch ausführlich begründet), also der direkten Anrede des polemischen Objekts, lässt sich insofern als bewusst eingesetzte Strategie der Streitinszenierung betrachten. Die dialogische Struktur der Schrift intensiviert und dynamisiert den polemischen Antagonismus, den der Text vor einem Publikum bzw. für ein Publikum entwirft.

Dass die polemische Instanz (Haupt-)Adressat ist, bestätigen auch die einzelnen Teile der einem Brief ähnlich aufgebauten Schrift: Der Titel, salutatio und peroratio (inklusive einer petitio) richten sich wie bereits erwähnt - nicht an das polemische Objekt, sondern an die polemische Instanz: Der Titel nennt Amsdorf in der 3. Person, in den Begrüßungsworten wünscht Hoffman allen gläubigen Christen die Gnade Gottes und die Schlussworte (die sich über fast eine ganze Seite erstrecken) sind sogar in der 2. Person Plural an die lieben auserwählten

${ }^{422}$ Die Existenz und die Auswirkungen der Sprachgrenze lassen sich z. B. daran zeigen, dass Martin Bucers Bericht Handlung inn dem offentlichen gesprech zủ Straßburg iünst im Synodo gehalten / gegen Melchior Hoffman / durch die Prediger daselbst I von vier fürnemen stucken Christlicher leere vnd haltung / sampt getrewem dar geben / auch der gründen / darauff Hoffmā seine irthumben seßet. Straßburg: [Mathias Apiarius] „auch in Münster durch den Prädikanten Adam Briccius Nordanus ,in die westphälische Sprache', also ins Niederdeutsche übersetzt [wurde], um dem in Münster verbreiteten Gerücht, Melchior Hoffman habe auf der Synode zu Straßburg gesiegt, den Boden zu entziehen. “ Kawerau (I954), S. 9. Binnenzitat aus Krohn (I784), S. 307.

423 Deppermann (I979), S. Ioo. 
Christen und Gottesheiligen gerichtet. ${ }^{224}$ Die ersten erklärenden Worte der polemischen Schrift sind ebenfalls so gestaltet, dass über Amsdorf in der 3. Person erzählt wird, was die Adressierung der salutatio unterstützt: „De kloge důre Heldt tho Meydeborch schrifft / vnde rho̊met sick gantz hoech / wo he den duiuel vnde synen Apostel so wol gedrapen hebbe“ (Arv). ${ }^{425}$ Hoffman gibt in den ersten Zeilen einen vagen Hinweis auf das, was der Anlass des Schreibens sei, und zwar in der Form, dass er sich nicht zuerst an den Gegner wendet, sondern über ihn in der 3. Person spricht, ohne überhaupt einen Adressaten durch direkte Anrede zu spezifizieren.

Anfang und Ende bzw. die Rahmenstruktur von Hoffmans Schrift entsprechen diesen Beobachtungen nach nicht der Strategie des direkten Polemisierens, denn in der briefähnlichen Rahmenstruktur wird anfangs noch unbestimmt, am Ende dann aber sehr konkret die polemische Instanz angesprochen, der Dialog wird mit dieser und nicht mit dem polemischen Objekt (Amsdorf) geführt. Innerhalb dieser einrahmenden Kommunikationssituation wird die direkte Anrede Amsdorfs in der grammatischen 2. Person, also der direkte, einseitige Dialog des polemischen Subjekts mit dem polemischen Objekt, jedoch zur dominanten Redesituation erhoben. In diesen Fällen ist das Prinzip des direkten Polemisierens erfüllt: Die Kommunikation findet in einer dialogischen literarischen Form in direkter Rede zwischen polemischem Subjekt und Objekt statt. Zudem wird in dem gesamten Schriftwechsel mit Amsdorf offen polemisiert, da sich sowohl Hoffman als auch Amsdorf als polemische Subjekte in ihren Texten inszenieren. Die Konstruktion der Kommunikationssituation des direkten Polemisierens kann eine Strategie der besonderen Inszenierung, Personalisierung und Dramatisierung des Streits bedeuten. Der Streit entfaltet und intensiviert sich performativ im Text - und zwar zwangsläufig vor den Augen der polemischen Instanz. ${ }^{226}$ Die Adressierung der polemischen Instanz ihrerseits bestärkt den Inszenierungscharakter der direkten Anrede des polemischen Objekts. Der Dialog zwischen dem polemi-

${ }^{424}$ Gruß: „DE gnade sy allen gelóuigen in christo Amen.“ Dat Nicolaus Amsdorff ( 528 ), A Iv. Beginn der Schlussworte: „Gy leuen vtherwelden Christen vnde Gades hylgen [...]". Ebd. A4r.

425 „Der kluge, teure Held zu Magdeburg schreibt und rühmt sich ganz hoch, dass er den Teufel und seinen Apostel so gut getroffen habe.“

${ }^{426}$ Die bereits diskutierten Faktoren, die Rahmenstruktur und die sprachliche Situation (Niederdeutsch vs. Hochdeutsch), lassen diesen Schluss zu. Auf verallgemeinernde Feststellungen wird jedoch verzichtet, da jede Schrift hinsichtlich ihres konkreten Adressaten gesondert analysiert werden muss. 
schen Subjekt und Objekt innerhalb des genannten Rahmens zeigt sich als polemische Strategie. Inwiefern sich die These konkret im Detail bestätigt, soll im Weiteren anhand der Untersuchung der konzipierten Kommunikationsszenarien, -teilnehmer und -wechsel erörtert werden.

\section{Die Kommunikationssituation als inszenatorisches Moment}

In Dat Nicolaus Amsdorff gibt es jeweils mehrere Formen der grammatischen Bezeichnungen für das polemische Subjekt, das polemische Objekt und die polemische Instanz. Grammatisch kommen die I. Person Singular, die 2. Person Singular sowie Plural und die 3. Person Singular vor. Die den Bezeichnungen entsprechenden Bezeichneten variieren allerdings in mehreren Fällen jeweils für das polemische Subjekt Melchior Hoffman und das polemische Objekt Nikolaus von Amsdorf. Die 3. Person Singular z. B. bezieht sich mal auf Amsdorf und mal auf Hoffman. ${ }^{427}$

Auf Seiten des polemischen Subjekts wird überwiegend das „Ich“ als Personaldeixis eingesetzt. Insgesamt vier Mal (über den gesamten Text verteilt) wechselt Hoffman diese jedoch und spricht über sich selbst in der 3. Person als dem „Pelzer“ (DNA, Arv, A2r \& A3v). ${ }^{428}$ Es fällt auf, dass er in dieser Form des Sprechens über sich selbst ausschließlich die Berufsbezeichnung für sich wählt. In Anbetracht der Feststellungen, die Johannes Schwitalla über das strategische „[Sprechen] [v]on sich selbst oder dem direkten Adressaten in der 3. Person" macht, ${ }^{429}$ erscheint

${ }^{427}$ Auch wenn es beim Lesen des Textes offensichtlich erscheint, muss bei der kontextuellen Verortung von polemischem Subjekt und Objekt verdeutlicht werden, dass die Textebene die Kontextebene (re)präsentiert. Hoffman inszeniert sich selbst als polemisches Subjekt, es liegt also kein verdecktes Sprechen vor, die Beteiligten werden namentlich genannt und es werden klare Bezüge zur Kontextebene gemacht: Hoffman bezieht sich z. B. auf seinen Gefängnisaufenthalt, den er auf Amsdorfs Initiative zurückführt (vgl. DNA, AIv).

${ }^{428}$ Die Referenz auf den „Pelzer“ kommt noch zwei weitere Male im Text vor, allerdings einmal in einer generalisierten Form, wo es um „einen Peltzer“ ( $\mathrm{A}_{3} \mathrm{r}$ ) geht und einmal in Kombination mit der I. Person: „dat du my [mich] Peltzer auerwinnen schalt [überwinden wirst]“ (DNA, A3v).

429 „In Bezug auf das Face-Management sind Selbstreferenzen eher selbstaufwertend, gerade auch bei der demonstrativen Vermeidung von Prahlerei. Bei der Fremdreferenz gibt es auch spöttische [...] und kritische bis verurteilende Einstellungen [...].“ Schwitalla, Johannes (20IOb): „Von sich selbst oder dem direkten Adressaten in der 3. Person sprechen “. In: Kallmeyer, Werner, Ewald Reuter \& Jürgen F. Schopp (Hg.): Perspektiven auf Kommunikation. Festschrift für Liisa Tiittula zum 60. Geburtstag. Berlin: Saxa, S. I63-184, hier S. I 83. Obwohl Schwitalla sich in diesem Aufsatz eher dem aktuellen Sprachgebrauch widmet, können seine Ergebnisse auch 
Hoffmans Wahl der Selbstreferenz bedeutsam. Schwitallas Feststellung folgend, dass die Selbstreferenz vorwiegend zur Selbstaufwertung beitragen soll, kann angenommen werden, dass Hoffman seinen Status als Kürschner nicht als einen Nachteil für die religiöse Auseinandersetzung gesehen, sondern diesen als ein positives Attribut verstanden hat. In diesem Zusammenhang sticht insbesondere eine Passage in der ersten Texthälfte heraus:

De wyle de Peltzer dat gesecht hefft / dat de tyde der tůgen sy / vnde dat de tůgen vorhanden synt / so hefft de Amsdorff darveh ermeten vnde erkant / dat de vij. yaer hebben angefangen / De Pelzer secht o̊uerst solckes nicht / vnde hefft ydt ock ny gesecht / De Amsdorff wolde eme gerne eine nasen maken[.] (A2r) $)^{430}$

Durch die Referenzen auf sich selbst und den Gegner Amsdorf in der 3. Person wirkt die Passage wie eine Nacherzählung durch einen unbeteiligten Dritten anstelle von Hoffman. Die Rede über sich selbst leistet insofern eine Perspektivenverschiebung, denn der Sprecher nimmt eine unbestimmte Position ein, von der aus eine neutrale Bewertung möglich ist. ${ }^{43^{\mathrm{I}}}$ Vergleicht man jedoch die Bezeichnungen der beiden Figuren, fällt die neutrale Referenz auf den Gegner Amsdorf auf. Er wird mit seinem Nachnamen anstatt der Berufsbezeichnung (wie z. B. als „Meydeborger Pastor" im Titel) genannt. Hoffman verzichtet an dieser Stelle sowohl auf eine ironische Anrede als auch auf eine Übereinstimmung der sich gegenübergestellten Fremd- und Selbstreferenz. Die Berufsbezeichnung „der Pelzer“ wird einerseits durch die paradigmatische Inkongruenz der Referenzen und andererseits durch die „markierte Verwendung“ der 3 . Person, die „sekundäre Bezugnahme auf sich“, 432 besonders hervorge-

auf das i6. Jahrhundert angewendet werden, da sie Allgemeingültigkeit beanspruchen können.

${ }^{430}$ „Dadurch dass der Pelzer gesagt hat, dass die Zeit der Zeugen angebrochen sei und dass die Zeugen existent sind, so hat der Amsdorf daraus ermessen und erkannt, dass die sieben Jahre angefangen haben. Der Pelzer sagt aber solches nicht und hat es auch nie gesagt. Der Amsdorf wollte ihm gerne eine Nase machen [= jemanden täuschen, siehe „NASE“, DWB I3, Spalte 408: ,viele redensarten können bestimmt auf die angedrehte wachsnase, die sich nach allen seiten biegen und wenden läszt, zurückgeführt werden“. In dem Zusammenhang wird auch „eine nase machen“ benutzt.].“

${ }^{43^{1}}$ „Im Zuge von berichtenden und anderen sprachlichen Tätigkeiten kann man über sich selbst von einem neutralen Standpunkt aus sprechen, [...]. Man behandelt sich dann wie einen Teil des Geschehens, über das gesprochen wird. “ Schwitalla (2010b), S. I69.

${ }^{432}$ Beide Zitate aus Schwitalla (20Iob), S. I 82. 
hoben. Diese besondere Akzentuierung der Rolle bzw. des gesellschaftlichen Status' Hoffmans dient kommunikativen Zwecken, womöglich in Anbetracht des überwiegend aus Laien bestehenden Publikums, und impliziert eine positive Konnotation des Kürschnerdaseins. ${ }^{433}$ Darüber hinaus kann sie auch eine ironische Bezugnahme darauf sein, dass Amsdorf Hoffman bei dem vorherigen Zusammentreffen in Magdeburg nahegelegt hat, sich lieber seinem Berufsstand zu widmen als theologischen Themen. ${ }^{434}$ In dem Zusammenhang lässt sich auch folgende Aufforderung an Amsdorf deuten:

Doe du eins leue Amsdorff / als S. Paulus i. Cor. xiiij. leret / Tritt mit dyner schrifft her vơr / legge den grunt anders vth / Kanstu den grundt mit warer schrifft anders vthleggen / vnde beter / ick wil dy ruem geuen / vnde wyken na S. Paulus leer / Wo o̊uerst nicht / so holde ick ydt dy nicht / deñ ydt gelt nicht schenden / vorlesteren ein werck / dat ick nicht weth beter tho maken / Dat ick einen Peltzer wolde in synem arbeide straffen / so moste ick se weten beter tho maken / Also ock mit allen Ampten / So du nicht solckes kanst / ho̊de dy vor straffen / vnde blyue men mit dynem losen geist tho huss / de mit fusche vnde blode dar ynheer swermet. Du sceldest my valsch in myner vthlegginge / dat mostu beweren / so kan me dy gelo̊ue / So du ydt ouerst nicht deist / bistu ein stock narr erfunden. $\left(\mathrm{A}_{3} \mathrm{r}-\mathrm{v}\right)^{435}$

433 „Auf sich mit einer Bezeichnung seiner eigenen privaten, beruflichen oder institutionellen Rolle zu verweisen, deutet auf kommunikative Bedingungen dieser Rolle hin und qualifiziert die Geltung der Rede als diejenige des Rolleninhabers. Der Sprecher fordert dann vom Adressaten die entsprechende Einstellung. “ Ebd., S. I69f.

${ }^{434}$ In Ein vormanung (A2v) fasst Amsdorf Hoffmans Besuch in Magdeburg wie folgt zusammen: „Darauff ist Melchior Hoffman am Mitwochen negst vorgangen ynn ein fremb haus zu mir kommen / vnd mich vngeferlich mit diesen worten angeredt / was mir an yhm feilet das ich brieffe von yhm geschrieben hette / dadurch yhm gros leid widerfaren were / [...] vnd als ich hort das er Melchior war / weiste ich yhn kurtz abe vnd sagt / er solt thun was er künde / denn es fiel mir nicht so eilend ynn was die Artikel waren vnd wie ich geschrieben hatte." (Hervorhebungen K. L.)

435 „Tu eins, lieber Amsdorf, wie es St. Paulus im I Kor I 4 lehrt: Tritt mit deiner Schrift hervor, lege den Grund anders aus. Kannst du den Grund mit wahrer Schrift anders auslegen und besser, will ich dir Ruhm geben und nach St. Paulus Lehre weichen. Wenn aber nicht, so glaube ich es dir nicht, denn es gilt nicht, ein Werk zu schänden oder über eins zu lästern, das ich nicht besser machen kann. Wenn ich einen Pelzer in seiner Arbeit tadeln wollte, müsste ich sie besser machen können. Gleiches gilt für alle Ämter. Wenn du solches nicht kannst, hüte dich vorm Tadeln und bleib mit deinem losen Geist zu Hause, der mit Pfusch und blöde da umher schwärmt. Du beschuldigst mich, mit meiner Auslegung falsch zu liegen. Das musst du beweisen, dann können wir dir glauben. So du es aber nicht tust, bist du als ein Stocknarr erwiesen." 
Hoffman appelliert an Amsdorf, die Bibel auszulegen und auf diese Weise einen Beweis anzubringen, dass Hoffmans Weissagung wirklich nicht der Wahrheit entspreche. Er kündigt an, dass er sich bei einer Beweisführung durch die Bibel fügen wolle ${ }^{436}$ und spielt Amsdorf damit vordergründig die Möglichkeit des Gewinns zu. Die Wenn-DannStruktur impliziert zwar oberflächlich, dass Amsdorf die Entscheidung in den Händen halte, aber durch den folgenden Vergleich mit dem Pelzerhandwerk wird ihm diese Fähigkeit abgesprochen: Dadurch, dass Hoffman die Situation umdreht und plötzlich von der Kürschnerarbeit spricht, die in keiner Weise von Amsdorf bislang angegriffen oder angezweifelt wurde - denn Amsdorf thematisiert ja gerade die theologische Tätigkeit Hoffmans und nicht sein Handwerk - lässt er Amsdorf als den Unkundigen erscheinen. Jener hätte keinesfalls die Arbeit eines Kürschners erledigen können und dieser Umstand wird für die Rezipienten ebenfalls offensichtlich gewesen sein. Hoffman rechtfertigt also seine Arbeit als Bibelausleger und Weissager mit einem invertierten Vergleich mit dem Kürschnerhandwerk und deutet an, dass Amsdorf die Bibel nicht besser auslegen könne als er selbst und somit der logischen Schlussfolgerung nach nur ein „stock narr“437 sein könne. Die Textstelle wird noch zusätzlich in dem Aufbau einer logischen Argumentation unterstützt, indem hier die Rede von „ick“ ist, und zwar in diesem Falle nicht von einem Ich, das sich deiktisch auf den Sprecher Hoffman bezieht, sondern eher die Funktion eines generalisierenden ,man' oder sogar eines , du' (stellvertretend für Amsdorf) übernimmt. ${ }^{43^{8}}$ Letzteres erscheint durch die implizite Rollenvertauschung

${ }^{436}$ Das Vorgeben einer potenziellen Einsicht, wenn denn nur gute Argumente von der Gegenpartei erbracht würden, ist eine allgemein genutzte Argumentationsstrategie. Sie soll suggerieren, dass der Verfasser nur an der Wahrheit interessiert und eine Persuasion grundsätzlich möglich sei, aber die rechten Argumente bisher gerade ausschließlich auf der eigenen Seite seien. So schreiben sich die Verfasser selbst Einsichtigkeit und die Fähigkeit, zwischen rechten und unrechten Argumenten unterscheiden zu können, auf den Leib, während sie gleichzeitig die Aussagen des Gegners als unrechte oder unwahre Argumentation beurteilen.

437 Der Stocknarr war während der Reformation eine durchaus geläufige Beschimpfung. Vgl. „STOCKNARR“, DWB I9, Sp. I 6 unter Punkt 2), Stichwort reformationsflugschriften. Siehe dazu auch: „STOCKNARR, [...] ursprünglich nicht eine blosze steigerung von narr, etwa wie oben erznarr [...], sondern ein narr von kurzer (oft verwachsener) gestalt wie ein stock, klotz [...] (bildungen wie diese haben neben [...] stockdunkel, stockfinster usw. die grosze menge der mit stock gebildeten verstärkenden zusammensetzungen erst angeregt). “ Ebd., Sp. I I 5 .

${ }_{43}^{8}$ Vgl. dazu: „Grammatische Kategorien sind nicht einfache Abbildungen außersprachlicher Kategorien. Ebensowenig wie das grammatische Genus eine einfache 
Hoffmans mit Amsdorf plausibel: Da Hoffman der Pelzer ist, kann er nicht gleichzeitig derjenige sein, der es besser als der Pelzer machen soll. Demnach ist das ,Ich` an dieser Stelle nicht stellvertretend für das polemische Subjekt, sondern für das polemische Objekt. Diese referenzielle Besonderheit komplettiert die Passage in ihrem Umgekehrtsein: Zum einen sind die Rollen Prediger und Kürschner vertauscht und zum anderen wird der von Amsdorf mündlich geäußerte und in Ein vormanung festgehaltene Zweifel an Hoffmans theologischer Kompetenz bei der Bibelauslegung entkräftet und an Amsdorf zurückgegeben. Der Status als Handwerker wird aufgewertet, so dass Hoffman sich selbst in seiner handwerklich-theologischen Doppelbegabung hervorzuheben vermag. Gleichzeitig wird suggeriert, dass Amsdorf mit dem Fehlen der handwerklichen Kompetenz auch seine theologische einbüßt.

\section{Der funktionalisierte Wechsel zwischen direktem und indirektem Polemisieren}

Der von der Häufigkeit der Anwendung auffälligste Wechsel der grammatischen Person ist der von der 2. zur 3. Person Singular (und vice versa) als indexikalischer Referent für das polemische Objekt Amsdorf. Überwiegend wird die Anrede Amsdorfs mit ,du'verwendet, vom höflicheren Ihrzen, das noch im Spätmittelalter die gebräuchliche Form der höflich distanzierten Anrede war, ${ }^{439}$ sieht Hoffman in Dat Nicolaus Amsdorff vollkommen ab. Das Duzen ist aber nicht nur in Hoffmans Schriften zu erkennen, sondern vielmehr ein allgemeines Phänomen im Reformationsschrifttum, denn „[d] as binäre T/V-System der Anredepronomina des Mittelalters beginnt sich in der Reformationszeit

Abbildung des biologischen Geschlechts ist oder das grammatische Tempus ein einfaches Modell der physikalischen Zeit, stellt die grammatische Kategorie Person eine digitale Eins-zu-eins-Abbildung der anthropologischen Kommunikationsrollen dar. Grammatische Kategorien sind analoge Modelle, also Metaphern außersprachlicher Kategorien. [...] Und so geht die Vorstellung, die grammatische ,2. Person Singular' sei die ,natürliche“ Bezeichnung der Gesprächsrolle Empfänger [...] am metaphorischen Charakter grammatischer Kategorien völlig vorbei." Kretzenbacher, Heinz Leonhard \& Wulf Segebrecht (I99I): Vom Sie zum Du-mehr als eine neue Konvention? Hamburg: Luchterhand, S. 22.

439 Vgl. Besch, Werner (2003): „Anredeformen des Deutschen im geschichtlichen Wandel“. In: Ders., Oskar Reichmann \& Anne Betten, Stefan Sonderegger (Hg.): Sprachgeschichte. Ein Handbuch zur Geschichte der deutschen Sprache und ihrer Erforschung. 3. Teilband. Berlin \& New York: De Gruyter, S. 2600-2628, hier S. 2600 . 
aufzulösen.“440 Dem Stil von Hoffmans Schrift entsprechend kommt das ehrerweisende und hierarchisch eine höhere Stellung markierende ,Ihr' dementsprechend gar nicht vor, sondern die direkte Anrede wird ausschließlich in der 2. Person Singular vorgenommen. ${ }^{44 \mathrm{I}}$ Dabei wird sie mehrheitlich abwertend gebraucht, was deutlich durch die ironischen oder beleidigenden Benennungen markiert wird. Die direkte Anrede ,du' wird am häufigsten mit einem ,Ich` kombiniert, so dass eine ,Ich-Du-Kommunikationssituation“ die überwiegende Form der Rede ausmacht. In dieser Hinsicht ist das dialogische Prinzip des direkten Polemisierens, bei dem das polemische Subjekt mit dem polemischen Objekt redet, für Dat Nicolaus Amsdorff dominant.

Die Wechsel zwischen direktem und indirektem Polemisieren sind zahlreich und fließend. Sie sind aber keinesfalls willkürlich, denn sie erfüllen bestimmte Funktionen bei der Inszenierung des Streits. Es ist beispielsweise zu erkennen, dass mit der 2. Person sehr oft konkrete Aufforderungen einhergehen:

I. Du ho̊nescher dreper / Du most noch anders datan / Meinstu dat du de godtlosen Papen vor der handt hebbest / Du werst feylen / Schrift mostu bringen / nasen laruens gylt hyr nicht / Mit minschen dreck werstu my ne̊n drepen don / Gades wort nym vor dy / lath sehen wat du kanst. (AIv) ${ }^{442}$

2. Leue Amsdorff scheme dy doch / vnde gha nicht mit so losem geswetze vmme / Wultu wat doen / so gha in krafft des wordes / so mach dyne sake bestant hebben[.] (A3r) ${ }^{443}$

3. Thom ersten ys dat myn begere an dy / de wyle du dy geleret lest důncken / vnde de Peltzer valsch / so legge my vth dat xij. Capit. ym Daniel. [...] Důsse dorchgha my alle van anfang beth

${ }^{440}$ Kretzenbacher \& Segebrecht (I99I), S. 24. „T/V“ steht für die lat. Pronomina tu und vos.

${ }^{44}$ Amsdorf hingegen benutzt vereinzelt und scheinbar recht willkürlich (denn der Wechsel zwischen du und ihr wird mitunter in zwei aufeinanderfolgenden Sätzen vollzogen) die höflichere Form des ,Ihr': „Ho̊rt yhrs auch Melchior hoffman [...]“ $\left(F P, \mathrm{~A}_{4} \mathrm{r}\right)$.

${ }^{442}$ „Du höhnischer Schütze, du musst es noch anders tun. Meinst du, dass du den gottlosen Papst vor dir hättest? Du wirst scheitern. Schrift musst du erbringen, sich zu maskieren gilt hier nicht. Mit Menschendreck wirst du mich nicht treffen können. Nimm dir Gottes Wort vor, lass sehen, was du kannst."

443 „Lieber Amsdorf, schäme dich doch und geh nicht mit so losem Geschwätz um. Willst du etwas tun, so gehe mit der Kraft des Wortes. So mag deine Sache Bestand haben." 
thom ende. Wo du dat nicht doen kanst / so blyff men mit dynem stanck tho huss / dat rade ick dy / edder ick werde dy ein Valete geuen / dat me seggen schal / ydt sy ein Valete. $\left(\mathrm{A}_{3} \mathrm{~V}\right)^{444}$

Mit der direkten Anrede des polemischen Objekts geht vermehrt die Nutzung des Imperativs einher, was das appellative Moment besonders deutlich und nachdrücklich macht. Insbesondere im Zitat I wird eine Steigerung der Aufforderung durch den Imperativ am Ende des Satzes („Gades wort nym vor dy / lath sehen wat du kanst“) erreicht. Die vorausgehenden Formulierungen mit dem Hilfsverb , müssen 'drücken zwar einen Zwang aus, sind aber nicht ebenso appellativ wie der Imperativ, der schließlich fast einem Befehl gleichkommt. Auch die Wahl des Imperativs im Zitat 3 („so legge my vth“) - eine Satzkonstruktion mit der Konjunktion „dass“ wäre ebenfalls eine denkbare Fortsetzung des begonnen Satzes ( „Thom ersten ys dat myn begere an dy“) gewesen wirkt bewusst gewählt, um die Herausforderung bzw. Aufforderung glaubwürdig zu inszenieren. Hoffmans Aufruf zur Auslegung der Bibel als Beweisführung ist nicht zuletzt daher als Inszenierung zu betrachten, weil er von der Unfähigkeit Amsdorfs, diesen Beweis zu erbringen, ausgeht. Der Appell ist insofern ein vorgetäuschter, dem die Antizipation inhärent ist, dass Amsdorf der abverlangten Handlung gerade nicht nachzukommen vermag, ohne dabei gleichzeitig Hoffman Recht geben zu müssen und seine eigene Position einzubüßen: Hoffman impliziert, dass Amsdorf bei korrekter Bibelauslegung zu Hoffmans Ergebnissen kommen müsse und Amsdorfs Position somit keinen Bestand hätte. Dementsprechend handelt es sich lediglich um einen strategischen Appell, der weniger eine reelle Appellfunktion erfüllt, als dass er Hoffmans Bibelauslegung und Position in ihrer Richtigkeit bestärken soll.

Die vermehrte Anwendung von Aufforderungen als theatralische Streittechnik steht funktional im engen Zusammenhang mit der bereits behandelten Textstelle (Hoffmans Berufung auf I Kor I4, A3r-v, s. Anmerkung 447), in der Hoffman lediglich suggeriert, Amsdorf im wörtlichen Sinne die Federführung in die Hände zu legen, ihm also die Möglichkeit zu geben, seinen Standpunkt anhand der Bibel zu bestätigen.

${ }^{444}$ „Zum ersten ist es mein Begehren an dich - da du dich als gelehrt ausgibst und den Pelzer als falsch - so lege mir das I 2. Kapitel des Buches Daniel aus. [...] Gehe mir diese alle vom Anfang bis zum Ende durch. Wenn du das nicht tun kannst, so bleib doch mit deinem Gestank zu Hause, das rate ich dir, oder ich werde dir den Laufpass geben, dass man sagen soll, es sei ein Laufpass.“ 
Ähnlich ist die Vorwegnahme von Amsdorfs Scheitern den anderen inszenierten Appellen eingeschrieben. Die direkt an Amsdorf gerichteten Aufforderungen zeigen sich als in Szene gesetzte Herausforderungen zum Kräftemessen, das zwar schon als entschieden vorausgesetzt wird, trotzdem aber seine dramatisierende Wirkung entfaltet. ${ }^{455}$ Es gilt für Hoffman das Scheitern Amsdorfs so zu implizieren, dass auch das Publikum dies erkennt.

Neben den Appellen ruft auch vor allem die Drohung, die Hoffman mit der Ankündigung eines ordentlichen „Valete“ ausspricht $\left(\mathrm{A}_{3} \mathrm{v}\right)$, bildlich Gewaltszenen hervor und intensiviert die Dringlichkeit der Sache und die Brisanz des Streits. Die Anwesenheit Amsdorfs ist in den Text eingeschrieben, während die polemische Instanz in die Rolle des schaulustigen Betrachters gerückt wird. Diese Konstellation gleicht der Situation bei einem Duell, das vor den Augen der Zuschauer durchgeführt wird. Die dialogische Kommunikationssituation des direkten Polemisierens (die Ich-Du-Situation) zeigt sich auf diese Weise als produktives Mittel des In-Szene-Setzens des Streits zwischen Hoffman und Amsdorf, indem sie bekannte Bilder und Szenen eines gewaltvollen (Zwei-)Kampfes oder eines inbrünstig geführten Streitgesprächs evoziert.

Die Rede über Amsdorf in der 3. Person - also indirektes Polemisieren - wird hingegen häufig dann eingesetzt, wenn berichtende, zusammenfassende oder nacherzählende Aussagen gemacht werden, insbesondere dann, wenn Hoffman rekapituliert, was Amsdorf gesagt oder geschrieben habe:

4. De kloge důre Heldt tho Meydeborch schrifft / vnde rho̊met sick gantz hoech / wo he den dủuel vnde synen Apostel so wol gedrapen hebbe[.] (AIv) $)^{446}$

5. Den andern punct / den de fyne dreper schrifft / ys de / wo Martinus syn vader sy / J hebbe nicht geweten / dat de fyne heldt eines Mo̊nnekes so̊ne was / vnde knecht / Jck woste nicht / wo syne voruolginge so hart wedder my vmme der warheit willen was / En hefft o̊uerst de arth der huren kinder gesteken / de in

${ }_{445}$ Hoffman bedient sich mit der (Zwei-)Kampfmetapher einer üblichen Strategie in polemischen Schriften der Reformationszeit. Wiederkehrend werden gelehrte Streitigkeiten z. B. als „Kampf Mann gegen Mann“ oder auch als „Schlacht zwischen ,Geschwadern““ inszeniert. Bremer (2005b), S. I30.

${ }_{446}$ Übersetzung siehe Anmerkung 425. 
dem alten Testament ock also de vtherwelden Gades vorfolgeden[.] (Arv) $)^{447}$

6. Ock schrifft de dappere stryder vnde auerwinner / ick schal eme mit schrifft bewysen / dat de Jůngeste dach in vij. yaren kamen schal[.] (A2r) $)^{448}$

7. Ock schal ick dem dapperen Helde seggen de ij. tůgen[.] (A2r) $)^{449}$

8. Ock sprickt dat schone kindt / de vorwesselde dủuel / Me scho̊le nichtes predigen / denn dat Christus beualen hebbe[.] (A2r) $)^{40}$

9. Ock secht dat schalcksoge / Me schal beden / vnde alle stunde waken[.] (A2v) ${ }^{45}$

In diesen Fällen, in denen Hoffman über Amsdorf in der 3. Person spricht, wird das anfangs definierte Publikum (alle gläubigen Christen) automatisch wieder zum Hauptadressaten der Rede. Zudem weicht die Streitinszenierung als performativer Akt der scheinbar sachlichen Aufklärung des Publikums, einer narratio, ${ }^{452}$ die als ein rewriting (Umschreiben) der Geschehnisse fungieren soll, so dass die Leserschaft die beschriebenen Ereignisse aus Hoffmans Perspektive bewertet oder umdeutet. Auffällig unsachlich ist jedoch in jeder dieser eingewebten berichtenden Abschnitte die Art und Weise der Referenz auf Amsdorf, die in fast allen Beispielen Teil einer Inquit-Formel ${ }^{453}$ ist. Er wird auf ironi-

447 „Den anderen Punkt, den der feine Schütze schreibt, ist der, in dem Martin sein Vater sei. Ich habe nicht gewusst, dass der feine Held eines Mönches Sohn und Knecht wäre. Ich wusste nicht, dass er mich so hart wegen der Wahrheit verfolgen würde und als Krönung dessen die Art der Hurenkinder angenommen hätte, die im Alten Testament ebenso die Auserwählten Gottes verfolgten.“

${ }^{44^{8}}$ „Auch schreibt der tapfere Streiter und Überwinder (= Gewinner), ich solle ihm mit der (Heiligen) Schrift beweisen, dass der Jüngste Tag in sieben Jahren kommen wird."

${ }_{449}$ „Auch soll ich dem tapferen Helden die zwei Zeugen nennen.“

$45^{\circ}$ „Auch spricht das schöne Kind, der verwechselte (maskierte) Teufel, dass man nichts predigen solle außer dem, was Christus befohlen habe.“

${ }^{45}$ "Auch sagt das Schalksauge, dass man beten solle und jederzeit Wache halten.“

${ }^{452}$ Bremer erkennt einen Zusammenhang von sachlichem Stil und dem Sprechen über den Gegner in der 3. Person in religionspolemischen Schriften: „Am Ende der Schrift wechselt Scherer in einen sachlichen Stil. Um diesen zu betonen, verzichtet er völlig auf die direkte Anrede und spricht nur noch über Osiander." Bremer (2005b), S. I42.

453 Die Inquit-Formeln haben im Text eine Strukturierungsfunktion, denn sie leiten in den meisten Fällen einen Themenwechsel (in Bezug auf die Argumentation) oder zumindest eine Verschiebung des Gesichtspunktes ein. Vgl. dazu Bremer, der eine ähnliche Funktion für die Leseranrede konstatiert: „Die Leseransprache zu Beginn von Absätzen kommt dem kursorischen Lesen nicht nur entgegen, sie unterstützt es regelrecht.“ Bremer, Kai (2005a): „Techniken der Leserlenkung und 
sche Weise als kluger, teurer oder tapferer Held, feiner Schütze oder tapferer Streiter und Überwinder (Gewinner) bezeichnet, womit Hoffman auch hier die in Reformationsschriften übliche Kampfesmetaphorik einsetzt. Der Streit wird als Kampf dargestellt, in dem Amsdorf - die Ironie Hoffmans impliziert es - sich auf der Seite des Siegers wähne und sich selbst als Helden sehe. Hoffman nimmt mit den ironischen Bezeichnungen Amsdorfs Bezug auf dessen narratio in Ein vormanung, in der das Zusammentreffen mit Hoffman in Magdeburg aus Amsdorfs Perspektive geschildert wird. Hoffman vermischt diese Leseeindrücke mit seiner eigenen persönlichen Erfahrung des Zusammentreffens ${ }^{454}$ und schildert Amsdorf als arrogant und überheblich und kritisiert dessen Verachtung, die er Hoffman gegenüber gezeigt hat, als er ihn abwies und ihm riet, „er solt thun was er künde / denn es fiel [ihm] nicht so eilend ynn was die Artikel waren vnd wie [er] geschrieben hatte“ $(E V, \mathrm{~A} 2 \mathrm{v})$. Amsdorfs Erklärung, warum er Hoffman abgewiesen habe, demonstriert sein Desinteresse an Hoffman und vor allem dem, was er zu sagen hätte, obwohl er seinen Lesern wenig später erklärt, „wie klug / gelert vnd beredt er [Hoffman] ist“ (EV, A3r). Die Ablehnung und Überlegenheit, die Amsdorf in Ein vormanung gegenüber seinem Gegner aufbaut, beantwortet Hoffman einerseits mit ironischem Sarkasmus, meist ad hominem gerichtet, andererseits mit bibelgestützter Argumentation, mittels derer er seine Weissagung zu bestätigen und Amsdorfs Bewertung derselben als „tunckel vorgebliche vnd vnnůtze rede“ ( $E V$, A2v) zu widerlegen bezweckt: Durch die Ironie der übertrieben positiven Bezeichnungen für Amsdorf (s. Zitat 4-8) führt Hoffman die Entlarvung des Gegners sowohl als arrogant als auch als

-selektion im volkssprachigen Buch der Gegenreformation um I600“. In: Enenkel, Karl A. E. \& Wolfgang Neuber (Hg.): Cognition and the Book. Typologies of Formal Organisations of Knowledge in the Printed Books of the Early Modern Period. Leiden: Brill, S. 509-53 I. Die Inquit-Formel bei Hoffman ist der von Bremer untersuchten Leseranrede in ihren Funktionen fast gleichzusetzen, denn eine direkte Anrede des Publikums wäre aufgrund der Rede von Amsdorf in der 3. Person denkbar und es erscheint insofern beinahe so, als wäre sie lediglich elliptisch ausgelassen.

${ }^{454}$ Die Integration textinterner und textexterner Informationen wird durch die Form des offenen Polemisierens ermöglicht. Ausführlicher untersucht wird die Funktion des offenen Polemisierens im Schriftwechsel zwischen Hoffman und Amsdorf in Kapitel 3.2.2 Imagekonstruktion und die Integration inter- und kontextueller Bezüge durch offenes Polemisieren in Das Niclas Amsdorff [...] ein lugenhafftiger falscher nasen geist sey. 
unprofessionell vor, denn Amsdorf habe die Bibel nicht ganz und korrekt ausgelegt, insbesondere nicht die apokalyptischen Kapitel.455

Die Ironie wird zum einen durch die mehrmaligen Wiederholungen der Bezeichnungen deutlich, z. B. taucht der „dreper“ (Schütze) mehrmals im Text auf, zweimalig als "fyner dreper“ und ein Mal als „hơnescher dreper“. ${ }^{456}$ Zum anderen ist sie daran erkennbar, dass Hoffman positive Bezeichnungen und frei geäußerte Beschimpfungen kombiniert, z. B. nennt er Amsdorf erst „dat schone kindt“, fügt dann aber „der vorwesselde düuel“ hinzu und behauptet, dass Amsdorf sich demnach nur als ein ungefährliches Kind maskiere bzw. als ein solches erscheine. Eine weitere Bedeutung bekommt die Bezeichnung Kind in Hinsicht auf die am Anfang geäußerte metaphorische Äußerung, dass Amsdorf der Sohn Luthers, also eines Mönches, sei und dass er die Art der Hurenkinder aus dem Alten Testament angenommen habe. Ein Kind eines Mönches galt als ,Bastard' und bezeugte darüber hinaus auch noch den Bruch des Zölibats, eine als ähnlich unehrenhaft angesehene Herkunft hatten die ,Hurenkinder' (s. Zitat 5). Insofern gibt es etliche Bezüge auf die Bezeichnung Kind, die trotz des Zusatzes „schön“ eine negative Konnotation haben. Diese pejorative Komponente überlagert ironisch die Denotation des Ausdrucks „dat schone kindt“. Solche ironischen Bezeichnungen nehmen im Verlauf der Schrift an Häufigkeit $\mathrm{ab}$ und weichen direkten Beschimpfungen. Schließlich ist z. B. die Rede vom „schalcksoge“,457 womit Hoffman Amsdorf eine „arglistige, böse anschauungsweise, denkungsart" ${ }_{45}^{8}$ zuschreibt.

Auf uneigentliche sowie auf unvermittelte, geradlinige Weise wird das Sprechen über Amsdorf in der 3. Person genutzt, um distanzierter zum Gegner ein scheinbar objektives Urteil zu sprechen. ${ }^{459}$ Die ironischen sowie die ironiefreien denunzierenden Zuschreibungen oder Kommentare werden durch das indirekte Polemisieren sowohl

\footnotetext{
455 Hoffman nennt „dat xij. Capit. ym Daniel.- Dat iij. vnde leste Capittel in Johel. Dat xxiiij. Cap. Matthei. Dat xxi. in Luca. Jn S. Paulus andern Epistel thon Tesalon. dat ij. Capit. Jm boeck der hemeliken Apenbarunge [heimliche Offenbarung] des Apostels Johannis dat xi. vnde xij. Capit“ (A3v).

${ }^{456}$ Die Zusammensetzung mit ,höhnisch“ sprengt die Ironie schließlich, so dass die Abwertung offenkundiger und gesteigert wird.

457 Mk 7, 2If: „denn von innen, aus dem Herzen der Menschen, gehen heraus böse Gedanken; Ehebruch, Hurerei, Mord / Dieberei, Geiz, Schalkheit, List, Unzucht, Schalksauge, Gotteslästerung, Hoffart, Unvernunft.“ www.bibel-online.net, nach Luther I9I 2 .

${ }^{458}$ „SCHALKSAUGE“, DWB I4. Sp. 2083.

459 Vgl. Schwitalla (20IOb), S. I79.
} 
vom polemischen Subjekt als Sprecher als auch vom gesamten Dialog zwischen polemischem Subjekt und Objekt gelöst. Damit geht eine Entdramatisierung bei gleichzeitiger Narrativisierung des Geschehens einher, was wiederum eine Objektivierung der Proposition zur Folge hat. In Kombination mit der Ironie lässt Hoffman Amsdorf auf diese Weise als lächerlich erscheinen:

Ock schal ick dem dapperen Helde seggen de ij. tůgen / dar ys syn herte so sere vpgestorrtet / wo he ydt vor der tydt nicht tho weten kryget / wert em ein hart beswyment thokamen / dem krancken / séken / begherigen / Ach dat doch ein Doctor vorhanden were / de dem sůluen den gecken snyden ko̊nde /Wo krencken dat harde begherent. (A2r) ${ }^{460}$

Das polemische Bild, das Hoffman von dem „dapperen Helde“ zeichnet, kommt dem Bild eines Anti-Helden gleich: Er entrüstet sich so sehr darüber, die Namen der zwei Zeugen nicht in Erfahrung bringen zu können, dass er Probleme mit seinem Herzen bzw. mit seinen überbordenden Gefühlen bekommt, die ihm letztendlich Schwindel bereiten und ihn (geistes-)krank machen. Zum einen wird die Heldenhaftigkeit, die sich Amsdorf laut Hoffmans Darstellung an dieser Stelle selbst zuschreibt, als Trugbild entlarvt. Für den Zweck bedient sich Hoffman der Rede über Amsdorf in der 3. Person, denn so erscheint die Zuschreibung des „dappere[n] Helde[n]“ als eine, die nicht ursprünglich aus Hoffmans Feder stammt. Es wird suggeriert, dass es sich um eine Selbstzuschreibung Amsdorfs oder - in Bezug auf eine Anhängerschaft Amsdorfs - eine Fremdzuschreibung Dritter handelt. In beiden Fällen wird die Umkehrung der positiven Zuschreibung mittels des im Anschluss beschriebenen Kränklichseins Amsdorfs bewirkt und bestärkt das Ironische in der Bezeichnung des „dapperen Helde[n]“. Daran anschließend treibt Hoffman das Bild des kranken Amsdorfs auf die Spitze: Durch die Reihung „dem krancken / se̊ken / begherigen“ wird die vermeintliche Kränklichkeit Amsdorfs besonders hervorgehoben. Das „Ach“ weckt den Eindruck gespielter Besorgnis auf Hoffmans Seiten, die Ironie und das verhöhnende Moment werden sofort deutlich, nicht zuletzt durch die im Konjunktiv Irrealis (II) geäußerte Erfordernis eines Doktors, der Amsdorf wie in Hans Sachs' Fastnachtsspiel Das

${ }^{460}$ „Auch soll ich dem tapferen Helden die zwei Zeugen nennen. Da ist sein Herz so sehr aufgeregt, wenn er es vor der Zeit nicht zu wissen kriege, würde ihn ein harter Schwindel überkommen, den Kranken, Siechenden, Begierigen. Ach, dass doch ein Doktor vorhanden wäre, der demselben den Gecken schneiden könnte, wo das harte Begehren krank macht." 
Narrenschneiden von I534 den "gecken snyden ko̊nde“.46r Das Verlangen Amsdorfs, dass Hoffman die Zeugen namentlich nennen solle, wird auf diese Weise als Torheit bzw. sogar als Geisteskrankheit charakterisiert und ins Lächerliche gezogen. Da die Redewendung (,einem den Gecken schneiden') auf ein sichtbares „Gehirnübel der Zuchtkälber" zurückzuführen ist, das durch Schneiden oder Stechen entfernt wurde, ${ }^{462}$ zeichnet sich der Vergleich Amsdorfs mit einem wild oder verrückt gewordenen Kalb zusätzlich ab, so dass die Vorstellung eines orientierungslos umherirrenden, irrsinnigen Amsdorfs durch den Tiervergleich gleichsam pointiert wird.

Wie einerseits anhand der Personenbezeichnungen und andererseits anhand der besprochenen Textstelle beispielhaft gezeigt wurde, kommt ironisches Sprechen in der kleinen Schrift Hoffmans wib wie in vielen streitinszenierenden Schriften der Reformation - in permanentem Wechsel mit Rechtfertigungen, ${ }^{463}$ Argumenten auf Grundlage der Bibel, ${ }^{464}$

${ }^{46 \mathrm{I}}$ Der Geck = Thor, Narr (vgl. „GECK“, DWB 4, Sp. I9I4 und Schiller-Lübben 2, S. 26. Zur Redewendung, jemandem einen Gecken schneiden“ siehe „GECK“, DWB 4, Sp. I920: „[5] d) der geck erscheint auch wie ein zweites, fremdes ich, das uns vorübergehend besitzt, in uns haust koboldartig, uns ansticht, beiszt, treibt u. ähnl." „e) daher einem den gecken schneiden, losschneiden, stechen, bohren, eigentlich ibn durch eine operation davon befreien, dann aber durch eine bekannte handbewegung [...] dieses stechen vorzunehmen miene machen und damit ihn für einen narren erklären, verhöhnen, auch anführen $u$. $\ddot{a}$.“. Als Variante gibt es auch „einem den narren schneiden“ (siehe „NARR“, DWB I3, Sp. 359). In dieser Variante setzt das Fastnachtsspiel Das Narrenscheiden (I 557 ) von Hans Sachs eben dieses von Hoffman beschriebene Entfernen des Narren durch den physischen Eingriff eines Arztes für die Bühne um.

${ }^{462}$ Das Entfernen dieses Übels durch Stechen oder Schneiden war aufgrund des erforderlichen Könnens für diese Behandlung hoch angesehen. Vgl. Hoffman-Krayer, Eduard \& Hanns Bächtold-Stäubli (1932/33): Handwörterbuch des deutschen Aberglaubens. Bd. 5. Knoblauch-Matthias. Berlin \& Leipzig: De Gruyter, Sp. I806.

${ }^{463}$ Hoffman erklärt z. B. seine Bibeltreue: „Wente ick hange an Gade / vnde an Christo Jhesu / vnde holde syne wòrde / De my valsch wil maken / de kan ydt mit der Bibel nicht endigen / denn ick bin mit der Bibel vnde nicht wedder de Bibel“. (A3r). „Denn ich hänge an Gott und Jesus Christus und halte seine Worte. Wer mich verleumden will, der kann es mit der Bibel nicht vollenden, denn ich bin auf Seiten der Bibel nicht gegen die Bibel.“

${ }^{464}$ Vgl. dazu: „S. Paulus hefft de wort ock wol gewust / hefft o̊nerst allikewol dat wedderspe̊l geschreuen ij. Tessa. ij. Vnde strafft de gennen / de ock vorkůndigeden / dat de Jůngeste dach vorhanden were / dat me syner alle stunde vorwachen scholde / S. Paulus secht / ydt sy nicht war“ (A2v) „St. Paulus hat die Worte auch wohl gewusst, hat aber dennoch das Gegenteil geschrieben (2 Thess 2) und straft diejenigen, die auch verkündigen, dass der Jüngste Tag vorhanden (immer aktuell) wäre, dass man ihn jederzeit erwarten sollte. St. Paulus sagt, es sei nicht wahr.“ 
Aufforderungen zur, korrekten' Bibelauslegung und Anprangerung der gegnerischen Vorwürfe als Lügen oder Fehlinterpretation. ${ }^{465}$

\section{Streitintensivierung durch emotionalen Ton, Invektiven und} Kampfesmetaphorik

Hoffman nutzt durchgehend eine wechselhafte Mischung von sachlicher und unsachlicher Argumentation, die sich mal ad rem und mal ad personam richtet. Während Amsdorf in Ein vormanung seinen Gegner fast ausschließlich mit rationaler Argumentation zu widerlegen versucht, schlägt Hoffman einen weitaus emotionaleren Ton an. Amsdorf verzichtet fast völlig auf Beschimpfungen, lediglich am Ende seiner Schrift weicht er von diesem sachlichen Konzept ab. Dafür wechselt er interessanterweise die Kommunikationssituation zum direkten Polemisieren, indem er Hoffman in direkter Rede mit „O du schwartzer teuffel“ ( $E V$, A3v) anspricht. Diese, durch die Interjektion einem spontanen Ausruf gleichende, Beschimpfung bleibt die einzige in Ein vormanung, denn selbst die Argumente, die Amsdorf gegen Hoffman (ad personam) hervorbringt, werden mit vorgeblich sachlicher Argumentation begründet. ${ }^{466}$ Nicht nur am Stil, sondern auch an der Struktur von Amsdorfs Schrift lässt sich die lateinische Disputationskultur ablesen: Ein vormanung hat sehr deutlich die Gestaltung der klassischen Rede, unterteilt in exordium, narratio, argumentatio und peroratio. Diese streng rhetorische Strukturierung, den sachlichen Stil und rational nüchternen Ton Amsdorfs beantwortet Hoffman mit einer beinahe willkürlich anmutenden Struktur, einer durchgehenden Mischung aus sachlichem sowie unsachlichem Stil und einem emotional aufgeladenen Ton. Hoffman passt sich insofern nicht dem schriftlichen Ausdruck der gelehrten

${ }_{465}$ Hoffman wirft Amsdorf z. B. vor, ihn misszuverstehen und damit die Wahrheit verkannt zu haben: „Werestu vth Gade Johan. i. van eme geleret Johan vi. wo̊rdest de warheit erkant hebben / vñ my vmme der warheit willen nicht geschendet hebben / vnde gequelet mit gefenckniss“ (AIv). „Wärst du von/aus Gott (geboren) (Joh I), hättest du von ihm gelernt (Joh 6), würdest du die Wahrheit erkannt haben und mich wegen der Wahrheit nicht geschändet haben und mit Gefängnis gequält.“

${ }^{466}$ Der Behauptung Hoffmans, dass er ein von Gott gesandter Prophet sei, begegnet Amsdorf mit dem Argument, dass er nur vom Teufel gesandt sein könne, da er erstens unberufen sei, zweitens nicht weissagen dürfe, bis er von Gott gesandt sei (denn ein ,Geist' der Weissagung allein reiche nicht aus, man müsse auch die Autorisierung haben), und drittens weder seine von Gott mitgegebene Botschaft anzeige noch etwas Neues predige oder Amsdorfs Position mit der Schrift widerlege. Aus diesen Argumenten zieht Amsdorf ex negativo den Schluss, dass Hoffman nur ein Gesandter des Teufels sein könne ( $\left.E V, \mathrm{~A}_{3} \mathrm{r}-\mathrm{v}\right)$. 
rhetorischen Streitkultur seines Widersachers an, sondern agiert von der Struktur und dem Stil von Amsdorfs Ein vormanung verhältnismäßig losgelöst. Die Gestaltung von Dat Nicolaus Amsdorff mischt grob die Briefstruktur mit Elementen der argumentatio der klassischen Rede. Innerhalb des Briefrahmens gleicht der Text einer Thesenliste, indem Hoffman einzelne Argumente Amsdorfs in scheinbar willkürlicher Reihenfolge wiedergibt und kommentiert und durch Argumente ad hominem, ad personam oder ad rem widerlegt. Injurien, Schimpfund Stigmawörter begleiten diese Argumentation von Anfang an und komplettieren die Inszenierung des Streits.

Schimpf- und Stigmawörter sowie andere Arten der Beleidigung kommen sowohl in direkter Anrede als auch in der Form des Sprechens über Amsdorf in der 3. Person vor. Die Verteilung erscheint jedoch nicht willkürlich: In der 3. Person gibt es mehr ironische Bezeichnungen (s. o.) als in der direkten Anrede in der 2. Person. Man kann dementsprechend eine Tendenz erkennen: Je direkter die Kommunikationssituation des Polemisierens, desto eher kommen Beleidigungen ohne die Anwendung von Ironie vor: z. B. „du ellender bloet důuel“ (A2v) ${ }^{467}$ oder „du lose larue“ (A2v).. ${ }^{468}$ Auch Possessivkonstruktionen kommen zum Einsatz, um Beleidigungen auszusprechen: Hoffman mahnt Amsdorf, dass er mit seinem „losen geist“ (A2v) und mit seinem „stanck tho huss“ (A2v) bleiben solle, dass er ihn mit seinem "lögen mule“ $\left(\mathrm{A}_{3} \mathrm{v}\right)$ in seinen „losen dreck“ ( $\left.\mathrm{A}_{3} \mathrm{v}\right)$ nicht verwickeln könne.

Sämtliche Angriffe Hoffmans scheinen aufeinander abgestimmt: Amsdorf wird hauptsächlich entweder als blind für die Wahrheit bzw.

${ }^{467}$ Das Schimpfwort ,Blutteufel' gehört zu den zahlreichen Komposita mit ,-teufel', die sich während der Reformation besonderer Beliebtheit erfreuten (z. B. auch Lügenteufel). Der Blut- oder auch der Fleischteufel sind oftmals bildliche Ausdrücke für die ,fleischlichen' Laster, insbesondere den Sexualtrieb, die ,Fleischeslust‘. Die Bezeichnung als ,Teufel' kann in Anlehnung an das Neue Testament und den vermutlich daher rührenden Glauben daran, dass bestimmte teuflische Geister in die Menschen fahren und infolgedessen die Lasterhaftigkeit der Menschen verursachen.

${ }^{468}$ Die "Larve“ hat mehrere Bedeutungen, in Luthers Texten wird sie meist im Sinne von ,Gestalt‘ oder auch ,Kostüm‘ verwendet. Grimms Wörterbuch zählt die vier für Beschimpfungen relevante Bedeutungen auf: „I) gespenst, schreckgestalt [...], 2) copie, darstellung einer solchen schreckgestalt um der unterhaltung willen: larfen machen [...], 3) larve, in manigfacher bildlicher verwendung; wie maske [...], 4) larve auch die form und erscheinung des menschlichen antlitzes [...]". „LARVE“, DWB I2, Sp. 207-209. Die ,Maske“ ist der üblichste der vier Bedeutungszweige, von daher ist hier von dieser Bedeutung auszugehen. 
ignorant ${ }^{469}$ oder - und dies ist weitaus häufiger der Fall - als Lügner bzw. Verleumder der Wahrheit dargestellt. ${ }^{470}$ In dem Zusammenhang steht auch die Auswahl der pejorativen Verben und Substantive des semantischen Wortfeldes SPRECHEN: Hoffman spricht von Amsdorfs „losem geswetze“ " $\left(\mathrm{A}_{3} \mathrm{r}\right.$ ) und „[s]ynem losen geist [...] de mit fusche vnde blode dar ynheer swermet" (A3v), er behauptet, dass Amsdorfs Reden keinen Bestand haben, denn „nasen laruens“ (AIv) gelte nicht,47I und klagt ihn u. a. an: „Du sceldest my valsch in myner vthlegginge [...]“ (A3v). Die Häufung des pejorativen Wortgebrauchs mündet in einer Fülle von negativ charakterisierenden Zuschreibungen, die die Funktion übernehmen, ein innerhalb der Schrift überwiegend einheitliches Feindbild (Amsdorf als Lügner) zu entfalten. Basierend auf diesen Zuschreibungen entwickelt Hoffman schließlich auch die Rechtfertigung für sein Schreiben: „Bystu doch alles scheldens ein anfanck / vnde heffst my tho schryuende gedrungen" (AIV).472 Hoffman begründet damit nicht nur sein Schreiben, sondern auch den Ton des Schreibens, denn er spricht vom ,Schelten' und dass Amsdorf mit dieser Art des Umgangs miteinander begonnen habe. Er nimmt damit eine mögliche Kritik vorweg, einen unangemessenen Ton in seiner Schrift anzuschlagen, und rechtfertigt seine polemische Schreibart als notwendiges apologetisches Vorgehen, seine polemischen Angriffe rekonstruiert er so lediglich als Abwehr unrechtmäßiger Vorwürfe und als Richtigstellung der Lügen über ihn und seine Daniel-Auslegung.

Hoffman macht mit der Rechtfertigung des ,Scheltens' gleichzeitig eine Aussage zur Streitkultur. Er rekurriert auf die impliziten Regeln des Streitens, indem er den Beginn des Streits als regelwidrig bezeichnet. Die Antwort auf einen Angriff wird zu einem legitimierten Akt, da sie vom Verhalten des Anderen forciert ist und somit dem Prinzip von actio und reactio folgt. Die Bedeutung des von äußeren Umständen

${ }^{469}$ „Du heffst ny der Apostel schrifft erkant nach vornamen / de bueck dủuel hefft dy de ogen vorblendet“ (A2v). „Wenn dyn gudtdůnckent sick dar hen strecken scholde / wo du ydt meinst / scholde de schrifft gantz wilde gegen einander staen“ (A3r). Siehe auch Textbeispiel bei Anmerkung 465 .

470 Der Lexemverband LÜGEN taucht beispielsweise insgesamt viermal auf.

${ }^{47 \mathrm{I}}$ „[Das] Nase-Maskieren gilt hier nicht“. Hier im Sinne von (vor)täuschen, etwas vorgeben (zu sein), ein falsches Spiel treiben (vgl. dazu die Verbform des bereits erklärten Wortes ,Larve' [siehe Anmerkung 468]: „LARVIEREN, verb. sich vermummen, maskenscherz treiben“. DWB I 2, Sp. 209).

${ }^{472}$ „Du hast doch mit sämtlichem Schelten begonnen und hast mich zum Schreiben gedrungen." 
auferlegten Zwangs weiter vorantreibend führt Hoffman unmittelbar darauf folgend aus:

Heddestu vnde Schuldorp frede geholden / were my leef gewest / vnde hedden my rouwen laten / De o̊uerst Rydder werden wil / einen anderen ym kampe nedderleggen / de moet sick streyke vormoden / dat he ock yo so balde vnder alse bauen ligge. (AIv-2r $)^{473}$

Aus der Kampfesmetaphorik abgeleitet, erklären sich die polemischen „streyke“ Hoffmans als unvermeidliche kausale Folge darauf, dass Amsdorf den Frieden mit seiner ersten Schrift gebrochen habe. Die Notwendigkeit einer Verteidigung bzw. eines Gegenangriffes bekommt mittels der metaphorischen Verbindung einen existenziellen Wert, denn im Gegensatz zu einer verbalen Auseinandersetzung beinhaltet der Quellbereich der Metapher ,Kampf' Verletzungs- oder mitunter Todesgefahr. Hoffman nennt zwar in diesem Textabschnitt nur ein undefiniertes Subjekt („de“, „he“) und ein ebensolches Objekt („einen anderen“), setzt sich selbst und Amsdorf (samt Schuldorp) aber durch den unmittelbar vorausgehenden Text in die bildhafte Szenerie eines Ritterkampfes und inszeniert den verbal geführten Streit als Gewaltakt und Waffengefecht.

Indem Hoffman sich hier auf die Regeln einer ,Kampfkultur' beruft, nimmt er auch Bezug auf die Regeln der ,rhetorischen Streitkultur': Ein polemischer Gegenangriff legitimiert sich nach Hoffman durch den böswilligen und aus seiner Sicht unbegründeten Angriff. Das Schelten bzw. das Polemisieren wird zum zulässigen Mittel der Verteidigung gegen einen ungerechtfertigten Angriff. Amsdorfs Ein vormanung und seine Auffassungen werden dementsprechend auf einer Metaebene als böswilliger Angriff, als unrechtmäßiges Verhalten gedeutet. Hoffman bezeichnet Amsdorfs Verbreitung von vermeintlichen Unwahrheiten in Ein vormanung als böswillige polemische Attacke, die den Streit begründet. Hoffman argumentiert, dass Amsdorf aufgrund seiner Unwissenheit und dem (absichtlichen) Missverstehen der hoffmanschen Auslegung sich Lügen ausdenken muss und zu unlauteren Streittechniken greift: „Darumme sơket Amsdorff lögen rèck / so eme de Bibel nicht mach

473 „Hätten du und Schuldorp Frieden gehalten, wäre mir [das] lieb gewesen, und hätte[t ihr] mich ruhen lassen. Wer oberster Ritter werden will [und] einen anderen im Kampf niederstrecken, der muss mit (Waffen-)Hieben rechnen, so dass er ebenso schnell verliert wie siegt.“ „rouwen“ wurde hier nach Grimms Wörterbuch mit „ruhen“ (vgl. „RUHEN“, DWB I4, Sp. I 427) und nicht mit „reuen, betrüben, trauern“ (vgl. Schiller-Lübben 3, S. 538) übersetzt. 
tho hůlpe kamen " (A3r). ${ }^{474}$ Der Vorwurf, sich falscher und unerlaubter Streittechniken zu bedienen, stellt selbst eine gebräuchliche Streittechnik dar, die durchweg in den Religionsstreitigkeiten des I6. Jahrhunderts zum Einsatz kommt. Ziel ist es, den Gegner als ernstzunehmende, ehrenvolle Persönlichkeit zu disqualifizieren und sich damit selbst als Sieger der Kontroverse zu qualifizieren, denn „the audience's favor will not be won unless it somehow comes to believe that the game has been played in all fairness by the contendants“..475 Die Demaskierung des Gegenübers als ein betrügerischer, sich unlauterer Mittel bedienender Charakter soll dementsprechend dahin führen, dass die inhaltlichen Argumente dieser Person ihre Wirksamkeit beim Publikum einbüßen. ${ }^{476}$ Sowohl in der 2. als auch in der 3. Person wird mittels Verwendung von Wörtern aus dem semantischen Wortfeld LÜGEN477 ebensolch ein Bild von Amsdorf gezeichnet, das ihn als Erfinder von Unwahrheiten, als Verdreher von Tatsachen bzw. von Hoffmans Auffassungen, als Denunziant und allgemein als Betrüger darstellt. Damit wird Amsdorf regelwidriges (Streit-)Verhalten unterstellt, dem sich Hoffman hilflos ausgeliefert sieht. Hoffmans Text inszeniert das sprechende Ich (in der ersten Person) bzw. den „Pelzer“ (in der 3. Person) dementsprechend mehrfach als das Opfer von Amsdorfs Angriffen: „Ey du fyner dreper / wo schoen heffstu en gesineten / Wo wee ys doch dem armen Pelzer gescheen“ (AIv). ${ }^{478}$ Als Gebeutelter versucht Hoffman die Sympathien auf seine Seite zu ziehen und seinen eigenen groben Angriff zu verharmlosen.

474 „Darum erfindet Amsdorf reichlich Lügen, sobald ihm die Bibel nicht zu Hilfe kommen kann.“

475 Dascal (I989), S. I 57.

${ }^{476}$ Vgl. dazu Paintners Feststellungen für die antijesuitische Publizistik in der zweiten Hälfte des I6. Jahrhunderts: „Protestantische Theologen setzen sich nicht nur inhaltlich mit den theologischen Thesen der Jesuiten auseinander, sondern kritisieren auf einer übergeordneten Ebene auch ihre Argumentationstechnik. Sachliche und logisch einwandfreie Argumentation und korrektes Zitieren werden vom Gegner gefordert; man geht davon aus, dass der jeweilige Kontrahent als Theologe eine akademische Ausbildung besitzt, und erwartet dementsprechend, dass er sich an die akademischen Gepflogenheiten hält. [...] Auf dieser Metaebene verlässt die Diskussion den Bereich der sachlichen Argumentation und wird persönlich, indem dem Gegner die Qualifikation zur Teilnahme an einer akademischen Auseinandersetzung schlichtweg abgesprochen wird. " Paintner (2010), S. I43.

477 Dazu zählen z. B.: „nase maken“, „nasen laruens“, „valsch maken“, „logner“, „logen mule“ und „lógenmuel“, „gudtdůnckent“, „scheldens“, „fusche“, „swermet“, „lose larue“ etc.

${ }^{478}$ „Ey, du feiner Schütze, wie herrlich hast du ihn im Visier gehabt; wie ist doch dem armen Pelzer Schaden zugefügt worden.“ 
Erstaunlicherweise wirft Hoffman im Titel seiner polemischen Schrift Amsdorf „synen gruweliken anlop“ vor, um diesen Angriff dann in Bezug auf den Ton sowie die Nutzung polemischer Mittel zu übertreffen. Die ,Verteidigung، Hoffmans besteht - im Gegensatz zu Amsdorfs ,anlop“ durch Ein vormanung - nicht nur aus sachlicher Widerlegung der Argumente, sondern zum Großteil aus polemischen (Gegen-)Angriffen, die die Imagezerstörung und Denunzierung Amsdorfs anstreben. Merkwürdig erscheint in diesem Zusammenhang auch der Nachsatz ans Publikum, sich wegen des Streits der Gelehrten nicht zu ärgern, da der Streit zwischen ihnen das klarere Gotteswort auf die Erde bringt $\left(\mathrm{A}_{4} \mathrm{r}\right)$. Diese positive Konnotation des Streits transportiert Hoffman an keiner anderen Stelle seiner Schrift, schon gar nicht in Bezug auf seinen Widersacher, dessen Streitbarkeit gänzlich negativ dargestellt wird. Die positive Illustration, die Hoffman in seiner petitio ans Publikum vornimmt, steht einerseits in Bezug zu Hoffmans Rechtfertigung der polemischen Ausformung seines Schreibens, und ist andererseits Reaktion auf Ein vormanung, in der Amsdorf seiner Leserschaft rät, Hoffman aufgrund seiner Unberufenheit bzw. seines Laienstatus' zu ignorieren $\left(E V, \mathrm{~A}_{3} \mathrm{r}-\mathrm{v}\right)$. Hoffman entgegnet diesem Argument, indem er seine

[...] bede an de geleueden Gades hylgen [anbringt] / dat se ne̊nen Lerer vorachten vmme solckes schriuens willen / De en men Christum predigen / dar sehen se vp / Dat ander wert sick all sůluest finden vnde begeuen mit der tydt / dat de důuel vnde dat kaff / vnde de valsche buecknecht wert geapenbart werden. $\left(\mathrm{A}_{4} \mathrm{r}\right)^{479}$

$479,[\ldots .$.$] Bitte an die gläubigen Gottesheiligen [anbringt], dass sie wegen eines solchen$ Schreibens keinen Lehrer/Gelehrten verachten. Die ihnen aber Christus predigen, denen sollen sie ihre Aufmerksamkeit schenken. Das andere wird sich alles selbst finden und es sich mit der Zeit ergeben, dass die Teufel und die Spreu und die falschen Bauchknechte offenbart werden. “ Das Stigmawort ,Bauchknecht” ist in Anlehnung an Röm I6, I8 („Denn solche dienen nicht dem HERRN Jesus Christus, sondern ihrem Bauche; und durch süße Worte und prächtige Reden verführen sie unschuldige Herzen. “) sowohl auf lutherischer, katholischer als auch auf radikalreformatorischer Seite benutzt worden und impliziert, dass die so bezeichneten Prediger auf ihren eigenen Vorteil mehr bedacht sind als auf das Gotteswort. Vgl. die Bildungen mit Bauch (Bauchdiener, -knecht, -prediger, -pfaff, -lehrer, -prophet usw.) in Lepp, Friedrich (1908): Schlagwörter des Reformationszeitalters. Leipzig: Verlag von M. Heinsius Nachfolger, S. I3 I-I34. Hoffman erweitert die Verwendung des Begriffs und greift mit dem Stigmawort generell das Empfangen von Pfründen als dem eigenen ,Bauch dienend‘ an. Als Laienprediger verlangte er selbst keine Bezahlung, sondern predigte aus rein religiösem Interesse. Diese idealistische Einstellung betont er in seinen Texten, indem er den berufenen Theologen materialistische Ziele unterstellt und sie als ,Bauchdiener' verurteilt. 
Er überlässt damit Gott und dem natürlichen Lauf der Zeit die Selektion der Lehrer, indem er das Vertrauen vermitteln will, dass das Böse entlarvt und das Gute siegen wird. Er wehrt damit indirekt Amsdorfs Rat an die Gemeinde in Magdeburg ab, bestimmte Lehrer zu ignorieren. Das Thema der Berufung umgeht er damit geschickt, ohne es zur Sprache und damit in den Fokus des Publikums zu bringen. Das Publikum solle lieber auf diejenigen achten, die Christus predigen. Dass Hoffman sich in dieser Gruppe verortet, wird im Verlauf des Textes deutlich, denn wiederholt bekundet er sein Selbstbewusstsein, auf der Seite des Siegers, also auf der Seite der Wahrheit zu stehen. Er mahnt Amsdorf:

Wultu my straffen / vnde valsch maken / so mostu andere schrifft vo̊ren / denn du noch vo̊rest / Du most der Bibel anders vnder de ogen sehen / De gantze Bibel schal dy vth Gades krafft nicht hůlplick syn / dat du my Peltzer auerwinnen schalt[.] $\left(\mathrm{A}_{3} \mathrm{r}\right)^{480}$

Dieses paradoxe Argument gleicht einer doppelten Verneinung: Amsdorf müsste eine andere Auslegung der Bibel liefern, um ihn zu widerlegen, was allerdings prinzipiell nicht möglich wäre, da die ganze Bibel ihm dazu keine Möglichkeit gäbe. Amsdorf ist demnach schon gescheitert und kann auch bei jedem neuen Versuch nur scheitern, denn Hoffman beansprucht, das Gesamtwerk der Bibel und damit das göttliche Wort auf seiner Seite zu haben. Hier zeigt sich ein weiteres Mal das theologische Selbstbewusstsein Hoffmans, das durch sein Handwerkerdasein und seinen Status als Laienprediger eher gestärkt als geschwächt wird.

Zusammenfassend zeigt sich in Hoffmans erster Schrift gegen Nicolaus von Amsdorf, dass das direkte Polemisieren als inszenatorisches Moment eingesetzt wird. Insbesondere die Verwendung der direkten Anrede bewirkt eine Verschärfung des Streits vor dem Publikum. Während das passagenweise Sprechen über Amsdorf in der 3. Person, also indirektes Polemisieren, zur Objektivierung von Argumenten beiträgt und eine Distanzierung Hoffmans von dem Geschriebenen ermöglicht, kreiert der Einsatz von direkter Anrede, Beschimpfungen und Imperativen wiederholt Szenen des mündlichen oder tätlichen Zweikampfes und bringt so den sich im Anfangsstadium befindenden Streit zwischen Hoffman und Amsdorf zur Aufführung. Indem Hoffman Amsdorfs abweisendes

${ }^{480}$ „Willst du mich strafen und mich als falsch darstellen, so musst du andere Argumente bringen, als du jetzt führst. Du musst der Bibel anders ins Gesicht schauen (sie anders lesen). Die ganze Bibel wird dir aus Gottes Kraft nicht hilfreich sein, dass du mich Pelzer überwinden wirst.“ 
Verhalten beim Zusammentreffen in Magdeburg und dessen darauf folgende Schrift Ein vormanung als bösartigen Angriff stilisiert, legitimiert er seine polemische Schrift als Apologie, die allerdings den Streit erst performativ entfaltet und somit weniger Replik als Initiationsschrift ist. Während Amsdorf sich in Ein vormanung darauf beschränkt, nüchtern und sachlich zu argumentieren und ein Streit zwischen den beiden Widersachern weder berichtet noch präsentiert wird, lässt Hoffman keinen Zweifel mehr an dem Vorhandensein eines Streits und setzt diesen vor seinem Publikum in Szene. Ironisches Sprechen und direktes Polemisieren dienen dabei als emotionalisierende und dramatisierende Mittel, die den Streit an sich und den Antagonismus zwischen Lüge und Wahrheit, falscher und rechter Lehre vor einem Publikum entstehen lassen. Der Text Hoffmans lässt mittels seiner performativen Funktion schließlich den Streit erst heranreifen und sich manifestieren. Die Ausweitung des Streits zu einer Kontroverse durch drei weitere Schriften bestätigt dies.

\section{Amsdorfs Reaktion auf Hoffmans Dat Nicolaus Amsdorff}

Amsdorfs Erwiderung ließ nicht lange auf sich warten und folgte noch in der ersten Hälfte des Jahres I 528 mit einer etwas längeren Schrift im Vergleich zu seinem ersten Warnschreiben Ein vormanung. Dieses Mal richtete er sich mit seinem Schreiben nicht mehr an die Magdeburger, sondern an die „heiligen vnnd gleubigen an Christum Jhesum zum Kiel vnd ym gantzen Holstein" (FP, A2r). ${ }^{48 \mathrm{I}}$ Die Distribution der in Magdeburg gedruckten Schrift im Kieler Stadtgebiet übernahm laut Hoffman Marquard Schuldorp. ${ }^{482}$ Der Kontakt zu ihm war vermutlich auch der Grund für die Umorientierung Amsdorfs in Bezug auf die Adressierung der Leserschaft. Es lässt sich vermuten, dass Hoffmans Schrift nicht ohne Nachhall in Kiel geblieben ist, und Amsdorf von Schuldorp über die Schrift und ihre Wirkung informiert wurde, so dass er trotz Unkenntnis des Niederdeutschen über die Inhalte von Dat Nicolaus Amsdorff Bescheid wusste. Seine Antwort mit dem Titel Das Melchior Hoffman ein falscher Prophet, und sein leer vom jüngsten Tag unrecht, falsch und wider Gott ist ${ }^{483}$ bezeugt dies, denn Amsdorf

${ }^{48 \pm}$ Die Initialen FP stehen für Amsdorfs Schrift Falscher Prophet.

${ }^{482}$ In der darauffolgenden Schrift Nasen geist gibt Hoffman dazu folgende Information: „Das du Schuldorff [...] mit des Amsdorffs buchlein mir das volck wolst abfellig machen / vnd du die selben allenhalben sendest / vnnd verkeuffest / kan ich wolleiden $[\ldots]^{*}\left(\mathrm{C}_{3} \mathrm{v}-\mathrm{C}_{4} \mathrm{r}\right)$.

${ }^{483}$ Amsdorf, Nikolaus von (I 528): Das Melchior Hoffman ein falscher Prophet / und sein leer vom jungsten Tag unrecht / falsch und wider Gott ist. [Magdeburg: Hans 
nimmt, wenn auch nicht im Detail, Bezug auf Dat Nicolaus Amsdorff, indem er zusammenfasst, was Hoffman in dem „bủchlein widder [ihn]“ $(F P, A 2 r)$ geschrieben hat:

Zum ersten / vertediget er seine leer vom Jůngsten tag / das er vber sieben iar komen sol / Zum andern / schilt er mich vbel / vrteilt vnd richt mein leben / das yhm doch unbekant ist / nicht mein leer vnd predigt / die er doch wol gehơrt vnd gelesen hat. (FP, A 2r)

Anhand dieser kurzen Zusammenfassung ist abzulesen, dass die vorherige Schrift Hoffmans von Amsdorf als polemischer Angriff ad personam aufgefasst wurde. Amsdorfs Reaktion ist hingegen sachlich, sie ist von dem emotionalen Stil Hoffmans scheinbar nicht beeinflusst und steht im Kontrast zu Hoffmans Schreiben. Vermutlich aus zwei Gründen zügelt Amsdorf sein Schreiben. Er scheint sich zum einen an den Gepflogenheiten der akademischen Disputationskultur zu orientieren, um sich als Angehöriger der Gelehrtenkultur, der Hoffman im Gegenzug nicht zugerechnet wird, in Szene zu setzen. ${ }^{484}$ Zum anderen ist die Vermutung naheliegend, dass Amsdorf in seiner Position als Superintendent mit dem Auftrag, die Reformation in Magdeburg einzuführen, „Rücksichten auf kirchliche und städtische Obrigkeiten zu nehmen hatte - und sich folglich nicht ganz ungehemmt ausdrücken konnte [...]“..485 Außerdem kann angenommen werden, dass er sich nicht so sehr an Hoffmans Schreiben orientiert hat, da er sich dieses aufgrund des Niederdeutschen nicht im Detail erschließen konnte.

Auf seinen elf Textseiten nimmt Amsdorf hauptsächlich auf zwei Punkte in Hoffmans vorausgehender Schrift Bezug: zum einen auf die Verteidigung der Lehre vom baldigst eintretenden Jüngsten Tag, zum anderen auf die Angriffe Hoffmans auf seine Person. Mit Bibelzitaten und logischen Schlüssen arbeitet Amsdorf strukturiert die zentralen inhaltlichen Punkte ab und bleibt dabei seiner Strukturierung aus Ein

Bart]. Kurztitel: Falscher Prophet. Die Quellenangaben bei Zitaten werden mit den Initialen FP und der Folienangabe der Übersichtlichkeit halber in Klammern gestellt. Insgesamt umfasst sie I4 Seiten, wovon I I Seiten Text sind. Paginierung: Titelblatt AIr-A4v, BIr-B3r.

${ }_{484} \mathrm{Ob}$ Amsdorfs Schrift bewusst als Schrift der Gelehrtentradition wahrgenommen wurde, kann für den einzelnen Rezeptionsfall nicht nachvollzogen werden. Es ist anzunehmen, dass ein geübter Leser (oder regelmäßiger Zuhörer) von Reformationsschriften Amsdorfs Stil, insbesondere auch hinsichtlich der Unterschiede zu Hoffmans Schrift (z. B. bezüglich des Tons, des Sachlichkeitsgrades), zumindest unbewusst als gelehrten Stil interpretieren konnte.

${ }_{485}$ Ilgner (2008), S. 263. 
vormanung treu: Zuerst widmet er sich Hoffmans Lehre (argumentum ad rem) und widerlegt sie in drei Punkten (A2r-A4v), in dem zweiten, einer Tadelrede (vituperatio) ähnelnden, Teil degradiert er seinen Gegner, indem er „diesen teuffel ynn Melchior Hoffman also abmal[t] / das [die Kieler Gläubigen] greiffen sol[len] / das er nicht von Gott ist" (FP, BIr). Er erklärt dem Kieler Publikum Hoffmans Charakter als lügnerisch und unchristlich, Hoffmans Handeln sei das eines ,falschen Propheten'. ${ }^{686}$ Der Idee der Tadelrede entsprechend konzentriert sich Amsdorf in diesem Abschnitt darauf, „die sprachliche Vorführung negativer Eigenschaften primär einer Person bzw. ihrer Handlungen “487 vorzunehmen und so das Publikum davon zu überzeugen, dass Hoffman nur vom Teufel gesandt sein könne, man ihm deshalb keinen Glauben schenken dürfe sowie seine Lehren missachten müsse. Amsdorf hält sich auch dabei weiterhin meistenteils an die Techniken der Widerlegung, die auf logischen Schlüssen basiert, was sich u. a. durch Schlüsselphrasen wie „Daraus schliessen wir aber eins vnwiddersprechlich“ (FP, B2r) äußert. Lediglich einige ironische Kommentare und rhetorische Fragen ragen aus dem sonst überwiegend sachlichen Schreibstil heraus: Mit beißender Ironie nennt er Christus und die Heilige Schrift einfältig im Vergleich zu dem hochverständigen Melchior Hoffman ${ }^{488}$ und lässt Gott zu einem Narren werden, der sich von eben diesem klugen Melchior Hoffman

${ }^{486}$ Das Stigmawort ,falscher Prophet` wurde sowohl auf protestantischer Seite für die Bezeichnung der radikalen Reformatoren, als auch von den Radikalen selbst für sowohl altgläubige als auch protestantische ,Irrlehrer' eingesetzt: „Im NT spielen sich fälschlich für Propheten ausgebende, also nicht über die Gabe rechter Prophetie aus dem wahren Bekenntnis zu Christus verfügende Prediger eine gefährliche Rolle [...]. Der falsche Prophet handelt nicht mehr aus ungestümer Schwärmerei, sondern aus Berechnung [...]. Bei den Schlagwörtern neue Propheten, himmlische Propheten, und falsche Propheten handelt es sich um eine Gruppe von Begriffen, die, von Luther geprägt und verbreitet, sich im Laufe der Auseinandersetzung in ihrer negativen Semantik verstärken und durch eine immer größere pejorative Affektivität gekennzeichnet sind. [...] Falsche Propheten bleiben letztlich alle, die gegen die jeweils absolut gesetzte Wahrheit polemisieren.“ Diekmannshenke (I994), S. 363-235. Vgl. dazu auch Jörgensen, Bent (20I4): Konfessionelle Selbst- und Fremdbezeichnungen: Zur Terminologie der Religionsparteien im I6. Jahrhundert. Berlin: Akademie Verlag, S. 99 \& I25.

${ }_{487}$ Bremer (2009b), HWRh 9, Sp. 4I9.

${ }^{488}$ Bey diesem einfeltigen verstandt / welchen ewer Melchior ein vnuerstandt no̊met / den vns der einfeltige / vnuerstendige Christus ynn der einfeltigen schrifft gegeben hat / woollen wir bleiben / vnd Melchior Hoffman mit seinem hohen verstandt / den yhm der hochuerstendige listige Satan eingegeben hat / faren lassen [...] “ (FP, BIr). 
Vorschriften machen lässt. ${ }^{489}$ Während solche ironischen Passagen häufiger vorkommen, wendet Amsdorf unmittelbare Beschimpfungen nur sehr vereinzelt an. Die wiederholten Beschimpfungen Hoffmans stehen diesem gemäßigten Tonfall Amsdorfs diametral gegenüber. Nur zusammenfassend thematisiert Amsdorf die Vielzahl der Beschimpfungen Hoffmans, ohne konkret auf einzelne der Anfeindungen zu antworten. Amsdorf inszeniert auf diese Weise seine Selbstbeherrschung, denn um seine Überlegenheit als Gelehrter zu demonstrieren, ignoriert er die Diffamierungen bewusst:

$\mathrm{Nu}$ wolan / die weil Melchior Hoffmans geist so frech vnd freuel ist / [...] so las ichs gehen vnd befiel es Gott / vnd denen die teglich mit mir vmbgehen / vnd lasse widderumb yderman richten / ob das die art des heiligen geists sey / das er seinen nechsten so leichtlich vmb eines stoltzen worts willen fur der gantzen welt schendt / lestert vnd dem teuffel gibt / Ein Christ hilfft seines nechsten sunde decken / aber Melchior lesset sich nicht daran genůgen / das er die sunde auff deckt / offenbart / vnd seinen nechsten zu schanden macht / sondern schendt vnd lestert auch yhn mit offentlichen erdichten lügen / wenn das Gots geist thut / so weis ich nicht was der teufel thut. $\left(F P, \mathrm{~B}_{2} \mathrm{v}\right)$

Dem Anschein nach legt er die richterliche Urteilskraft in Gottes Hände sowie in die des Publikums, das durch den Zuspruch der Urteilsfähigkeit aufgewertet und umschmeichelt wird. Er stellt sich auf diese Weise als zurückhaltend dar (Bescheidenheitstopos), was einen Urteilsspruch betrifft. Er setzt sich selbst als jemand in Szene, der den Gerechtigkeitssinn nicht für sich beansprucht, sondern den Urteilsspruch in die Hände anderer legt, während er sich gleichzeitig von Hoffmans emotionalem Stil distanziert und damit ein klares Urteil der Missbilligung spricht. Hoffman wird zu einem unchristlichen Zeitgenossen deklariert, der seinen Nächsten lästert, anstatt dessen Sünde zu decken, Amsdorf selbst wird zum reuigen Sünder und Opfer böser Lästerei stilisiert. ${ }^{490}$

${ }^{489}$ „Denn Gott ist ein narr worden / er weis nicht stund vnd zeit / wenn er einem volck prediger senden sol / Darumb muste Melchior Hoffman / als ein kluger / vnserm Gott stund vnd zeit setzen / wenn yn Liffland solt geprediget werden “ (FP, Biv-B2r).

${ }^{490}$ Es ist nicht ganz klar, worauf Amsdorf hier Bezug nimmt. Denkbar wäre, dass Amsdorf auf die Trauung Marquard Schuldorps mit der Tochter seiner Schwester (vor Beendigung des Jahres I 525), die er selbst vollzog, Bezug nimmt. Die Heirat der beiden wurde aufgrund des nahen Verwandtschaftsgrades selbst bei Reformationsanhängern mit Argwohn betrachtet und verursachte starke Gegenreaktionen (auch Hoffman verurteilte diese Eheschließung). Luther hingegen 
Abschließend dementiert Amsdorf noch zwei Aussagen, die Hoffman angeblich über ihn verbreitet habe: Er habe weder mit Hoffmans Verhaftung zu tun, noch habe er in seiner Flugschrift geschrieben, dass Hoffman in Magdeburg hätte predigen wollen. Die darauf folgenden Schlussworte wirken abschätzig und abwinkend: Hoffman sei ein „vnnützer schwetzer / der viel wort kan machen da nichts hinder ist" $\left(F P, \mathrm{~B}_{3} \mathrm{r}\right)$, und darum kümmere sich Amsdorf nicht um die restlichen Dinge, die gesagt wurden, und gebe es in Gottes Hand. Diese beinahe gleichgültig und nüchtern anmutende Einstellung gegenüber Hoffmans Schreiben am Ende wird in der gesamten Schrift immer wieder passagenweise geschaffen. Gekrönt wird diese betonte emotionale Distanz durch das In-Szene-Setzen der Geringschätzung durch gezielt eingesetztes Schweigen über das, „[w] as sonst mehr fur vnnůtz geschwetz ynn seinem [Hoffmans] bůchlein ist" (FP, B 3 r $)$.49r Amsdorf wiederholt mit dieser Aussage die Verachtung, die er Hoffman auch schon beim persönlichen Zusammentreffen I527 in Magdeburg entgegenbrachte.

hatte die Ehe gebilligt. Die allseitigen Proteste führten in kürzester Zeit so weit, dass I 526 eine auf Niederdeutsch gedruckte Rechtfertigungsschrift zu dem Thema veröffentlicht wurde, in der je ein Teil von Amsdorf, Luther (Brief vom 05.0I.I 526) und Schuldorp verfasst ist: Grundt vnd orsake worup Marquardus Schuldorp hefft syner suster dochter thor ehe genamen / boweret dorch Ern Nicolaū Amßtorp Licentiaten / vn Ern Martinum Luther Doctor yn der hylligen schrifft. Anno I 526. [o. O.: o. Dr.]. Amsdorfs Teil hat die Überschrift Eyn apenbar bokantnisse Ern Nicolaus Amstorp / Liceciaten yn der hylligen schrifft / dat he christlich vnd gotlich

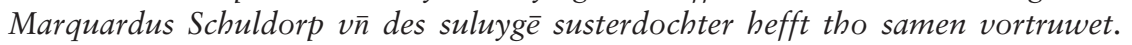
Luthers Brief an zweiter Stelle ist folgendermaßen betitelt: Dem Erbarn fursichtigen Marquardo Schuldorp vam kile / wunst e ick Martinus Luther gnad vnd frede yn Christo. Schuldorps eigener Teil der Schrift ist nicht betitelt, sondern wird lediglich durch den wesentlich größeren Anfangsbuchstaben eingeleitet. Amsdorf war infolge der Trauung kritisiert worden (u. a. von den Dompredigern). Daher ist es denkbar, dass Amsdorf mit der begangenen Sünde die Durchführung der Trauung meint. Es ist ebenfalls möglich, dass Amsdorf generell auf seine Zeit als altgläubiger Theologe rekurriert und diese Zeit als seine Sünde erachtet. Auch in Hoffmans vorausgehender Schrift Dat Nicolaus Amsdorff werden die genauen Umstände nicht erklärt.

${ }^{491}$ Amsdorf bedient sich mit der Inszenierung des Schweigens einer Streittechnik aus dem Bereich des mündlichen Gesprächs. In schriftlicher Form kann ein demonstratives Schweigen nicht real stattfinden, sondern nur als ein solches in Szene gesetzt werden, und zwar erst durch die Form des Schreibens - also des Nicht-Schweigens. Vgl. dazu Paintner: „Diese Möglichkeit [seinen Protest durch Verweigerung zu äußern] ist in der Publizistik nicht gegeben, wollte er die Anschuldigungen durch demonstratives Schweigen entkräften, so müsste er auch dies paradoxerweise durch eine Publikation kundtun." Paintner (2010), S. I46. 


\subsubsection{Imagekonstruktion und die Integration inter- und kontextueller Bezüge durch offenes Polemisieren in Das Niclas Amsdorff [...] ein lugenhafftiger falscher nasen geist sey}

Hoffman setzte den Schlagabtausch fort, indem er nur kurze Zeit später (ebenfalls I 528) seine bis zu dem Zeitpunkt polemischste Schrift und insofern sein bereits in Dat Nicolaus Amsdorff angedrohtes "Valete“ (DNA, A3v) mit dem Titel: Das Niclas Amsdorff der Magdeburger Pastor ein lugenhafftiger falscher nasen geist sey / offentlich bewiesen durch Melchior Hoffman / Königlicher wirdē gesetzter prediger zum Kyll / ym landt zu Holstein ${ }^{492}$ verfasste. Der genaue Zeitpunkt des Drucks, der erneut mit Hoffmans eigener Druckerpresse erfolgte, ist ebenfalls nicht bekannt. Es wird geschätzt, dass er in der Mitte des Jahres I 528 publiziert worden ist. ${ }^{493}$ Diese polemische Schrift Hoffmans ist seine zweite im Zusammenhang des Streits mit Amsdorf und damit die vierte in der Chronologie des Schriftwechsels. Im Vergleich zu Hoffmans erster Schrift nimmt sie aber eine weitaus prominentere Stellung ein, da sie sich ausführlicher und schärfer dem polemischen Thema und der Denunzierung des polemischen Objekts widmet. Zudem fasst Hoffman in seiner Schrift (fortan Nasen geist) seine Lehre von der Apokalypse kurz zusammen. Er verteidigt sie damit, dass er sich in die Reihe biblischer Propheten stellt, die ebenfalls nur vage Prophetien ausgesprochen haben und begegnet somit Amsdorfs Argument, dass seine Weissagung vom Jüngsten Tag aufgrund der Ungenauigkeit nicht wahr sei. Er begründet seine figürliche Auslegung der Bibel, die er dem pejorativ umgedeuteten „einfeltigen sinn“ (A4v), der wörtlichen Auslegung Luthers, entgegenstellt. Im Gegensatz zu seiner ersten Schrift nimmt Hoffman hier Amsdorfs Argument der Berufung als Kriterium für rechte Lehre auf ${ }^{494}$ und wendet es gegen Amsdorf, indem er diesem vorwirft, nur die Berufung anstatt die wahre Liebe zu Gott zu sehen. Den Laienstatus hebt Hoffman als besonders positiv hervor, während Amsdorf konträr

${ }^{492}$ Unter dem Titel befindet sich derselbe Holzschnitt, der bereits das Titelblatt der ersten Schrift, Dat Nicolaus Amsdorff, ziert: Er bildet den Weltenrichter auf dem Hintergrund der fünfblättrigen Lutherrose ab. Darunter sind noch Psalm 6I und die Jahresangabe abgedruckt: Du bist mein zuuersicht / ein starcker thurn vor meinen feinden / Psalm. 6I. M. D XXviij. Quellenangaben für diese Schrift werden aufgrund der zentralen Stellung in diesem Kapitel in Klammern ohne Initialen (sonst mit den Initialen NG) nachgestellt.

493 Vgl. Deppermann (I979), S. I05.

494 Amsdorf hatte die Forderung nach kirchlicher Berufung schon in Ein vormanung gegen Hoffman verwendet, der dieses Argument jedoch zu ignorieren schien und in Dat Nicolaus Amsdorff nicht thematisierte. 
dazu als ein ,Papist' dargestellt und verhöhnt wird. Neben verschiedenen Argumentationsstrategien gibt es eine beträchtliche Menge an Beschimpfungen und polemischen Wendungen, so dass mit Ausnahme der ersten Textseite durchgängig Schimpfnamen und grobianische Ausdrücke den Ton der Schrift ausmachen.

Die Schrift Nasen geist ${ }^{495}$ zählt insgesamt I 8 Seiten Text.496 Im Unterschied zur ersten Schrift gegen Amsdorf ist diese zweite nicht nur wesentlich länger, sondern auch auf Hochdeutsch verfasst. Hoffman kann damit bezweckt haben, den Wirkungskreis seiner Schrift zu vergrößern und auf den hochdeutschen Sprachraum auszuweiten. Eventuell sollte damit insbesondere das Zentrum der lutherischen Reformation, Wittenberg, deutlicher angesprochen werden, denn Hoffman sah sich selbst noch als Anhänger Luthers ${ }^{497}$ und hoffte wohl trotz des misslungenen zweiten Besuchs in Wittenberg (I 527 ) auf dessen Unterstützung. $\mathrm{Ob}$ Hoffman auch oder gar vorrangig intendierte, seinem Gegner

495 Die bei dieser Arbeit verwendete Ausgabe ist eine Nachbildung: „Auf Grund des Kopenhagener Exemplars ist die vorliegende Nachbildung gemacht worden und zwar nach Schwarz-Weiß-Photographien, nach denen die Firma Meisenbach, Rissarth \& Co. die Druckstöcke hergestellt hat.“ Ficker, Gerhard (I926): „Anmerkungen“. In: Ders. (Hg.): Schriften des Vereins für Schleswig-Holsteinische Kirchengeschichte. 4. Sonderheft, Preetz: J. M. Hansen, S. II.

${ }^{496}$ Insgesamt umfasst die Schrift 20 Seiten. In der Nachbildung ist die Anordnung der Seiten dem Original entsprechend falsch. Da nach dem Titelblatt fälschlicherweise eine leere Seite eingefügt wurde, sind sämtliche Seiten um eine Position verschoben, so dass die Verso-Seiten jeweils auf der rechten Seite abgedruckt wurden. Im Folgenden sind die originalen Seitenangaben AII, AIII usw. jeweils auf der linken Seite abgedruckt, obwohl sie die Recto-Seite anzeigen. Bei sämtlichen Seitenangaben in dieser Arbeit wird dieser Anordnungsfehler ignoriert und die Seiten nach dem üblichen System benannt: Seiten mit einer Paginierung werden als ,recto` bzw. ,r' bezeichnet, die jeweils darauffolgende Seite gilt als das respektive, verso' bzw. ,v'. Für die Schrift ergibt sich so folgende Paginierung: Titelblatt Aır-A4v, B Ir-B2v, CIr-C4v (C4v leer). Dieselbe Paginierung wendet auch Deppermann in seiner Monographie zu Hoffman an. Vgl. Deppermann (I979), besonders S. 83-I09. Richard G. Bailey erklärt die falsche Folienzählung als einen Fehler seitens Hoffman: „His mistake of reversing the signatures in Das Niclas Amsdorff (the verso of folio AI should have been the recto of folio A2) suggests that he was self-taught, worked without professional help, and drew from well of knowledge of the art accumulated from past contacts with printers in Livonia, Sweden, and Lübeck. It was probably a ,one man press,' which makes his work schedule for I 528/29 even more impressive. "Bailey (I990), S. I 87.

497 Dass er auch bei dieser zweiten Schrift denselben Holzschnitt auf dem Titelblatt verwendet, welcher die Lutherrose im Hintergrund des Weltenrichters deutlich erkennen lässt, ist ein Indiz dafür, dass Hoffman die sich abzeichnenden Abweichungen seiner Lehre von der Wittenberger Reform noch nicht als Grund für eine Abgrenzung von dieser erachtete. 
Amsdorf die Rezeption zu erleichtern, um mit diesem in den direkten Dialog zu treten, ist unsicher bzw. eher unwahrscheinlich, da Hoffman diesen Zweck bei seiner ersten Schrift gegen Amsdorf nicht offenkundig verfolgte.

Die Struktur dieser zweiten Schrift betont - wie auch die Struktur von Dat Nicolaus Amsdorff - zudem die Ausrichtung auf die polemische Instanz. Die erste Seite und die Schlusszeilen auf der letzten Seite bilden einen Rahmen, in denen die polemische Instanz in Form einer nicht definierten Leserschaft angesprochen wird. Dieser Rahmen weist abermals Elemente der Briefstruktur auf (salutatio und captatio benevolentiae auf der Anfangsseite; petitio und peroratio im letzten Abschnitt) und ist der Funktion zur unmittelbaren Kontaktaufnahme ${ }^{498}$ entsprechend gespickt mit Strategien zur Meinungsbildung beim Publikum. In seiner kurzen salutatio verwendet Hoffman eine allgemein übliche Anrede an den gläubigen Leser, die man ähnlicher Natur häufig in Flugschriften der Reformation antrifft:

Gnad und der ewig fried - und das ewig heyl / sey allen gleubigen von Gott vnserm vater durch Christum Jhesum vnsern Heylandt / der vns geliebet hat / vnd gewasschen van den sunden mit seinem blut / vnd hat vns zu königen vnd Priestern gemacht / fur Gott vnd seinem vater / Dem selbigen sey preys vnd reich /von ewigkeit zu ewigkeit / A M E N. (Arv)

Hoffman spricht hier nicht nur einfach einen Gruß an die Gläubigen aus, sondern legitimiert sein Predigerdasein, indem er für seine eigenen Begrüßungsworte den Gruß Johannes' in der Offenbarung (Offb I, 5-6) zitiert. Darüber hinaus drängt sich auch der intertextuelle Bezug auf Luthers Schrift An den christlichen Adel deutscher Nation förmlich auf, denn dort wird u. a. eben diese Stelle aus der Offenbarung zitiert. ${ }^{499}$ Sie liefert die Legitimation für laikale Predigertätigkeiten mit dem ,Priestertum aller Gläubigen‘.

${ }_{498} \mathrm{Vgl}$. Haug (I985), S. 9.

499 „Demnach so werden wir durch die Taufe allesamt zu Priestern geweiht, wie Sanct Peter I Petr. 2 sagt: ,Ihr seid ein königlich Priestertum und ein priesterlich Königreich'; und die Offenbarung: ,Du hast uns gemacht durch Dein Blut zu Priestern und Königen.' Denn wo nicht eine höhere Weihe in uns wäre, denn der Papst oder Bischof giebt, so würde nimmermehr durch Papsts oder Bischofs Weihe ein Priester gemacht, könnte auch weder Messe halten noch predigen noch absolvieren. "Luther, Martin (I 524): An den christlichen Adel deutscher Nation von des christlichen Standes Besserung. Hg. von Karl Benrath (= Schriften des Vereins für Reformationsgeschichte 4, I884). Halle: Niemeyer, S. 7. 
Insbesondere nach dem Bauernkrieg musste Hoffman als nicht ausgebildeter Theologe seine Predigten und schriftlichen Auslegungen gesondert rechtfertigen, ${ }^{500}$ was auch in dieser Schrift auf vielerlei Weise zu erkennen ist. Schon im Titel bezeichnet er sich selbst als „königlicher wirden gesetzter prediger zum Kyll / ym landt zu Holstein" "501 und weckt damit die Assoziation, er sei womöglich ein Hofprediger des Königs. Hoffman bezieht sich hier auf ein Schreiben des Königs Friedrich I., in dem ihm unter dem Schutzmantel des Königs das Predigen in ganz Schleswig-Holstein erlaubt wurde. Durch das Nennen des Königs im Titel verschafft sich Hoffman den Eindruck des Beistands dieser prominenten Autorität und suggeriert die Berufung zum Predigeramt durch die Obrigkeit. Später im Text rekurriert er sogar erneut darauf und inszeniert sich in dieser Rolle, um Amsdorf zu widerlegen, denn letzterer hatte die Kieler aufgerufen, sie sollten ihrem „Melchior ynn seiner leer keinen glauben geben / sondern yhn fur einen falschen Propheten vnd lůgner halten “ (FP, B2v). Hoffman kommentiert dieses Argument mit der rhetorischen Frage, was „doch das fur ein schwermer vnd auffrůrischer mordischer bo̊swicht [sei] / der einem fromen Christlichen Ko̊nig / ein

${ }_{500}$ Nach dem Bauernkrieg wurden Einschränkungen aller sozialen Änderungen, die zuvor von Luther vorangetrieben worden waren, vorgenommen. Die Reformation schlug einen neuen, institutionalisierten Weg ein, um die Glaubensreform nicht durch das sozialrevolutionäre Aufbäumen der „Schwärmer“ zu gefährden. „Kaum waren diese Lehren ausgesprochen, so wurden sie auch schon wieder eingeschränkt. Angesichts des Bauernkriegs bestritt Melanchthon das Recht der Gemeinden, allein ihre Pfarrer wählen zu dürfen. Tatsächlich blieb das aus dem germanischen Eigenkirchenwesen stammende Kirchenpatronat des Adels, der Stadtmagistrate und der Landesherren erhalten. An die Stelle des proklamierten Selbstbestimmungsrechtes der einzelnen Gemeinde trat das landesherrliche Kirchenregiment. Alle Reformatoren verwarfen die von den aufständischen Bauern und von den Täufern geforderte Verfügungsgewalt der Gemeinde über den Kirchenzehnten.“ Deppermann, Klaus (I975): „Melchior Hoffmans Weg von Luther zu den Täufern“. In: Hans-Jürgen Goertz (Hg.): Umstrittenes Täufertum I525-1975. Neue Forschungen. Göttingen: Vandenhoeck \& Ruprecht, S. I73-205, hier S. 202f. Luther schränkte seine Lehre vom Priestertum aller Gläubigen ein: Nicht jeder hätte das Recht zur Predigt, sondern eine Berufung (vom Kirchenpatron bzw. Landesherren) wäre nötig. Durch diese Einschränkungen war auch Hoffmans Predigertätigkeit gefährdet. „Nicht nur der biblische Text, sondern auch die ,reine Lehre` der Reformatoren erhielt eine pseudosakramentale Weihe. Im Dogma von der Realpräsenz Christi in den Abendmahlselementen wurde das Heil wieder verdinglicht. Die alte Herrschaft der Geistlichen über ihre Gemeinden stellte sich in verwandelter Form wieder ein.“ Deppermann (I975), S. 203.

5or Dies war schon in Dat Nicolaus Amsdorff der Fall, dort nahm die Bezeichnung jedoch noch nicht solch einen prominenten Platz im Titel ein. 
solch vngehorsam vnd abfellich volck wolt machen / vnd zu auffrur weisen“ (CIV). Im direkten Anschluss betont er, dass seine Lehre „Königliche wirde von Denmarck“ (C2r) nicht nur wohl bekannt sei, sondern das dieser sie sogar „mit seinen gelerten helden wol gepróbet vnd versucht“ (ebd.) habe. Nach dieser Prüfung habe der König Hoffman „den[en] zu Kyll zu eim prediger gesandt / vnd befestiget / befolhen “ (ebd.). Infolge seiner königlichen Berufung und Legitimation als Prediger interpretiert Hoffman Amsdorfs petitio an die Kieler als Aufruf zum Abfall von der göttlichen Lehre und vom Glauben überhaupt:

Vnnd du schreibst nu / das sie mir der Götlichen lere sollen abfellig werden / vnd nicht gleuben / es wil dir auffrurischen bo̊swicht aber nicht gelingen / denn die o̊brigkeit ym land zu Holstein kennen auch aus Gottis gnaden schwarz vnd weis / die warheit vnd die vnwarheit[.] (C2r)

Hoffman nutzt seinen Status als von der Obrigkeit eingesetzter Prediger, indem er ausgehend von der zentralen Stellung des Königs in seiner Argumentation implizite Vergleiche zieht: Zum einen lässt er unter der Oberfläche mitschwingen, dass die weltliche Autorität des Königs mit der göttlichen Autorität gleichzusetzen ist (der König kennt die göttliche Wahrheit), zum anderen überträgt er die königliche Autorität auf sich selbst. Durch die wiederholte Beleuchtung seiner Relation zum König macht Hoffman sich dessen Glaubwürdigkeit zunutze. Seine eigene Glaubenslehre wird daher zur einzigen weltlich und göttlich legitimierten, die als Alternative daneben nur ihren Gegensatz - den Unglauben übrig lässt. Gegen Ende von Nasen geist geht Hoffman sogar so weit, sein Leben in die Hände des Königs zu geben:

Vnd ist es sach das ewer einer mit der warheitt kan beweisen / vnd an tag stellen aus Gottis wort / das ich das volck verfür / vnd nicht rechtlere / so hab ich den hals / vnd Königliche wirden von Dennmarck das schwerde / vnd ich beger auch kein gnad meines lebens nicht auff diesem erderich“ (C3v)

Geschickt legt er damit ein weiteres Mal die Entscheidungsgewalt in die Hände des Königs, während er gleichzeitig seine Gegner als Urteilsprechende entmachtet. Stattdessen stellt Hoffman sie in die Beweispflicht, ihn zu widerlegen. Diese Forderung nach Widerlegung bei gleichzeitigem Einsatz des eigenen Lebens bestärkt implizit aber nur mehr die Gültigkeit seiner Lehre.

Dieses Beispiel zeigt, dass Hoffman mit unterschiedlichen Mitteln seine Autorität und Authentizität zu steigern versucht. Dies beruht 
unter anderem darauf, dass er auch in Nasen geist offen polemisiert. Da Hoffman sich offen als polemisches Subjekt ausweist, muss er sich im Gegensatz zu einer verdeckten polemischen Situation - selbst als Melchior Hoffman positiv in Szene setzen, um der Polemik grundsätzliche Wirkmächtigkeit zu verleihen. Da Amsdorf in seinen zwei Schriften Hoffmans Image bereits angegriffen bzw. als negativ konstruiert hat, ist Hoffman zum einen gezwungen, auf diese Imageverletzungen zu reagieren, zum anderen gehört die positive Selbstimagebildung grundsätzlich zur Polemik und den antagonistischen Positionen, die sie entwirft, hinzu.

Um eine Festigung des polemischen Antagonismus zu seinen Gunsten zu erreichen, legt Hoffman in seiner zweiten Schrift gegen Amsdorf besonderes Gewicht auf die Imagekonstruktion - und zwar sowohl das Selbstbild als auch das Fremdbild betreffend. Da der Streit nach dem Austausch von drei polemischen Schriften bereits weiter fortgeschritten war und Amsdorf in seiner vorausgehenden Schrift Falscher Prophet ganz explizit ein Publikum ansprach, das Melchior Hoffman eher zugewandt sein mochte, ${ }^{502}$ tat es ihm vermutlich besonders not daran, den Kampf um den polemischen Antagonismus zu seinen Gunsten zu wenden, Unentschlossene oder Zweifler zu überzeugen sowie den Zusammenhalt seiner Anhänger zu stärken. Infolgedessen verwendet Hoffman in seinem zweiten polemischen Text wesentlich intensiver unterschiedliche Formen von Selbst- und Fremdzuschreibungen, die den inszenierten Rollen des polemischen Subjekts und Objekts zudem inhaltliche Dimensionen hinzufügen und deutlicher oppositäre Profile verleihen.

Schon in seiner ersten Schrift gegen Amsdorf entwirft Hoffman gegensätzliche Rollen für sich selbst und seinen Gegner Amsdorf: Dort wird Amsdorf als ein hetzerischer Lügner charakterisiert, der sein unschuldiges Opfer hart mit seinen Verleumdungen attackiert und sich als gelehrter Geistlicher dem gebildeten Laien gegenüber arrogant und überheblich verhält. Nach Hoffmans Beschreibung des Sachverhalts ist der arme Pelzer diesen vorsätzlich bösen Angriffen völlig schutzlos ausgeliefert, obwohl jener doch die Wahrheit vertritt, und sieht sich deshalb zum Verfassen einer polemischen Verteidigungsschrift genötigt. Die oppositären Rollenstilisierungen von Täter vs. Opfer, von Lügner vs. - im

${ }_{502}$ Amsdorf schreibt unter anderem „ewer prediger Melchior Hoffman“ (FP, A2r), „ewer Melchior Hoffman“ (FP, A3r \& A4r) oder auch nur „ewer/m Melchior“ (FP, A2v, Bir \& B2v). 
wörtlichen sowie übertragenen Sinne - Wahrsager und schließlich von Geistlicher vs. Laie werden auf verschiedene Weise in Nasen geist fortgeführt, erweitert und intensiviert. Für die Umsetzung dessen bedient sich Hoffman insbesondere der Bibel als Argumentationsstütze und Bezugsfolie für die Imagekonstruktion, nutzt das semantische Potential von Schimpf- und Stigmawörtern und verwendet verschiedene Formen bildlicher Sprache, wie im Folgenden erörtert wird.

\section{Die Bibel als Argumentationsstütze und Bezugsfolie für die Imagekonstruktion}

In reformationspolemischen Texten allgegenwärtig ist das Bibelzitat. Es ist eine der wichtigsten Überzeugungs- bzw. Argumentationsstrategien der Reformatoren. Im Sinne des protestantischen Prinzip des sola scriptura findet die Bibel als alleinige Quelle der sogenannten ,göttlichen Wahrheit' Einzug in sämtliche religiösen Debatten. Insbesondere dem bibelkundigen Laien Hoffman, ${ }^{503}$ dem andere religiöse Literatur durch fehlende Lateinkenntnisse verschlossen blieb, kam die Einschätzung der Bibel als alleinige Autorität in Religionsfragen zur Hilfe. Durch zahlreiche Bibelübersetzungen hatten Laien wie Hoffman auch ohne Lateinschule und theologisches Studium Zugang zum Diskurs erhalten. Angesichts dessen verwendeten sie die Heilige Schrift „auch zur Untermauerung ihrer Kenntnisse der christlichen Lehre", ${ }^{504}$ da sie die fehlenden Kenntnisse der lateinischen Schriften der Theologie so zu kompensieren wussten. ${ }^{505}$ Überraschenderweise stellte die Bibel für viele Laienprediger die einzige Autorität dar; andere Reformatoren wie z. B. Luther oder Zwingli wurden nur vereinzelt zitiert oder genannt. ${ }^{506}$ Auch Hoffman

${ }^{503}$ Vgl. dazu: „Hofmann's knowledge of the Bible was widely recognized and was said to exceed that of most of the regular clergy. "Noll (I973), S. 49.

504 Schwitalla, Johannes (200I): „Schreibstile von Laien in der Zeit der frühen Reformation “. In: Jakobs, Eva-Maria \& Annely Rothkegel (Hg.): Perspektiven auf Stil. Tübingen: Niemeyer, S. 459-477, hier S. 462.

505 Schwitalla gibt eine kurze Übersicht über die Veränderungen, die zur Aufwertung des Laienstatus geführt haben. In den Reformationsdialogen wird der bibelkundige Laie dem unwissenden Priester oftmals sogar diametral gegenüber gestellt. „Irrelevant war außerdem von reformatorischer Seite das Kriterium des Studiums, speziell des Theologiestudiums für die Interpretation der Bibel. Den Reformatoren war die Bibel ohne Erläuterungsinstanz verständlich (,scriptura sui ipsius interpres $\left.^{6}\right)$. Die Vertreter der römischen Kirche warfen den Laien vor, sie könnten kein Latein und könnten deshalb auch nicht von göttlichen Dingen reden. " Schwitalla (200I), S. 462.

${ }_{506}$ Miriam U. Chrisman kommt bei ihren Untersuchungen des Laienschrifttums zu dem Ergebnis: „[L]ay men and women did not simply repeat, parrot fashion, the 
verzichtet in seinen Texten darauf, sich mittels Referenz auf Luther den er noch bis zur Flensburger Disputation I 529 als seinen geistigen Führer empfunden haben muss - Autorität zu verschaffen. Anstatt auf die Theologie des angesehenen Reformators zurückzugreifen, um sich Gehör zu verschaffen, präsentierte Hoffman seine eigenen Auslegungen, erklärte seine individuellen Ansichten und theologische Vorstellungen und kreierte ein eigenständiges Lehrgebäude. ${ }^{507}$ Lediglich intertextuelle Bezüge zur Bibel durch Zitate, Paraphrasierungen, Anspielungen oder Referenzen ${ }^{508}$ komplettierten die eigenständige Deutung der Bibel sowie der zeitgenössischen Diskussionen und Geschehnisse.

Hoffman nutzt die Bibel jedoch nicht nur als Beleg oder Nachweis seiner Argumente, sondern verwendet sie vielmehr als Bezugsfolie für seine Polemik. Sie wird mitunter zu einem narrativen Projektionsraum, in den Hoffman sich selbst, seinen Gegner Amsdorf und die für ihn relevanten Geschehnisse überträgt. Er setzt Elemente aus der biblischen

arguments of the theologians. The theological points, the blasphemy of the monastic services [...] had been stated by Luther, Zwingli and other reformers; but in each case the lay person constructed his own argument, reflecting his own particular grasp of the problem. “ Chrisman, Miriam U. (I980): „Lay Response to the Protestant Reformation in Germany, I $520-1528$. "In: Brooks, Peter Newman (Hg.): Reformation Principle and Practice. London: Scolar Press, S. 33-52, hier S. 43. Vgl. dazu auch Lundström, Kerstin (2OI2): „Lay Pamphlets in the Early Reformation: Turning Points in Religious Discourse and the Pamphlet Genre? “ In: Nünning, Ansgar \& Kai Marcel Sicks (Hg.): Turning Points. Concepts and Narratives of Change in Literature and Other Media. Berlin: De Gruyter, S. 319-336.

507 Hoffmans Lehre ist ein Produkt der andauernden Wechselwirkung eigener Lektüre mit unterschiedlichen Fremdeinflüssen. Darin sieht Deppermann viele „irritierende Widersprüche in seiner Entwicklung und [...] heterogene Elemente in seinem Denken“ begründet. Deppermann (I975), S. I74. William R. Estep nennt ihn einen „marginal Anabaptist“, denn „Hofmann concocted a strange mixture of spiritualism, Christology (derived from Caspar Schwenckfeld), and elements of Anabaptism [...]. “Estep, William R. (1996): The Anabaptist Story: An Introduction to Sixteenth-Century Anabaptism. Grand Rapids: Eerdmans.

${ }_{508}$ Bibelzitat und -paraphrasierung sind oftmals schwer voneinander zu trennen, da der exakte Wortlaut nicht immer nachvollziehbar ist. Da die Übereinstimmung des exakten Wortlauts für die vorliegende Untersuchung nicht relevant ist, wird im Weiteren vom Bibelzitat gesprochen, wenn offensichtlich zusammenhängende Abschnitte als Bibeltext ausgezeichnet werden oder eine Ähnlichkeit der Formulierung erkennbar ist. Eine Anspielung kann davon abgegrenzt werden, wenn nur einzelne Worte, Ausdrücke, Namen, Gleichnisse und Geschichten oder ähnliches genannt werden. Anspielungen setzen für ihr Verständnis die Kenntnis des Bezugstextes voraus. Bibelreferenzen hingegen bestehen aus einem expliziten Hinweis auf das relevante Buch (und das Kapitel), das an einer bestimmten Stelle von Bedeutung ist. Ein Nachschlagen ist somit durch eine konkrete Quellenangabe möglich. Referenzen tauchen z. B. in Marginalien oder hinter einem Argument (als z. B. , I Thess 2 ${ }^{6}$ ) auf. 
und der eigenen, Welt' in eine Parallele zueinander oder integriert sie bisweilen sogar. Schon zu Anfang von Nasen geist, bevor er Amsdorf im Fließtext erwähnt oder sich überhaupt dem polemischen Thema widmet, nimmt Hoffman eine Einschätzung seiner Zeit vor, indem er sie mit der Zeit der Apostel vergleicht. Er bittet

„alle[] lieben freunde der Gơtlichen warheit / das sie sich nicht ergern [...]. Denn es was auch ein solcher lauff zu der zeitt der Apostel / das dreyerley art prediger waren / doch nur eine recht / Das etliche vmbs bauchs willen predigten / etliche vmb neidt vnd hass willen / also wils ytzt auch sein / da ein yder nur mit gedult auff sehe / Denn die warheit wird den sieg behalten / vnd der geist der li̊gen ym dreck sitzen bleiben / als von anfang der welt dē falschen lůgengeistern geschehen ist. (Arv)

Hoffman vergleicht die aktuelle Situation mit den Begebenheiten zur apostolischen Zeit, der frühchristlichen Geschichte, und setzt so die für ihn aktuellen Geschehnisse und Unruhen der christlichen Lehre in den Kontext der Judenbekehrung. ${ }^{509}$ Die Parallele, die Hoffman schafft, ist deutlich: Es geht um die Bekehrung zum rechten Glauben. In der Apostelzeit waren es die Juden, die zum Christentum bekehrt wurden, für Hoffman ist seine Zeit erneut eine solche Phase, in der die Menschen zum rechten Glauben geführt werden müssen. Dass Hoffman sich zu denen zählt, die den rechten Glauben besitzen und ihn vor allem lehren, ist zum einen durch Logik zu erschließen, zum anderen aber auch dadurch begründet, dass Hoffman sich selbst schon zu Anfang als Apostel bezeichnet, denn er begründet sein Schreiben damit, dass er „der verantwortung vberbütig sein [will] als des Apostels befelh ist“ (AIv) $)^{\text {sto }}$. Damit deutet er schon seine Rollenidentifizierung an, die dann im weiteren Verlauf weiterentwickelt wird. Durch den sich daraufhin anschließenden intertextuellen Bezug auf die Evangelien und die Apostelgeschichte, lässt sich der Vergleich leicht aufschlüsseln. Wie zur Zeit der Apostel gibt es schlechte Lehrer - diese Rolle fällt dem Titel nach dem „lugenhafftigen falschen nasen geist“ Amsdorf zu. Die

${ }^{509}$ Bereits in den Schlussworten von Dat Nicolaus Amsdorff macht er den Vergleich mit der Zeit der Apostel: „Den by der Apostel tydt ghinck ydt ock also tho / dat ein deyl sick vpworpen / beter tho syn / denn de rechten Apostele / gelerder vnde geschickter / dar van S. Paulus in synen Epistelen schrifft" (A4r). Was er hier nur kurz anschneidet, führt er in Nasen geist weiter und knüpft somit an die Thematik und seine vorherige Schrift wieder an.

510 Paraphrasierung zum Verständnis: Er will sich der Verantwortung beugen, wie es des Apostels Auftrag ist. Der „Befehl“ wird in dieser Lesart vom Apostel empfangen und nicht ausgesprochen. 
Rolle des rechten Predigers, der die wahre christliche Lehre verbreitet, hat folglich Hoffman selbst inne. Aber Letzterer stellt sich selbst weniger als individueller Akteur dar, sondern sieht sich in der Funktion des Botschafters, dessen Auftraggeber Jesus Christus ist.

Das angesprochene Problem, das Auftauchen falscher Prediger, wird allerdings schon von Anfang an als sich selbst lösend erklärt: „Denn die warheit wird den sieg behalten / vnd der geist der lůgen ym dreck sitzen bleiben / als von anfang der welt dē falschen li̊gengeistern geschehen ist“ (AIv). Dies steht im eigentlichen Widerspruch dazu, dass Hoffman hier eine Schrift vorlegt, um die einzig gültige Wahrheit festzustellen, zu verteidigen und die Lügen der Gegenseite zu entlarven. Die Analogie mit der Apostelzeit lässt dennoch die Vorausdeutung Hoffmans bezüglich des Siegs der ,wahren Lehre' zu, denn dort ist der Prozess schon abgeschlossen, den Hoffman für seine Zeit noch als im Vollzug deklariert. Dass Amsdorf in dieser Analogie als ein Widersacher der Apostel und folglich auch Gegner der rechten Lehre gilt, lassen der Titel und der ähnliche Wortlaut der Beschimpfungen („dē falschen lo̊gengeistern“ und „lugenhafftiger falscher nasen geist“) vermuten.

Aber nicht nur wird eine bestimmte biblische Zeit als Bezugsfolie für Hoffmans Gegenwart benutzt, sondern es werden auch potenzielle Szenarios entworfen, in denen die beiden ,Zeiten', die Bibelgeschichte und die hoffmansche, Wirklichkeit', imaginär aufeinandertreffen. So stellt Hoffman beispielsweise Überlegungen an, wie es gewesen wäre, wenn Amsdorf mit seinen Argumenten auf Christus getroffen wäre:

Der lügenhafftige laruen geist schreibt / so Melchior nicht anzeigt anfang der zeit / vnd das ende vom Jůngesten tag / so ist sein lere falsch / den sein geist der yhm heilig ist / redt nicht so dunckel / Růltz / filtz / nasen vnd laruen geist / schreibstu doch selbs ${ }^{511} /$ das Christus seinen iůngern sagt / das yhn nicht gebůr zu wissen der sticke $\bar{e}^{\text {I2 }} /$ Werestu ellender laruen geist zu der zeit gewest / soltest eben also gesagt haben zu Christo dem Heilandt. (A3v, Hervorhebung K. L.)

${ }_{511}$ Hier referiert Hoffman auf Amsdorfs Schrift Falscher Prophet: „Christus gebeut seinen Jüngern vnd allen Christen / das sie wachen vnd beten sollen / denn es ist vmb vnsert willen geschrieben / vnd gehet vns eben so wol an als die Aposteln selbst $[\ldots]$ “. (A4r).

${ }^{512}$ Der ,sticken', eigentlich „jedes langgestreckte, spitze (nadelförmige) Ding“ (SchillerLübben 4, S. 397 f., Hervorhebung im Original), kann hier aufgrund der produktiven Verwendung in Redensarten mit ,Ende` oder auch, Zeitpunkt ${ }^{\star}$ übersetzt werden. Vgl.: „hierzu verschiedene redensarten, vor allem den sticken stecken in mannigfachen bedeutungsschattierungen, z. B. ,ein ende machen'[.] “ „STICKEN“, DWB I 8, Sp. 2736. 
Mit der Verwendung des Konjunktivs versetzt Hoffman Amsdorf imaginär in einen biblischen Kontext, um ihn in Interaktion mit Christus dem Leser vor Augen zu stellen. Hoffman bedient sich hier des Mittels der Evidenz (evidentia), ${ }^{513}$ d. h. er nutzt eine Strategie, „strukturelle Performativität" ${ }^{514} \mathrm{zu}$ erzeugen, um ein Bild vor den Augen des Lesers entstehen $\mathrm{zu}$ lassen. ${ }^{515}$ Anstatt ein explizites Gegenargument auf Amsdorfs Forderung nach genauen Angaben des Anfangs und des Endes der Prophetie anzubringen, konstruiert Hoffman ein fiktives Szenario, das die Absurdität von Amsdorfs Forderung ironisch zur Schau stellt, ohne dass es einer Erklärung bedürfe. Die evozierte Szene, in der Amsdorf zu Jesus Christus sagen würde, dass seine Prophetien nicht stimmen können, weil sie „dunckel vnd finster geredt“ (FP, A2r) seien, ja dass es sogar „des teuffels wort [sei] / der so finster vnd dunkkel zu reden pflegt" ( $F P, \mathrm{~A} 2 \mathrm{v})$, lässt für den ,christlichen Leser ' nur eine Interpretation zu: Der Zweifel an Jesus Christus kommt einer Gotteslästerung gleich. Bei der Rückübertragung der virtuellen Szene in die aktuelle Situation bleibt dann der neu gewonnene Eindruck von Amsdorf als ebensolch eines Lästerers der göttlichen Wahrheit, obgleich es sich ursprünglich um Zweifel an Hoffmans und nicht Christus' Prophetien handelte. Dadurch aber, dass Hoffman seinen Gegner in die Zeit von Christus versetzt, gelingt es ihm zum einen, die Bibel als Autorität für seine Sache einzubinden, und zum anderen, Christus an seine eigene Stelle zu setzen und damit eine Analogie zu sich selbst herzustellen. Auf diese Weise schreibt sich Hoffman die Rolle eines (neuen) Messias auf den Leib. Amsdorf bleibt in diesem Zusammenhang nur die Rolle eines Pharisäers. Die vorausgesetzte Kenntnis des Neuen Testaments legt diese Deutung nahe, ohne dass Hoffman es weiter ausführen muss. Amsdorf wird in den narrativen Raum der biblischen

${ }^{513}$ „Evidenz (lat. evidentia, griech. enárgeia, hypotýposis) bedeutet das Prinzip der Anschaulichkeit, des Vor-Augen-Stellens von etwas (ante oculus ponere). [...] Im Gegensatz zur Klarheit, die intellektuell belehrt, und zum Schmuck, der das ästhetische Vermögen bereichert, eignen sich die Mittel der Evidenz zum Bewegen der Affekte. [...] Dieser [der Rezipient] wird zum ,fiktiven Augenzeugen' (Lausberg) eines inneren Schauspiels, wozu der Text manchmal durch die cernas-Formel (,sieh doch, wie [...] $]^{\text {) }}$ ausdrücklich einlädt. [...] Das Endziel der ,enargetischen“ Darstellung ist die Ununterscheidbarkeit von Fiktion und Wirklichkeit, anders gesprochen: eine Illusionswirkung.“ Plett (200I), S. 32.

${ }^{114}$ Häsner et al. (20II), S. 82.

${ }^{515}$ Bo Andersson identifiziert eine ähnliche Form der Evidenz in Gregorius Richters Pasquill gegen Jacob Böhme (imaginäre Gegenüberstellung Christi und Böhmes) und würdigt sie als eine „außerordentlich wichtige rhetorische Technik“. Andersson (2012), S. 39 . 
Geschichte eingebettet und wird zu einem Akteur innerhalb dieser bereits existierenden Narration. Amsdorfs Einbindung in die Geschichte ändert sie jedoch nicht in ihrem Verlauf, vielmehr nimmt er eine bereits existierende Rolle ein, die dann auf die Interpretation zurückwirkt. Daher kann das bekannte Ende der Narration ebenfalls gedanklich aktiviert werden, so dass die Kreuzigung Christi implizit mitschwingt. Die performative Einbettung Amsdorfs in die biblische Geschichte birgt insofern ein weitaus höheres Potential, Emotionen auf Seiten der Leser hervorzurufen, als es ein sachlich formuliertes Gegenargument Hoffmans könnte. Die Strategie Hoffmans, die Leserschaft zu überzeugen, ist der Appell an das Pathos.

Hoffman nutzt die Strategie des Vor-Augen-Stellens noch mehrmals, um seine Prophetie als wahrhaftig zu beweisen und sich damit gegen die Anschuldigungen Amsdorfs zu verteidigen. Letzterer sieht seine Angriffspunkte darin, dass Hoffman einerseits vom begonnen Prozess der apokalyptischen Zeitrechnung von sieben Jahren ausgeht, andererseits aber keinen exakten Zeitpunkt für den Jüngsten Tag nennen will. Amsdorf kritisiert dies als einen Widerspruch, da Hoffman doch auch einen Endpunkt setzen müsse, wenn er behaupte, dass der Prozess schon begonnen habe. Auch die zwei Zeugen, die Hoffman als die Vernichter des Antichristen erwähnt, könne er nicht beim Namen nennen. ${ }^{116}$ Deshalb sei die Prophetie ungenau und Hoffman ein „falscher Prophet" (FP, A2r-v). Den Vorwürfen Amsdorfs, ein Gesandter des Teufels zu sein $\left(E V, A_{3} v\right)$ bzw. den Teufel zum Gott zu haben (FP, A4r), entgegnet Hoffman auf die Weise, dass er sich in eine Reihe mit Propheten aus der Bibel stellt, die ebenfalls ungenaue Prophezeiungen gemacht haben.

Dabei geht Hoffman rhetorisch geschickt vor und setzt in mehrfacher Weise Stilfiguren der Wiederholung und Amplifikation ein. Er reiht Beispiel an Beispiel, Name an Name und wiederholt jeweils immer wieder, dass auch jene Propheten, die er aufzählt, weder Anfang noch Ende genannt haben. Durch die immer dichter werdende

${ }^{516}$ „Ein stůck ist wol deudsch geredt das yderman verstehen kan / nemlich / wenn die zwen zeugen nidderliggen / das die halbe zeit der sieben iar vmme sey / Es bleibt aber gleichwol finster / dunckel vnd vnbekant / in welchem iar das mittel der sieben iar seyn wirt / denn niemant weis es / er zeigt es auch nicht an / wenn die zeugen vnterliggen / ia niemant weis wer die zeugen sind / odder wo sie sind / Derhalben die weil er nicht anzeigt wer die zeugen sind / wo sie sind / odder auffs wenigste wenn sie angefangen haben / so bleibt anfang / mittel vnd ende der sieben iar vngewiss / finster vnd dunckel“" (FP, A2r). 
Wiederholungsstruktur und die sich inhaltlich summierenden sowie semantisch anschwellenden Aufzählungen intensivieren sich spürbar die Ironie und die emotionale Aufgeladenheit der Passage. Beginnend damit, dass mit Amsdorfs Anklage der Ungenauigkeit „das figurlich ampt gar hart gelestert" (A2v) würde, erklärt Hoffman, dass andere Propheten in der Bibel die Forderungen Amsdorfs nicht erfüllten:

Auch Jacob der Patriarch prophetirt vō Christo / so das zepter wůrd weg genommen von Juda / were der Heylandt verhanden / Do war auch kein anfang vnd end / als mein narrenfex schreibt / Joseph weissaget vor seinen brůdern / vnd vor der mutter vnd seinem vater / sagt nicht anfang vnd end / darumb solts nicht Gots geist sein / Gott verhiesch Adam vnnd Eua den Heylandt / sagt nicht anfang vnd end / darumb mus es dem luggengeist nicht Gottis wort sein / Des gleichen die verheisschung die geschehen ist zu Mohe / Abraham / Isaac / Jacob / David vnd der gleich / ist yhn nicht verkůndet anfang / end / Darumb ists nicht war / denn des Amsdorffs heiliger geist redt nicht so dunckel / auch darzu haben alle Propheten Gottis aus Gottis mund prophetirt / aber nicht gesagt anfang end den sticken des meist teil / Darumb ists nicht war / dann Amsdorfs heiliger geist redt nicht so dunckel / auch haben die Aposteln des gleichen / den tag der letzten zeit verkůndet / Christus selber zeiget nicht an den sticken / Darumb ists nicht war / denn Amsdorffs heiliger geist redet nicht so dunckel / So sind nu alle / die geprophetiret haben aus Gottis krafft / die nicht anfang vnd end gemeldet haben / falsch / den Amsdorffs heiliger geist redt nicht so dunckel. $\left(\mathrm{A}_{3} \mathrm{r}\right)^{517}$

Mit der Aufzählung verschiedener Propheten, sowohl aus dem Alten als auch aus dem Neuen Testament, holt Hoffman sich die biblische Legitimation für seine Art des Prophezeiens.

Das Sich-Einreihen in die biblischen Propheten funktioniert wie das Aufdecken eines logischen Fehlschlusses. Amsdorfs Satz, der widerlegt werden soll, könnte in etwa wie folgt lauten: Prophetien ohne Anfang und Ende sind falsche Prophetien. Gegen diesen Satz stellt Hoffman die Beispiele der biblischen Propheten, woraus sich folgender Satz ableiten ließe: Viele biblische Prophetien haben keinen Anfang und kein Ende. Durch die Autorität der Bibel ist zudem implizit: Biblische Prophetien sind wahr. Die Schlussfolgerung daraus ist, dass Amsdorfs Satz nicht wahr sein kann, da er auf die biblischen Beispiele nicht passt.

${ }_{517}$ Die Hervorhebungen sind von der Verfasserin so gewählt, um die Wiederholungen der zwei markierten Phrasen zu verdeutlichen. Der Fettdruck und die Unterstreichungen markieren jeweils ihre Zusammengehörigkeit. 
Hoffman bedient sich auf diese Weise einer Widerlegungsstrategie, die Arthur Schopenhauer unter dem Begriff der „Instanz, [...] exemplum in contrarium ", ${ }^{518}$ fasst. Die Autorität der Bibel gilt dabei als entscheidender Wahrheitsindikator, ${ }^{519}$ der notwendig für das Funktionieren des Gegenbeispiels ist.

Diese Widerlegungsstrategie wird durch die Anwendung von sich verschärfender Ironie begleitet. Hoffman verdreht strategisch Amsdorfs Aussage, so dass sie sich schließlich mittels Ironisierung gegen ihn selbst wendet. Um deutlich zu machen, wie diese Verdrehung im Detail erfolgt, bedarf es einer kurzen Darlegung, auf welche Aussagen Amsdorfs sich Hoffman bezieht.

In Falscher Prophet betont Amsdorf mehrere Male, dass Melchior Hoffmans Informationen über den Beginn und das Ende der vorhergesagten Geschehnisse unklar sind. Die gebrauchte Bildhaftigkeit von heller und dunkler Rede ist dabei der Schlüssel der Polemik Amsdorfs gegen Hoffman, da hell und dunkel gleichzeitig auch konnotativ für Himmel und Hölle, Gott und den Teufel stehen. Amsdorf erklärt seinen Lesern in seiner zweiten Schrift gegen Hoffman, letzterer habe selbst geschrieben, „er hab den anfang der sieben iar nicht angezeigt / aber das mittel der sieben iar hab er klar vnd hell angezeigt" (FP, A2r). In mehrfacher Ausführung kommentiert Amsdorf diese fälschlich wiedergegebene Aussage Hoffmans - eine äquivalente Textstelle lässt sich in Dat Nicolaus Amsdorff nicht finden ${ }^{520}$ - und wiederholt dabei immer wieder die antithetische Gegenüberstellung:

I. [W]enn das klar vnd hell geredt ist / so weis ich nicht was dunkkel vnd finster geredt ist. (FP, A2r)

2. Es bleibt aber gleichwol finster / dunckel vnd vnbekant / in welchem iar das mittel der sieben iar seyn wirt [...]. (FP, A2r)

${ }_{518}$ Die Instanz ist nach Schopenhauer die „Widerlegung des allgemeinen Satzes durch direkte Nachweisung einzelner unter seiner Aussage begriffener Fälle, von denen er doch nicht gilt, also selbst falsch seyn muß. “ Schopenhauer (I923), S. 406.

519 Wahrheit wird hier als das als wahr angenommene verstanden. Vgl. dazu Schopenhauer, der die objektive Wahrheit für die (eristische) Dialektik als irrelevant erklärt. Schopenhauer (I923), S. 403-405.

${ }^{520}$ Hoffman schreibt lediglich, dass er seine Prophetie vom Jüngsten Tag genügend in seiner Daniel-Auslegung begründet habe, die Amsdorf nur richtig verstehen müsse. Die Adjektive ,klar' und ,hell' benutzt er nicht: „Jck hebbe dy grundes genoechsam angeto̊get / wat ick vam Jůngesten dage geschreuen hebbe / vnde der schrifft ynholt / Vorstae myn Bo̊keschen Daniel recht / vnde doe de ogen vp“ (DNA, A2r). 
3. [S]o bleibt anfang / mittel vnd ende der sieben iar vngewiss / finster vnd dunckel / denn wenn das mittel gewiss were klar vnd hell / so were der anfang auch klar vnd hell / Die weil aber das mittel vngewiss ist [...] so ist auch vngewiss finster vnd dunckel anfang vnd ende [...]. (FP, A2r-v)

4. [...] das ist [...] des teuffels wort / der so finster vnd dunckel zu reden pflegt. $(F P, \mathrm{~A} 2 \mathrm{v})$

5. [Wenn Melchior Hoffman die genaue Zeit und die Zeugen nenne,] so würde er vns solchs alles klarlich anzeygen [...] das were klar / gewiss vnd hell von der sach geredt / wie der heilige geist thut [...]. (FP, A2v)

(Hervorhebungen K. L.)

Insbesondere die letzte Aussage (Zitat 5 ) greift Hoffman auf und verdreht sie zu seinen Gunsten, indem er den Heiligen Geist, der „gewiss vnd hell von der sach“ spricht, in den „geist der yhm [Amsdorf] heilig ist" $\left(\mathrm{A}_{3} \mathrm{r}\right)$ verkehrt. Es findet eine Umdeutung statt, die den Heiligen Geist zu Amsdorfs heiligem Geist macht. Damit ist angedeutet, dass es nicht der Heilige Geist sei, von dem Amsdorf spreche, sondern ein Geist, der gerade nur von Amsdorf für heilig befunden würde. Bei der Umdeutung des Heiligen Geistes handelt es sich um eine übliche Form der Reformationspolemik. Die Verwendung von ,Geist' besitzt zum Teil Stigmawortcharakter, ${ }^{521}$ der hier allerdings nicht zum Einsatz kommt, da von Hoffman keine Programmatik angedeutet wird. Vielmehr geht es darum, eine spirituelle Verwirrung anstatt einer spiritualistischen Programmatik anzuzeigen, die mit Aufruhr in Verbindung gebracht wird. Zwar mag es sein, dass der Gebrauch des Stigmawortes ebenfalls ins Gedächtnis gerufen wird, aber vordergründig geht es darum, Amsdorf als verwirrt bloßzustellen und ihm so seine geistigen Fähigkeiten in Bezug auf die Argumentation abzusprechen. Ähnliche Techniken der Polemik, die darauf abzielen, Amsdorfs Glaubwürdigkeit zu diskreditieren, wendet Hoffman bereits in seiner ersten Schrift an, indem er nach einem Arzt ,ausruft', der Amsdorf den Gecken schneiden möge, da dieser offenbar irrwitzig geworden sei.

Infolge der Charakterisierung von Amsdorfs Geist als einen anderen als den Heiligen Geist, wird die positive Bedeutung davon, dass dieser

${ }^{521}$ Siehe Diekmannshenke (I994), S. 369-375. Bei der Anwendung des Stigmawortes ist „die spezielle, spiritualistische Programmatik und de[r] damit verbundene[] Willen zur revolutionären Umgestaltung der feudalen Gesellschaft [samt Aufruhr gemeint]“. Ein deutliches Beispiel dafür ist der ,Rottengeist‘. 
Geist nicht „so dunkel redet“, ironisiert und als Trugschluss entlarvt. ${ }^{522}$ Durch die Häufung ähnlicher Aussagen, die schließlich in einer viermaligen Wiederholung des gleichen Wortlauts „Darumb ists nicht war / denn des Amsdorffs heiliger geist redt nicht so dunckel“ mündet, wird der Effekt der Ironie noch verstärkt. In der etwa eine Seite umfassenden Passage verflechtet Hoffman die Widerlegung mittels einer Klimax der prophetischen Gegenbeispiele ${ }^{523}$ mit der ironischen Verdrehung von Amsdorfs eigenem Argument und verstärkt so doppelt seinen polemischen Gegenangriff.

Ergänzend wird auch die Rede Amsdorfs vom Anfang, Mittel und Ende permanent wiederholt. Allein in der kurzen zitierten Passage (s. o.) ist die Rede sieben Mal von „anfang vnd end“ (bzw. „sticken“). Hoffman wiederholt damit ebenfalls eine Formulierung, die Amsdorf in Falscher Prophet mehrfach in seinem Argument gegen Hoffman verwendet. Auch in diesem Fall nutzt er den argumentativen Angriff für seine eigenen Zwecke. Zunächst zeigt er - wie bereits erörtert -, dass auch andere Propheten auf die gleiche Art und Weise prophezeit haben. Danach geht Hoffman noch zusätzlich auf die Argumentation Amsdorfs ein, denn letzterer führt in Falscher Prophet als drittes Argument gegen die Lehre vom Jüngsten Tag an, dass sie wider Gott, sein heiliges Wort und die Evangelien sei, da Christus klar formuliere, dass man alle Tage wachen solle. ${ }^{24}$ Anstatt auf die einzelnen Bibelstellen (sämtliche aus den Evangelien) einzugehen, kontert Hoffman mit Paulus, der „hell vnd klar [sagt] / wenn vnnd zu welcher zeit man Christum verwachten ist zum iůngsten tag“ (A3v).525 Mit Paulus sieht Hoffman bestätigt, dass

${ }_{522}$ Später im Verlauf der Schrift wird das Thema des Amsdorfschen Geistes erneut aufgegriffen. Dort verwendet Hoffman aber keine Ironie, sondern spricht ein direktes Urteil über den Geist Amsdorfs: „Darumb ist dein geist eben ein solcher vnuerstendiger geist / als der ienigen geist war widder die sanct Paulus schreibt / vnd sie verfurrer nennet $[\ldots]^{“}$. ( $\left(\mathrm{A}_{3} \mathrm{v}\right)$ Hier ist allerdings nicht der spirituelle Geist, sondern ausschließlich der Verstand gemeint.

523 Von einzelnen Figuren wie Moses, Joseph, Abraham etc. über die alttestamentlichen Propheten zu den neutestamentlichen Aposteln hin zu „alle[n] / die geprophetiret haben aus Gottis krafft“ (A3r).

524 Amsdorf gibt eine Vielzahl von Bibelstellen an, da er die implizite Herausforderung Hoffmans, er „ko̊nne mit der warheit nicht beweisen / das man des iůngsten tags alle tag wachten sol“ (FP, A3v), scheinbar annimmt. Er zitiert für den Zweck des Beweisens folgende Bibelstellen: Mt 24: 44 \& 50, Mt 25: I3, Mk I3: 33, 35 \& 36 und $\mathrm{Lk} 2 \mathrm{r}$ : 36 . (FP, $\left.\mathrm{A}_{3} \mathrm{r}-\mathrm{A}_{4} \mathrm{r}\right)$.

525 Hoffman bezieht sich hier auf 2 Thess 2 und sieht das Eintreten der Weissagung darin begründet, dass der Papst als Antichrist entlarvt wurde: „Vnd spricht der heilig Paulus also / der Jůngst tag kom nicht / es geschehe denn zuuor der abfal / vnd 
seine Prophezeiung wahr sei und betont dies durch die direkte Anrede Amsdorfs:

Thu die augen auff du luggen geist / vnd sich was du ellender nasen geist fur lůgen schreibest / vnnd sihe das dis der erste punct ist / das dein schreiben vom Jůngsten tag falsch sey / vnd die wort also nicht zu verstehn sein / die du furgibst vom stets wachen / sondern wenn die zeit vollendet ist / die hie Paulus an tag stecket / so gehn denn die wort ynn krafft / das man sol auff sehen vnd wachen / [...] so merck nu du li̊gen geist recht auff / wie die wort klingen / das du nicht also die wort rausser qwaxst / hin vnd widder ynn der schrifft / sondern sihe auch an den vor klapff vnd das ende / was mittel / end / anfang darbey thut / Denn so ich dir also solt zugeben die schrifft also zu brechen / soltest mir wol die gantz Bibel verwirren / das man weder anfang end noch seiner art verstehn wůste. $\left(\mathrm{A}_{4} \mathrm{r}\right)$

Mit dem Wechsel zum direkten Polemisieren wird ebenso der performative Charakter der Polemik evoziert. Die Leserschaft bekommt eine Szenerie vor Augen gestellt, die durch die direkte Anrede, die Wiederholungen der Ansprache als Lügen- oder Nasengeist und bildliche Sprache (,quaken' anstatt ,sagen') gefördert wird. Als Schlusspunkt des Abschnitts und finales Statement greift Hoffman dann wieder die bereits mehrfach verwendeten Schlüsselbegriffe „anfang vnd end“ auf. Hoffman entnimmt sie dem vorherigen Kontext der Diskussion um die Prophetie und deren Beginn und Erfüllung und stellt sie in einen neuen Kontext: Dieses Mal geht es um die Ordnung in der Bibel, die er durch Amsdorfs Auslegung in Gefahr sieht. Hoffman nutzt so die Redewiedergabe und die Wiederholung im Allgemeinen, um eine teils ironische Verdrehung, teils eine semantische Umdeutung zu seinen Gunsten zu erreichen. Der Bezug auf die Bibel spielt auch hier eine wichtige Rolle, denn sie ist die Quelle der ,objektiven Wahrheit', an der alles gemessen werden kann. Die eigene Lesart der heiligen Schrift als diejenige zu stilisieren, die diese objektive Wahrheit gleichsam sichtbar zu machen vermag, ist das Ziel der polemischen Argumentation schlechthin.

Es kann an dieser Stelle festgehalten werden, dass der Einsatz der Bibel als Bezugsfolie und integratives Narrativ sowohl die Eigenimage- als auch die Fremdimagekonstruktion unterstützt, indem Analogien zu

das geoffenbart werd das kindt der verterbuug [sic!] / welchen der Herr erwurgen wird mit dem geist seines mūdes / welches ytzt ynn krafft geschicht vnd verhanden ist $[\ldots]$ “. $\left(\mathrm{NG}, \mathrm{A}_{3} \mathrm{v}\right)$. 
biblischen Geschichten und Figuren hergestellt werden, die nicht zuletzt durch ihren Pathosgehalt dem erwünschten polemischen Antagonismus dienen. Dadurch, dass Hoffman sich dabei an Amsdorfs Schrift orientiert und den Gegner durch die Figuren der Wiederholung, Gradation und Amplifikation in mehrerer Hinsicht zu überbieten sucht, ist die Polemik gegen Amsdorf besonders eingängig und wirkungsvoll. Durch die Kenntnis der vorausgehenden Schrift entfaltet sich die polemische Wirkungsmächtigkeit vollends für die Leserschaft. Die Form des offenen Polemisierens kann (durch Kenntnis des Autornamens der zu beantwortenden Schrift) dem Publikum dazu dienen, diesen intertextuellen Bezug zur vorausgehenden Schrift zu erkennen.

\section{Die Replik beim offenen Polemisieren: Die Integration inter- und kontextueller Bezüge}

Das offene Polemisieren hat nicht nur zur Folge, dass die Leserschaft einen leichteren Zugang zu einem Schriftwechsel bekommt, sondern wirkt sich auch auf die Möglichkeiten der schreibenden Kontrahenten aus: Repliken auf verdeckt polemisierende Texte haben eine beschränkte Angriffsfläche, denn bei dieser Form des Polemisierens bleibt allein die textinterne Inszenierung des polemischen Subjekts ein bekannter und deshalb sicherer Angriffspunkt für den Antwortenden. Die Situation des verdeckten Polemisierens hat zur Folge, dass der, Wahrheitsgehalt ${ }^{\star}$ der Inszenierung nicht überprüft bzw. die kontextuellen Bezüge nicht hergestellt werden können. Infolgedessen bleiben Aussagen hinsichtlich des Urhebers, dessen Hintergrunds und der konkreten Umstände Spekulationen, da sie auf Informationen bauen, die sich aus der Inszenierung ergeben. Insofern ist eine Replik auf eine verdeckt polemisierenden Schrift von der textinternen Inszenierung vorbestimmt.

Beim offenen Polemisieren hingegen hat der antwortende Polemiker bereits bei der ersten Replik die Möglichkeit zur direkten Bezugnahme auf die gegnerische Schrift unter Zuhilfenahme des personellen Kontexts. Die intertextuelle Bezugnahme bei einer Replik kann also nicht nur aufgrund der vorliegenden textuellen Inszenierung geschehen, sondern es kann zugleich Bezug auf die Person und deren Handlungen (jenseits des vorliegenden Textes) genommen werden..$^{526}$ Die Inszenierung beim offenen Polemisieren erlaubt somit grundsätzlich eine Prüfung durch bzw. einen Abgleich mit dem Kontext. Fragen

${ }^{526}$ Inwiefern sich diese theoretische Antwortmöglichkeit beim offenen Polemisieren auch in der Praxis niederschlägt, ist in jedem konkreten Fall zu überprüfen. 
nach dem Urheber, dessen Hintergrund und den konkreten Umständen sind nicht nur möglich, sondern in der Regel auch beabsichtigt. Für eine Antwort oder einen Schriftwechsel bedeutet dies, dass bei der Polemik sowohl Bezug auf die Inszenierung im Text - hier besonders auf das polemische Subjekt und Thema - als auch auf die ,realexistente', kontextuelle Situation genommen werden kann. In erster Linie sind es die Figur und die Handlungen des ,realen' Autors der gegnerischen Schrift, welche die Angriffspunkte für die antwortende Polemik liefern. Es eröffnen sich andere Möglichkeiten für die Argumentationen ad hominem und ad personam bzw. zum „Persönlichwerden“",527 da die Replik über die Textgrundlage hinaus entfaltet werden kann. ${ }^{528}$ So kann der Angegriffene auf eine Beleidigung oder argumentum ad personam ebenfalls mit Persönlichwerden kontern, anstatt sich zu verteidigen oder die Aussage zu entkräften. Es kann viel eher zu einem sehr persönlichen Schlagabtausch kommen als beim verdeckten Polemisieren, weil in letzterem Fall die dahinter stehende ,Persönlichkeit ${ }^{`}$ verborgen und unangreifbar bleibt.

Bei dem Streit zwischen Hoffman und Amsdorf ist genau dies der Fall, denn in dem gesamten polemischen Schriftwechsel wird auf beiden Seiten offen polemisiert, so dass der jeweils Schreibende sowohl die Rolle des Verfassers als auch die des polemischen Subjekts übernimmt. Durch Amsdorfs gedruckte Warnschrift (Ein vormanung) einerseits und Hoffmans ebenfalls publizierte Antwort (Dat Nicolaus Amsdorff) andererseits entwickelte sich der bereits beim persönlichen Aufeinandertreffen der Kontrahenten in Magdeburg bestehende Konflikt zu einem öffentlichen Streit. Die Streitinszenierung mittels offen polemisierender Schriften eröffnet schon bei der ersten Replik die Möglichkeit, die gegnerische Schrift in Kombination mit dem Kontext als strukturelle und inhaltliche Unterlage für die eigene Polemik zu benutzen. Sowohl Hoffman als auch Amsdorf setzen dieses theoretische Potential auch in die Praxis um und bedienen sich der Integration intertextueller und kontextueller Bezüge als Streittechnik während des polemischen Schriftwechsels.

527 Dieckmann (2005), S. 63-76 (Hervorhebung im Original). Zum Unterschied zwischen argumentum ad personam nach Schopenhauer und Persönlichwerden nach Dieckmann siehe Anmerkung 254.

${ }_{528}$ Im Falle verdeckten Polemisierens fällt die Möglichkeit der Bezugnahme auf den ,realen'Autor weg und damit auch die Chance die Person jenseits der im Text mitgelieferten Informationen anzugreifen und gegen sie zu argumentieren. 
Den obigen Ausführungen zur Folge erscheint das offene Polemisieren zunächst einmal nachteilig für Amsdorf als Verfasser der Initiationsschrift. Er macht sich persönlich angreifbar, indem er sich in seiner Schrift gegen Hoffman als Autor preisgibt. Für Hoffman eröffnet sich dadurch die Möglichkeit, jenseits der res und der Inszenierung im Text anzuknüpfen und sich polemisch an der persona ${ }^{529}$ Amsdorfs abzuarbeiten. Jedoch bietet gerade die Selbstkonstruktion Amsdorfs im Initiationsschreiben die Chance, das bereits bestehende textexterne Image auf eine positive Weise und den Gegner in Opposition dazu darzustellen, so dass die (antagonistischen) Positionen, die durch die Erstschrift gesetzt wurden, zunächst umgestoßen werden müssen, bevor sie glaubhaft neu konstruiert werden können. Nicht zuletzt deswegen ist der Bezug auf die gegnerische Schrift - beispielsweise in Form der Widerlegung von aufgestellten Behauptungen oder der Anklage, der Gegner nutze unlautere Mittel - üblich. Die Überprüfung der gegnerischen Streitinszenierung anhand des Kontextes wird dabei vorgeblich als Strategie der Wahrheitsfindung eingesetzt. Letztendlich ist dieser Wahrheitsabgleich jedoch die subjektive Interpretation des Verfassers, die zur objektiven Wahrheit stilisiert wird..$^{530}$

In seiner ersten Schrift Dat Nicolaus Amsdorff nimmt Hoffman bereits Bezug auf die Initiationsschrift Amsdorfs (Ein vormanung) und stellt immer wieder Verbindungen zu textexternem Wissen über Amsdorfs Leben und Handlungen her, ${ }^{53 \mathrm{I}}$ um Amsdorfs Aussagen zu entwerten und seine eigene Position und Glaubwürdigkeit zu stärken, d. h. die ,Wahrheit' aus seinen Worten sprechen zu lassen. Dieses Vorgehen intensiviert Hoffman in Nasen geist, indem er das Potential des Wechselspiels zwischen intertextuellem und kontextuellem Bezug umfassender ausschöpft. Er reagiert dabei stellenweise auf einzelne Formulierungen Amsdorfs mit umfangreichen Repliken, in denen er die Gegenargumente mit Amsdorfs beruflicher Funktion und dessen vorausgegangenen Handlungen eng verknüpft. Nahezu jeder

529 Der Begriff persona beinhaltet das Resultat sämtlicher „, acts of identity“ (Fludernik \& Gehrke 2004) und demnach sowohl die textinterne Imagekonstruktion als auch das Spannungsfeld der Identitätskonstruktion Amsdorfs, das als textexterner oder kontextueller Hintergrund zu verstehen ist.

530 Siehe dazu die Diskussion über die objektive Wahrheit bei Aristoteles sowie bei der eristischen Dialektik in Schopenhauer (I923), S. 403-405.

${ }^{531}$ Beispielsweise erzählt Hoffman (ebenfalls wie Amsdorf) von den Geschehnissen des Zusammentreffens und nimmt dazu aus seiner Perspektive Stellung. Zudem erwähnt er seine Verhaftung in Magdeburg und klagt Amsdorf an, jene initiiert zu haben. 
Argumentationsstrang stellt eine Bezugnahme auf Amsdorfs Falscher Prophet dar, meistens gekoppelt mit Angriffen auf Amsdorfs persona, so dass die Schrift Nasen geist sich nicht nur auf die Entkräftung von Amsdorfs Argumentation, sondern auch auf die Zerstörung seines Images konzentriert. Hoffmans zweites Schreiben stellt insofern eine polemische Steigerung sowohl von Amsdorfs als auch von seiner eigenen Schrift dar.

\section{Der Pelzer gegen den Geschmierten}

Wie bereits in Ein vormanung - und auch schon in dem I 525 geführten Schriftwechsel mit dem Zwickauer Mediziner Wolfgang Cyclop - bringt Amsdorf in Falscher Prophet sein „Verständnis des Amtes und der Berufung " 532 als Hauptargument gegen Hoffmans Person an, ${ }^{533}$ der er sich in dem einer Tadelrede gleichkommenden zweiten Teil von Falscher Prophet widmet: Nur ein Berufener (Priester) dürfe das Gotteswort predigen, nicht einmal Jesus Christus hätte ohne Berufung gepredigt (BIv). So könne Hoffman nur

einer [sein] da Christus von sagt / Sie werden komen yn meinem namen / ich werde sie nicht senden / auch nicht fordern lassen / dennoch werden sie komen / vnd ynn meinem namen / das ist / sie werden sich rhůmen meines worts vnd geists [...]. (FP, B Ir $)$

Demzufolge müsse er ein „falscher Prophet“ (FP, BIv) und vom Teufel gesandt sein, da kein „apostel / prophet odder prediger ynn der gant-

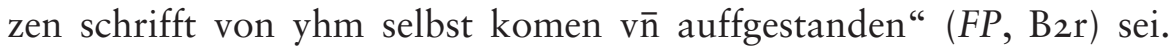
Hoffman setzt diese von Amsdorf bereits in Ein vormanung begonnene und in Falscher Prophet wiederholte Thematisierung der Berufung in seiner zweiten Replik Nasen geist explizit fort und kontert in mehrerer Hinsicht: Zum einen nennt Hoffman mit Apollos und Stephanus Beispiele für biblische Vertreter, ${ }^{534}$ die laut Hoffman „vngeeisschet

${ }_{532}$ Ilgner (2008), S. 269. Zu dem Streit mit Cyclop siehe auch Kapitel 3.2 Der Streit mit Nikolaus von Amsdorf II: Die Schriften und Anmerkung 405 in der vorliegenden Arbeit.

533 Bereits die salutatio Amsdorfs betont diese Argumentation: „Allen heiligen vnnd gleubigen an Christum Jhesum zum Kiel vnd gantzen Holstein / wůnsch ich Niclas Amsdorff ytzt zu Magdeburg ein beruffener knecht des Evangelij Jhesu Christi / Gnad vnd sterck des heiligen geistes." Amsdorf (I 528): Falscher Prophet, A2r (Hervorhebung K.L).

534 Apollos taucht insbesondere im I. Brief an die Korinther auf, in dem darauf Bezug genommen wird, dass er zeitlich nach Paulus in Korinth gepredigt und die Gemeinde 
geprediget yn der not" (BIr), um das Argument Amsdorfs, dass nur Berufene in der Bibel predigen, zu widerlegen. ${ }^{335}$ Zum anderen stellt Hoffman die Berufung, von der Amsdorf spricht, generell in Frage und zweifelt zudem die Allgemeingültigkeit und das System der kirchlichen Berufung an. Auf den Vorwurf, ein falscher Prophet zu sein, der lediglich vorgebe, im Namen Jesus Christi zu predigen, stattdessen aber mangels Berufung nur vom Teufel geschickt sein könne, reagiert Hoffman zunächst damit, denselben als einen Angriff ad personam darzustellen:

Nu weis ich wenn ich ein gesmirter were / vnd latinisch kůnd / vnnd nicht ein Kơrßner odder peltzer / so wůrd ich wol vō euch laruengeistern frid haben / aber der teuffelisch bluteiffer vnnd der auffgeblosen nasengeist treibt solches ynn etlichen geschmirten esels laruē. (BIv)

Hoffman formuliert hier zum einen die Erfahrung, als Laienprediger nicht ernst genommen zu werden und versucht diese negativen Erfahrungen für die eigenen argumentativen Zwecke einzusetzen. Als Handwerker und Lateinunkundiger erfahre er eine generelle Ablehnung, die in ihrer Oberflächlichkeit nicht seine Lehren und deren Gehalt, sondern lediglich die äußeren Umstände - d. h. die soziale Ordnung - betrachte. Die Abwertung der Lehren Hoffmans werde demnach aufgrund von Vorurteilen seiner Stellung und Person gegenüber getroffen und nicht auf Basis einer fairen inhaltlichen Prüfung. Zum einen äußert Hoffman auf diese Weise die anzunehmende gesammelte Frustration darüber, als Verkünder der christlichen Lehre nicht ernst genommen zu werden, zum anderen kreidet er Amsdorf auf einer Metaebene an, den Streit nicht um der Wahrheitsfindung willen zu führen, sondern zur Verteidigung

in Korinth sich infolgedessen in zwei Lager gespalten habe (I Kor I: I 2 und 3: 4-22). Hoffman könnte sich zudem auf die Apostelgeschichte beziehen, in der Apollos als Jude, der christlich zu predigen beginnt, eingeführt wird (Apg I 8: 24-28). Stephanus gilt als der erste christliche Märtyrer, da er für den christlichen Glauben gesteinigt wurde (Apg 6: 5-I 5 und 7). Stephanus war in sein Amt berufen worden, von daher ist anzunehmen, dass Hoffman sich in diesem Fall auf die christliche Predigt bezieht, die nicht erbeten war. Diese Vermutung liegt auch im Falle Apollos' nahe.

535 „Sihe doch du ellende larue / sein das vnrechte prediger / die Gottis wort ynn der not yhre mitbrůder vnd schwestern leren / Wo wiltu doch das beweisen mein lieber laruen geist / so dein wort solt krafft haben welches du so o̊de aus scheumest / so must der Apollo [sic!] auch falsch sein vnd der heilig Steffanus / die da haben vngeeisschet geprediget yn der not / Wie viel hundert die Gotis wort wol also gelert haben / vnd Christus selber spricht / Ein stadt auff einem berg kan nicht verborgen bleibē / also auch ein angetzůndt liecht sol leuchten vnd nicht yns důster gesetzt sein als du laruen geist furgibst." Hoffman ( I 528 ), Nasen geist, BIr-v (Bibelparaphrase: Mt 5: I4). 
des klerikalen Alleinrechts auf theologische Auslegung. Er unterstellt ihm zudem eine unlautere Vorgehensweise, nämlich ad personam und nicht ad rem zu argumentieren. Anstatt die Sache in den Mittelpunkt zu stellen, zeige Amsdorf nur seine überhebliche Einstellung gegenüber Laien, die, verursacht durch den „teuffelisch bluteiffer ${ }^{536}$ vnnd de[n] auffgeblosen nasengeist“ (BIV), nicht nur bei Amsdorf wiederzufinden sei, sondern bei „etlichen geschmirten esels larue““ (ebd.). Durch die Verwendung der in der protestantischen Polemik üblichen spöttischen Bezeichnung, Geschmierter ${ }^{{ }^{5} 37}$ für den geweihten Priester knüpft Hoffman an die antiklerikale Polemik Luthers $a^{538}$ und weitet diese

${ }^{536}$ Der ,Bluteifer' mag sowohl die Bedeutung des heutigen Wortes ,Eifersucht', als auch des ,Zorns' (auf Luthers Deutung von ,Eifer' basierend) beinhalten. Durch das vorangestellte ,Blut-‘ wird zudem eine körperliche Komponente hinzugefügt, die im Kontext der Ablehnung der Körperlichkeit zugunsten einer Vergeistigung während der Reformation und besonders bei Hoffman pejorativ zu verstehen ist. Siehe dazu: „Das Substantiv Eifer, zuerst in der 2. Hälfte des I 5. Jhs. für 'Eifersucht' (zu eifern als postverbale Ableitung?), findet durch Luthers Bibelübersetzung Eingang in die nhd. Literatursprache. Luther verwendet es mit der Bedeutung 'aus Sorge und liebevoller Anteilnahme erwachsende zornige Erregung' zur Wiedergabe von griech.-lat. zèlus und begründet diese Entscheidung ausdrücklich. Hieraus geht der heutige Gebrauch hervor, während der ursprüngliche Sinn 'Eifersucht' im I8. Jh. zurücktritt." Etymologisches Wörterbuch (nach Pfeifer) (= Digitales Wörterbuch der deutschen Sprache), URL: http://www.dwds.de/?qu=Eifer\&submit_button=Suche\&view=I (I8.I0.20I5).

537 Das Schimpfwort ,Geschmierter' lässt noch weitere Bedeutungen anklingen: Das Grimmsche Wörterbuch verzeichnet z. B. für „GESCHMIERT“ folgende: „I) gesalbt, spöttisch von katholischen geistlichen [...] 2) geschminkt, falsch [...] ,3) listig, schlau [...] 4) bestochen“. DWB 5, Sp. 3945. Ergänzend lassen sich noch weitere Bedeutungen des Verbs „SCHMIEREN“ nennen: „schmieren, in weiterer sinnlicher bedeutung, mit dem nebenbegriff des sudelns oder besudelns“. DWB I 5 , Sp. Iо8 3 . „schlechthin einen schmieren, in selbstsüchtiger absicht liebkosen, schmeicheln“. Ebd., Sp. I085. Aufgrund dieser anderen Bedeutungszweige, beinhaltet der ,Geschmierte' eine wesentlich pejorativere Konnotation als der ,Gesalbte' und eignet sich als Schimpfwort für den geweihten Priester.

${ }_{53}{ }^{8}$ Siehe z. B.: „Die Clericken hayst er seyne gaystlichen / darunder er der o̊berste priester vnd fürste seyn will / welche er damit allain gaystlich macht / das er sie beschirt / mit o̊le schmirt an fingern / vnd das sie lange klayder tragen / hayst vnnd gibt für / das er in ain vnaußleschlich malzaychen in ire seele drucke / wels doch nichts anders ist / den das maltzaychen der Bestien in Apocalip. Also das der / wer des Bapsts pfaffe ist / hayst nicht Christen (denn der Christliche name stinckt vor dem aller höchsten vatter) aber er hayst der beschorne / geschmirte / gezaychnete vnd wolgeklaydte Clerick der ist bey im hoch vnd wolgehalten. Vnd diese eynsatzung hayst man den hayligen orden oder die haylige weyhung / ains von den siben sacramenten / vil hayliger vnnd besser / denn die tauff selbst. “ Luther, Martin (I 522 ): Vom Mißbrauch der Messen. Wittenberg: [o. Dr.], Riv. Die Doppelung „beschorne vnd geschmirte“ Priester und andere Formen von "geschmirt" kommen noch mehrmals in Luthers Text vor. 
von seiner Position als Laie aus. Was sich zuvor bei Luther noch auf die Papstanhänger und auf den Sakramentsstatus der Weihe bezog, gilt bei Hoffman, der sich außerhalb dieser Gruppe befindet, für den ordinierten Priester im Allgemeinen.

Nachdem Hoffman Amsdorfs Schmähung des Kürschners aufgrund äußerlicher Gegebenheiten als eine regelwidrige Streittechnik erklärt hat, geht er direkt daran anknüpfend auf den Inhalt des Vorwurfs ein, um ihn mit einer zu Amsdorfs Deutung konträr stehenden Interpretation desselben Textes von Mt 24: $5^{539}$ (ähnlich auch bei Mk I3: 6 und Lk 2 I: 8) zu entkräften:

So bringt diser laruengeist ein spruch herein mich zu dempffen / vnd ist doch der selbige spruch gesagt auff die widder Christen / welcher Amsdorff auch so lang einer gewesen ist / vnd ist ein lerer der nu meint das er aus des widderchrists hauffen gesprungen sey / vnnd versteht doch nicht diesen spruch Mat 24. da Christ[us] spricht / Es werden viel kommen vnter meinem namen v⿳亠 sagen / ich bin Christus / Da horrstu narrenfex das Christus von den sagt / die sich fur Christum dar geben / die / welche den menschen helffen kůnden mit yhren Messen / beten / fasten / keuscheit vnd andern der gleichen wercken / der du esels larff io auch ein solcher falscher verfurrer gewest bist / Gott weis was du noch ym hertzen bist. (BIv, Hervorhebung K. L.)

In seiner Deutung der Aussage Jesus Christi knüpft Hoffman ebenfalls an bereits bestehende protestantische Polemik an: Er stützt sich auf die lutherische (antipäpstliche) Antichrist-Polemik ${ }^{540}$ und macht sich die bereits etablierten Feindbilder des Papstes als Antichrist ${ }^{541}$ und der altgläubigen Kirchenvertreter als die „widder Christen“ zunutze, wendet dann aber erneut jene polemische Waffe, die bis dahin die Reformatoren gegen die Altgläubigen ausspielten, selbst gegen den Reformator Amsdorf. Als Laie ist es Hoffman ein Leichtes, die (kirchlich) Berufenen

539 „Denn es werden viele kommen unter meinem Namen, und sagen: ,Ich bin Christus“ und werden viele verführen." www.bibel-online.net, nach Luther I9 2.

$54^{\circ}$ Siehe dazu Sebaß, Gottfried (I978): „Antichrist IV“. In: Krause, Gerhard \& Gerhard Müller (Hg.): Theologische Realenzyklopädie. Bd. 3. Anselm von Laon-Aristoteles, Aristotelismus. Berlin \& New York: De Gruyter, S. 28-43.

${ }_{541}$ Vgl. dazu auch: „Die Gestalt des Antichristen wurde [...] immer dann besonders populär, wenn die Menschen der Überzeugung waren, kurz vor dem Weltende zu stehen. [...] Auch Luther war von Endzeiterwartungen geprägt. Daher verwundert es nicht, dass sich bei ihm der erste Nachweis für ,Antichrist' bereits I 509 findet, also noch lange vor dem Ausbruch des Konflikts in Rom. [...] Mit dem Werk ,Avdersus execrabilem Antichristi bullam' setzte er Papst und Antichrist entgültig gleich. Auf Deutsch vertrat er diese Ansicht erstmals in seiner Schrift ,An den Christlichen Adel deutscher Nation'. Jörgensen (2014), S. 66. 
als eine Gruppe abzuurteilen: Da er kein Mitglied dieser Gruppe ist, ist er nicht nur nicht darauf angewiesen, den Ruf des geistlichen Standes partiell zu schützen, sondern kann sämtlichen berufenen Klerus als Einheit von sich und seiner Position als laikalem Reformator abgrenzen. ${ }^{542}$ Demzufolge kehrt Hoffman Amsdorfs Verdikt, dass die mangelnde Berufung Hoffman unglaubwürdig mache, ins Gegenteil um, wertet den Stand der Berufenen mittels diskursiver Anspielung auf antiklerikales Gedankengut ab und macht sprichwörtlich die Not zu einer Tugend, indem er sich selbst außerhalb der Gruppe der berufenen Prediger positioniert. Durch die Instrumentalisierung der protestantischen Polemik, die sich ursprünglich nur gegen einen Teil des Klerus - die lasterhaften ,Papisten' - richtete, als Polemik auf die Gesamtheit aller Berufener (und damit auch als anti-protestantische Polemik) verstärkt Hoffman die antagonistischen Positionen von Theologe und Laie. Er bemüht sich demnach nicht, Amsdorfs Rollendenken entgegenzuwirken, sondern intensiviert umso mehr die Unaufhebbarkeit der Opposition der Stände, indem er die Grenzziehung zwischen berufenem und laikalem Prediger rezitiert. In seiner Position als ein durch äußere Umstände (Status, Ausbildung etc.) Ausgegrenzter vermag Hoffman die Grenzziehung selbst nicht glaubwürdig aufzuheben, sondern muss von Anbeginn seiner Tätigkeit die ihm zugängliche Position stärken, indem er sie neu beurteilt: Die fehlende Berufung und das „armgeistige“ Leben werden zum Ideal,543

${ }^{542}$ Diese explizite Form des Antiklerikalismus ist nicht allein typisch für Hoffman, sondern generell für die Laienbewegungen. Vgl. dazu: „Im Täufertum, das sich je länger je mehr zu einer ausgesprochenen Bewegung von Laien entwickelte, nahm der Antiklerikalismus eine besonders handfeste, wenig subtile Form an: Wort und Widerwort, Schlag und Gegenschlag, Typ und Gegentyp. Daraus erklärt sich die auffällige Tendenz im Täufertum, den Glauben zu ethisieren und auf den frommen Laien hin zu personalisieren. Nicht Priester oder Mönch, sondern der fromme, tätige Laie war der eigentliche homo spiritualis. " Goertz (I993), S. 86f.

543 Für Hoffman kommt die Gnade Gottes gerade den Armen zu. „Vnd Gott in solchen seinen hohen gaben des heyligen geistes oder seines můthes / kein anseher der person ist / sunder vß allen geschlehcten vnnd zungē heiden / vo̊lckern / vnnd scharen / seine vsserwo̊lten rüfft / herschet / vnnd durch Christum zeücht vnd erwo̊let / fürnemlich die armen / welche da seind eins zerschlagnen zerknutschten gemüts / geistes vnnd hertzens die er an numpt / vnnd jm ein wolgefellig vnd süsses opffer seind / das er nit verschmahē thůt wie der heylige Dauid vermeldet / Psal.I. vnd Christus Matth.v. die armen des geistes selig spricht / aber was from / heilig / vnd in reichem hoffertigem geist hereiner drit / mag gott nicht gefallen [...]. “ Hoffman (I 530), Außlegūg der heimlichē Offenbarung, A4r (vollständige Angabe bei Anmerkung 39). Die Armut ist jedoch nicht bloß Voraussetzung für die Empfängnis des göttlichen Geistes, sondern der empfangene Geist zieht auch die Weltabkehr und somit die Armut wiederum mit sich. Siehe dazu auch Kawerau (I954), S. I02-IO5. 
um die Position als Laienreformator und Auserwählter zu legitimieren und mittels Anknüpfens an zeitgenössische Frömmigkeitsideale und Kleruskritik zu unterstützen. ${ }^{544}$ Konsequenterweise betont Hoffman Amsdorfs Zugehörigkeit zum Klerus und somit zu des „widderchrists hauffen“, obgleich letzterer selbst die Meinung habe, diesem entsprungen zu sein. So begonnen, führt Hoffman in direktem Anschluss weiter aus:

Auch schreibt der narrenfex / Es werden falsche Propheten zu euch ynn schaffskleidern komen / fur den wachtet euch / Mein lůgen geist / geht der

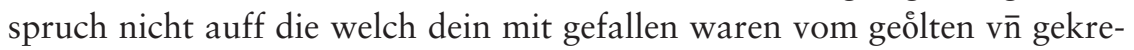
samten hauffen / Verstehestu aber die schrifft nicht / schempstu dich nicht / das dich ein peltzer erst die schrifft lernen sol / hörestu nicht / das Christus auff die selben wort spricht / An yhren frůchten solt yhr sie erkennen / Jch mein du mit deinem geo̊lten hauffen habe hůpsche frucht bracht / als du denn auch noch solche faule frůcht ertzeigen thust / Du ellender laruen geist als ich sihe so verstehstu dich eben auff Gottis wort / als sich ein Kue versteht auff ein muscaten / es wer gnug / das ein o̊der vnsinniger narr diese schrifft geschrieben het. (BIV-B2r)

Die polemische Bezeichnung der Berufenen als „geo̊lte[r] v⿳亠幺 gekresamte[r] hauffen " und die Rede von den Früchten, an denen man gute und falsche Prediger erkennen möge, machen zusätzlich deutlich, dass es nicht Hoffmans Ziel ist, die Opposition zwischen Priester und Laie aufzuheben, ${ }^{545}$ sondern sie vielmehr aufrecht zu erhalten, dabei aber neu zu interpretieren. Die Theologen, Amsdorf inbegriffen, hätten schließlich „faule frůcht“ gebracht, wohingegen Hoffman sich an dieser

${ }_{544}$ Zur Verbindung von Volksfrömmigkeit und Antiklerikalismus konstatiert Rainer Postel: „Andererseits war die Volksfrömmigkeit offenbar gerade deshalb für außerkirchliche Vorstellungen empfänglich, weil in den Augen der Gläubigen Kirche und Klerus den eigenen Maßstäben weithin nicht mehr genügten und weil insbesondere der Weltklerus zu durchgreifenden Reformen unfähig erschien. Die Frömmigkeit bewies sich geradezu in der zunehmenden Kritik an Kirche und Geistlichen, weil deren vermeintliche oder wirkliche Verfehlungen und Unzulänglichkeiten vor allem die Gewissen der Gläubigen bekümmerten und deren Unmut hervorriefen.“ Postel, Rainer (2002): „Ouvertüre zur Reformation? Die spätmittelalterliche Kirche zwischen Beharrung, Reform und Laienfrömmigkeit“. In: Deventer, Jörg, Susanne Rau \& Anne Conrad (Hg.): Zeitenwenden. Herrschaft, Selbstbehauptung, und Integration zwischen Reformation und Liberalismus. Festgabe für Arno Herzig zum 65. Geburtstag. Münster: Lit Verlag, S. 205-2I7, hier S. 2I3.

545 Vgl. dazu: „Die soziale Kategorie Laie (idiota, vir indoctus) stand zwei anderen sozialen Kategorien gegenüber: der des Gelehrten (vir doctus, litterarus) und der des Priesters. Diese zweite Opposition wurde sozusagen von heute auf morgen für irrelevant erklärt und blieb es im Protestantismus auch [...]. "Schwitalla (200I), S. 460. 
Stelle durch sein höheres Verständnis der heiligen Schrift auszeichne, denn der „peltzer" müsse Amsdorf erst noch die Schrift lehren. ${ }^{546}$

In diesem Vorwurf wird ganz besonders auch textexternes und intertextuelles Wissen aktiviert, indem der Text an Reformdiskurse vor I 525 anknüpft, die Hoffmans Interpretation teilen, dass Laien die verständigeren Leser der Bibel seien, während die Altgläubigen vielfach Missbrauch mit der Schrift betrieben hätten. ${ }^{547}$ Gleichzeitig macht Hoffman Amsdorf in seiner Priesterfunktion lächerlich und verspottet ihn, weil er sich von einem Pelzer in seiner eigentlichen Profession belehren lassen müsse. Mit der darauf folgenden Redewendung, dass Amsdorf sich auf Gottes Wort so gut verstünde wie eine Kuh auf Muskat, ${ }^{54^{8}}$ gibt Hoffman seinen Gegner schließlich mit bildlicher, volksnaher Sprache der Lächerlichkeit preis. Anlass des salopp formulierten Spottes ist deutlich der Kampf um den „Anspruch auf Deutungshoheit“, ${ }^{449}$ den es zu gewinnen gilt, damit die Umdeutung des bereits durch Amsdorf etablierten Antagonismus (Laie vs. berufener Priester) gelingt. Um diesen Kampf zu gewinnen, schließt Hoffman den Abschnitt seiner Polemik gegen Amsdorf (in Position des Berufenen) mit Verhöhnung von dessen Argumentation ab. Mittels rhetorischer Fragen stempelt Hoffman diese als heuchlerisch ab:

So du aber so seer stehst auff die beruffung der menschen / so ist doch des gantzen Babstes hauffe beruffen / warumb stehstu denn widder sie / darumb weistu nicht lieber lůgen geist was du schreipst / so du nu sagst von der beruffung Christi durch Gottis stim vom vater gesandt / kanstu nicht auch so lang harren vnd dein lallen stehn lassen / bis du ein solche offenbarung von hymel kriegest / was wiltu mir ein sonders kochen / das du selber nie

${ }^{546}$ Das Verständnis der Schrift speist sich für Hoffman nicht mehr aus dem äußerlichen Amt des Klerikers, sondern aus dem verinnerlichten göttlichen Geist, der die Erkenntnis der Schrift möglich macht. „Wenn Gnade und Armut die Bedingungen für das richtige Auslegen der Schrift sind, so schließt das ein, daß die buchstabischen Bauchknechte die Schrift nicht richtig auslegen können. “ Kawerau (I954), S. I07.

547 Vgl. dazu: „Anstelle der Fremdsprachen trat die Bibelkenntnis. In den Streitdialogen wurden die Laien als in der Bibel beschlagen, die Geistlichen dagegen als unwissend dargestellt." Schwitalla (200I), S. 462.

${ }^{548}$ Die hier angewandte Redewendung hat ihren Ursprung in den Varianten der Sprichwörter „Was soll einer Kuh Muscatnus; es thuts jhr noch wol Haberstroh“ (auch z. B. Was soll der Kuh der Muskaten?) und „Die Kuh nimmt Haberstroh für Muskaten“. Wander, Karl Friedrich Wilhelm (I 870): Deutsches SprichwörterLexikon. Bd. 2. Gott-Lehren. Leipzig: Brockhaus, S. 44I \& 566.

549 Bachorski, Hans-Jürgen, Jürgen Behütuns \& Petra Boden (2000): „Editorial“. In: Dies. (Hg.): Literaturstreit (= Mitteilungen des Deutschen Germanistenverbands 47: 4). Bielefeld: Aisthesis Verlag, S. 370-373, hier S. 372. 
versucht / gehort / gesehen / noch geschmecket hast. (B2r, Hervorhebungen K. L.)

Hoffman unterscheidet hier klar zwischen der Berufung durch die Menschen und der Berufung durch „Gottis stim vom vater gesandt“ und impliziert damit, dass Amsdorf sich lediglich auf die menschliche und damit auf eine nichtige Berufung konzentriert. Für Hoffman ist diese Form der Berufung durch Menschenhand nur ein nichtiges Verfahren, das mit religiöser Überzeugung und Verinnerlichung der Gottesfurcht und des Glaubens in keinem Zusammenhang steht. Wie auch bei anderen Laienreformatoren begründet Hoffman seine Legitimation nicht mit äußerlichen, menschlichen Ritualen wie der Salbung, sondern durch eine rein internalisierte Form des Glaubens, der ohne äußerliche, liturgische Rituale auskommt. Stattdessen erhebt er es in seiner Daniel-Auslegung zum christlichen Ideal, den weltlichen Gütern, Ruhm und Ehre zu entsagen und sämtliches persönliches Streben (auch das Streben nach dem Seelenheil) aufzugeben, um sich vollends in Gottes Hände zu geben und diesem aus reiner Liebe zu dienen. ${ }^{50}$ Der ideale Christenmensch wird bei Hoffman in Anlehnung an mystisches Gedankengut ${ }^{551}$ durch das Bild „des ,gelassenen Menschen“[,] der die Furcht vor Strafe und die Hoffnung auf Lohn hinter sich gelassen hat", 552 verkörpert.553 Hoffman spricht von dem „vergo̊tten

550 Vgl. Deppermann (I979), S. 73.

${ }^{55}$ Calvin Augustine Pater und Richard G. Bailey zeigen z. B. den Bezug zur Mystik an Hoffmans Kommentar Dat Boeck Cantica Canticorum von I 529. Pater, Calvin Augustine (I977): „Melchior Hoffman's Explication of the Songs (!) of Songs“. Archiv für Reformationsgeschichte 68, S. I73-I9I und Bailey, Richard G. (I99I): „Some Remarks on St. Bernard of Clairvaux as a Literary Source for Melchior Hoffman's Commentary Dat Boeck Cantica Canticorum (I 529)“. The Sixteenth Century Journal 22: I, S. 9I-96. Bailey fasst seine Ergebnisse folgendermaßen zusammen: „The transmission of the bernardine spiritual tradition through works of medieval piety to Melchior Hoffman is a reasonable argument. The tentative evidence put forward here suggests that Hoffman studied the glosses in the Lübeck Bible and they, coupled with German mystical and Karlstadtian influences, became formative in shaping the spiritualizing hermeneutic used in his commentary Cantica Canticorum. "Ebd., S. 96. In Anmerkung 27 fügt er noch hinzu: „This conclusion supplements W. Packull's findings vis-à-vis Hoffman's links to Spiritual Franciscan eschatology. Hoffman borrowed liberally from the ideas contained in the currents of medieval popular piety. His semi-mystical assumptions, spiritualizing hermeneutic, and eschatology can all be traced back to medieval prototypes." Ebd. Siehe dazu auch Deppermann (I979), S. 95 f.

552 Deppermann (I979), S. 74.

553 Zu Meister Eckharts Neuschöpfung von, gelassen“ als Adjektiv (neben, gelassen“ als Partizip Perfekt von ,lassen“) siehe Eintrag „GELASSEN“, DWB 5, Sp. 2864-2872, insbesondere Sp. 2865. 
menschen / der in gātzer gelossenheit steht / daß er nicht acht wie es gott mit yhm macht / zum leben oder sterben / zum reich des lebēs oder des dodes / ist yhm als eyns". ${ }^{554}$ Das Menschenideal Hoffmans ist vollkommen unabhängig von Stand, Bildung oder kirchlicher Berufung, sondern geprägt von innerer Bereitschaft zum Leid und zur Aufgabe des menschlichen Strebens - der Mensch solle sein Schicksal völlig in Gottes Hände legen.555 Hoffman sieht in Amsdorf jedoch jemanden, der sich insbesondere auf die weltlichen Dinge und Regeln beruft, anstatt dem mystischen Ideal der Selbstaufgabe zugunsten der Gottesliebe zu folgen. ${ }^{556}$ Demzufolge spricht er Amsdorf das Recht ab, von einer solchen Gotteserfahrung, die als synästhetisch-körperliche Erfahrung (hören, sehen, schmecken) geschildert wird, 557 überhaupt sprechen zu können. Aus Hoffmans Perspektive konzentriert sich Amsdorf insofern auf die falschen - eben die weltlichen - Werte und äußerlichen Dinge, so dass er in Hoffmans Augen nur als eine dem neuen Glauben feindlich gesinnte Person gelten kann. Hoffman verteidigt sich nicht nur, sondern

554 Hoffman, Melchior (I 526): Das xij Capitel [...] Danielis, $\mathrm{C}_{3} \mathrm{r}$.

555 Hoffman steht hier noch in der Tradition der mittelalterlichen Mystik, geprägt durch u. a. Meister Eckhart, Johannes Tauler und der von Luther I 5 I 6 im Druck herausgebrachten Theologia deutsch (Ende des I4. Jahrhunderts entstanden). Vgl. dazu: „Und in dieser Wiederherstellung und Besserung [des menschlichen Falls (durch Adam)] kann und mag und soll ich nichts dazu thun als ein bloßes lauteres Leiden, also daß Gott allein alle Dinge in mir thue und wirke und ich leide Ihn und alle Seine Werke und Seinen göttlichen Willen." Theologia deutsch ( I 855 ). Zweite verbesserte und mit einer neudeutschen Übersetzung vermehrte Auflage. Hg. von Franz Pfeiffer. Stuttgart: Verlag von Samuel Gottlieb Liesching, S. I I. Ob Hoffman diese Schrift rezipiert hat, ist nicht belegt, jedoch weisen die Spuren ähnlichen mystischen Gedankenguts auf die generelle Rezeption mystischer Texte und Ideen hin. Vgl. dazu: „The Theologia Germanica, for example, was the most read theological treatise of the Reformation and it was probably contained in the inventory of Hoffman's own printing office. There is also evidence that Eckhart, Tauler and Suso helped to prepare the introduction to the East and Westphalian Cologne Bibles which Hoffman may have used. These Bibles were the forerunners to the Lübeck Bible which Hoffman did use. "Bailey (I99I), S. 95.

556 Deppermann fasst in seiner Forschungsdiskussion zusammen: „[Es] zeichnet sich $\mathrm{ab}, \mathrm{da}$ die theologische Differenz zwischen Reformation und Täufertum aus dem unterschiedlichen Grad der Bindung an mittelalterliche Traditionen resultiert. Während bei den Reformatoren der Einfluß der Mystik im Laufe ihrer Entwicklung sank, blieb bei vielen Täufern das mystisch-apokalyptische, aber auch das asketische Erbe des Mittelalters in hohem Maße erhalten, womit freilich nicht behauptet werden soll, daß dadurch das ,Täufertum' theologisch wieder zu einer festen Gestalt und klar umrissenen Größe geworden ist.“ Deppermann (I979), S. I4f.

557 Auch in der Theologia deutsch ist die Rede von der Verinnerlichung Gottes als dem höchsten Ziel, das unter anderem auch „geschmeckt und empfunden wird“. Theologia deutsch (I855), S. 33. 
greift Amsdorf im Gegenzug scharf an, indem er ihn als einen Gegner des Evangeliums und des rechten Glaubens stilisiert.

Durch das offene Polemisieren (im gesamten Schriftwechsel) stehen Hoffman dafür nicht nur Informationen aus den Texten zur Verfügung, sondern er kann auch textexternes Wissen über Amsdorfs Leben einflechten. Um die Wirkung zu maximieren werden speziell solche Informationen mit eingebaut, die der Imagezerstörung des Magdeburger Pfarrers dienen: Im Kreuzfeuer steht Amsdorf demzufolge besonders aufgrund seiner Vergangenheit als Anhänger der Papstkirche bzw. als ,Papist'. Paradoxerweise setzt Hoffman Information sowohl über Amsdorfs altgläubige Vergangenheit („du mit deinem geôlten hauffen habe hůpsche frucht bracht“, B2r) als auch über dessen Gesinnungswandel hin zum Protestanten ein („warumb stehstu denn widder sie“, B2r), um Amsdorf in ein schlechtes Licht zu rücken und dessen Berufungs-Argument gegen den Laienprediger Hoffman in seiner Glaubwürdigkeit zu entkräften. Hoffman schwankt demnach dazwischen, dass Amsdorf immer noch ein Papstanhänger sei und dass er „wol newe strick legen [solle] / herter denn der Babst vorhin gethan hat" $(\mathrm{C} 2 \mathrm{v})$. Hier ist deutlich die strategische Verwendung jeweils einzelner, isoliert betrachteter Informationen aus dem Leben Amsdorfs zu erkennen. Die Informationen werden aus der Integration von Texthinweisen und textexternen Quellen generiert und die personengerichtete Polemik darauf aufgebaut. Dabei hebt Hoffman die von Amsdorf aufgegriffenen Differenzen zwischen „peltzer“ und "gesmirter“ nicht auf, sondern verstärkt vielmehr die antagonistische Rolleninszenierung durch die Wiederholung der polarisierenden Selbstund Fremdzuschreibungen. Gegen Ende der Schrift fordert er z. B. seine Gegner auf: „Nu yhr blutteuffelischen geister / thut all zu hauff / last sehen was yhr kůndt / als viel ewer sein / die lust haben sich an dem peltzer zu versuchen " $\left(\mathrm{C}_{3} \mathrm{v}\right)$ und betont seinen Status als Handwerker, indem er auf sich selbst in der 3. Person mit der Berufsbezeichnung referiert. Ein paar Zeilen später betont er seinen Status als Laie ein weiteres Mal:

Das sey nu euch scorpion geistern gesagt / last sehen / braucht ewer bestes / was yhr kůnd widder diesen armen leyen / peltzer odder korßner auffbringen / so yhr doch euch důnckt die gelerten / vnnd der arm peltzer ein vngelerter / noch ewrem nasen geist / auch ein vngeôlter kreßemter knecht. ( $3 \mathrm{v}$ )

Hoffman greift erneut auf die Differenzen zwischen Amsdorf und ihm zurück und stilisiert sich selbst als den „armen leyen“, der zu Unrecht 
angegriffen wird, da Gott doch auf seiner Seite steht. ${ }^{55^{8}}$ Das Anliegen Hoffmans mit der wiederholten Zitation der Statusunterschiede scheint die konnotative Umdeutung seines Status' zu sein. Die Entscheidung, pejorative Synonyme (,Geschmierter ${ }^{6}$ etc.) anstelle der exakten Wiedergabe des von Amsdorf ursprünglich verwendeten ,Berufenen“ einzusetzen, bestärkt diesen „semantischen Kampf“559 um die zugrunde liegenden Deutungsmuster und somit die Wirkungsabsicht einer performativen Rolleninszenierung. Diese Form der Wortwahl gehört in den Bereich der für Polemik genutzten Strategien, die nicht argumentativ sind.

\section{Nicht-argumentative Strategien bei der antagonistischen}

\section{Rollenkonstituierung}

Unterstützende und komplettierende Funktionen für die Inszenierung des Antagonismus bestimmter Rollen (z. B. als Laie oder berufener Prediger) bzw. für den Aufbau bestimmter Eigen- und Fremdimages im Allgemeinen erfüllen die nicht-argumentativen Mittel der Polemik wie z. B. Schlag- und Schimpfwörter, Schimpfnamen, bildhafte Sprache (mittels Sprichwörtern, Redewendungen, Metaphern oder Vergleichen), Ironie und Witz. Durch sie werden die argumentative Seite der Polemik lebendiger und die streitinszenierenden Texte anschaulicher, eindringlicher, plastischer und insofern performativer. Indem sie andere (Be-)Deutungsbereiche integrieren, gedanklich Bilder und Szenarien hervorrufen und auf bekannte Handlungsabläufe in belustigender Art verweisen, geben sie der Polemik ihre besondere individuelle Form und Wirkmächtigkeit.

Insbesondere in Bezug auf diese Techniken der Streitführung, lassen sich die Schriften der Kontrahenten Amsdorf und Hoffman als auffallend unterschiedlich charakterisieren. Während Amsdorf überwiegend auf die argumentativen Mittel der Widerlegung setzt und sogar die Tadelreden auf Hoffman grundlegend argumentative Züge besitzen,

\footnotetext{
${ }^{55^{8}}$ Hoffman schreibt: ,ich wil mein trost nemen vnd den hort meines heils / vnnd wil sehen wie mich mein Gott vnd Heylandt fur euch blut teuffeln erhelt“ (C $3 v)$.

559 „Unter ,semantischem Kampf “ wird [...] der Versuch verstanden, in einer Wissensdomäne bestimmte sprachliche Formen als Ausdruck spezifischer, interessensgeleiteter und handlungsleitender Denkmuster durchzusetzen." Felder, Ekkehard (200): „Semantische Kämpfe in Wissensdomänen. Eine Einführung in Benennungs-, Bedeutungs- und Sachverhaltsfixierungs-Konkurrenzen“. In: Ders. (Hg.): Semantische Kämpfe. Macht und Sprache in den Wissenschaften. Berlin \& New York: De Gruyter, S. I3-46, hier S. I4.
} 
zielt Hoffman vielmehr darauf ab, seinen Gegner zu beleidigen, zu schmähen und zu verspotten. Zwar nutzen beide Kontrahenten die Mittel der Ironie zur Verhöhnung des jeweiligen polemischen Objekts, aber hinsichtlich persönlicher Invektiven unterscheiden sich die für die Polemik verwendeten Strategien. Amsdorfs gemäßigter Ton, der mitunter eine emotionale Distanziertheit inszeniert, steht in scharfem Kontrast zu Hoffmans aggressiven Schimpftiraden.

Bereits durch die Wahl der Bezeichnungen bzw. der Namensgebung für den jeweiligen Gegner inszeniert sich Hoffman in seinen Schriften als emotionaler Verfechter der in seinen Augen rechten Sache - ganz im Gegensatz zu dem sich meist sachlich äußernden Amsdorf. Während Letzterer sowohl in Ein vormanung als auch in Falscher Prophet Melchior Hoffman fast ausschließlich in der 3. Person und beim vollen Namen oder beim Vornamen nennt, ${ }^{560}$ wartet sein Kontrahent mit Salven von Schimpfnamen für ihn auf. ${ }^{61}$ Die im Titel angekündigte Gleichsetzung Nikolaus von Amsdorfs mit einem „lugenhafftige[n] falsche[n] nasen geist“ wird dann im restlichen Text zur programmatischen Konzeption der Referenz auf Amsdorf: Die Bezeichnungen „nasen geist“, „lůgen geist“ und „laruen geist" werden durchgängig im Laufe der Schrift wiederholt, dabei z. T. miteinander und mit unterschiedlichen Attributen kombiniert. ${ }^{562}$ Die häufigen Komposita

${ }^{560}$ In der längeren Schrift Falscher Prophet ist dies weitaus öfter der Fall, in Ein vormanung referiert Amsdorf kaum explizit auf Hoffman. Der volle Name wird in beiden Schriften insgesamt ca. 20-mal, der Vorname allein etwa I3-mal genannt. Exemplarischen Charakter haben auch die Phrasen „ewer Melchior Hoffman“ und „ewer Melchior“ in Falscher Prophet, die Amsdorf nutzt, um bei der Referenz auf Hoffman gleichzeitig die polemische Instanz anzusprechen. Wenige Ausnahmen dieser namentlichen Referenz stellen „du schwartzer teuffel“ (EV, $\left.\mathrm{A}_{3} \mathrm{v} \& \mathrm{FP}, \mathrm{A}_{4} \mathrm{v}\right)$, „du lediger teuffel“ (FP, B2r), „,teuffel“ (FP, A4r \& BIv) und „ein vnnůtzer schwetzer" $\left(E V, \mathrm{~B}_{3} \mathrm{r}\right)$ dar.

${ }^{561}$ Hoffmans Kreativität und Unermüdlichkeit beim Beschimpfen ist keine Ausnahme im Vergleich zu anderen Flugschriftenautoren: „Ist ein Ausdruck genügend ausgepresst, so greift man in den reichen Vorrat neuer Möglichkeiten, junger Ersatz tritt in die gelichteten Reihen, bis auch er wieder frischem Sprachgut weichen muss. Es herrscht ein stetiger Wechsel das ganze Jahrhundert hindurch. Solange die Ideen lebendig bleiben, ist man um Wendungen, sie deutlich auszudrücken, nie verlegen. Ein ungeheurer Drang macht sich bei der allgemeinen Gärung und Aufregung der Zeit geltend Schimpfnamen zu häufen, um dadurch die Wirkung zu erhöhen. Manche Schriftsteller leisten darin Unglaubliches.“ Lepp (I908), S. 5 (Hervorhebung im Original).

${ }_{562}$ Man begegnet im Verlauf der Schrift u. a. folgenden Kombinationen: „ellender laruen geist“ (A2r, A2v, B2r, C2r \& C2v), „ellender nasen geist“ (A4r), „li̊gengeistiger larue“ (A2v), ,lůgenhafftige laruen geist“ (A2v), „li̊genhafftiger laruen vnd nasen geist“ (A2v), „der falsche li̊genhafftige laruen vnd nasen geist“ $\left(\mathrm{A}_{3} \mathrm{r}\right)$, , lieber li̊gen 
mit einem nachgestellten ,geist ${ }^{`}$ werden durch andere Invektiven komplettiert: Hoffman lässt seinen Widersachern - sei es in der 2. oder der 3. Person - eine Vielzahl an Schimpfnamen aus verschiedenen Bereichen zukommen:

- Narrheit/Narrendasein: „narrenfex“ (A3r, A4v, BIr, Bıv, B2r \& C2r), „narrenmaul“ (BIr), ,grober esel“ (B2r), „narren larff“ (B2v) „esels larff“ (B2v)

- Verstellung/Lüge: „ellendelarue“(BIr),sämtliche,geist'-Komposita

- Schwärmertum: „stoltzer schwermer“ (B2v), „nerrisches schwermerhirn“ (B2v), „schwermer vnd auffrůrischer mordischer bo̊swicht“ (C IV), ,auffrurischen bo̊swicht (C2r), „dein auffrůrisch schwermerisch schreiben" (C2r)

- Ketzerei/Gotteslästerung: „Du Gottis ehr dieb / vnd du ellender Gottis verrethrischer lesterer“ ( $\left.\mathrm{A}_{3} \mathrm{r}\right)$, „lesterer vnd sehender Gơtlicher warheit" ( $\left.\mathrm{C}_{3} \mathrm{r}\right)$

- Sonstige: „grober vnuerschempter růltz / filtz vnd lůgengeistiger larue“ (A2v), „Růltz / filtz / nasen vnd laruen geist“ (A2v), „ellender maden sack“ $\left(\mathrm{C}_{3} \mathrm{r}\right)$, „mein lieber Organist“ $\left(\mathrm{C}_{3} \mathrm{v}\right)$

Die Anhänger Amsdorfs vergleicht Hoffman mit „schlůpfferigen eel odder solcher art fisch“, "nottern / scorpion[en] vnd [...] schlangen“ $\left(\mathrm{C}_{3} \mathrm{r}\right)$, „lůgen meuler“ $\left(\mathrm{C}_{3} \mathrm{v}\right)$, ,scorpion geister[]“ $\left(\mathrm{C}_{3} \mathrm{v}\right)$ und „blut teuffel[]“ $\left(\mathrm{C}_{3} \mathrm{v}\right)$ oder einer Schar von Eseln oder Kühen, den „io brůder / wenn einer y a schreyet / so schreyen sie all y a / wenn ein Kue biset / so bisen sie alle" $\left(\mathrm{C}_{3} \mathrm{r}-\mathrm{C}_{4} \mathrm{r}\right) .{ }^{563}$ Die Vielzahl der beleidigenden Bezeichnungen und Vergleiche zielt darauf ab, dass der Gegner schließlich mit der durch sie hervorgerufenen Stimmung zu einer unzertrennbaren Einheit verschweißt wird, denn ein „wichtige[s] Kampfmittel im Schlagabtausch ist [...] die Einbettung der pejorativen Prädikation, die weniger beleidigen als unglaubwürdig machen soll, in einen aggressiv aufgeladenen Argumentationszusammenhang [...]." ${ }^{664}$ Auf diese Weise trägt die Wahl

geist“ (A4v, BIr, B2r \& C2r), „lieber laruen geist“ (BIr \& $\mathrm{C}_{2} r$ ), „auffgeblosen nasengeist“ (BIv), „yhr losen nasen geister“ (C2v).

${ }_{563}$ Hoffman nimmt hier die bereits populäre anti-katholische Esels-Polemik auf: „So machte man sich lustig über die ,vollen und faulen Mönche und Pfaffen“ und der Vergleich mit dem bequemen Esel war deshalb - treffend - bevorzugt, zumal auch das Chorsingen der Mönche mit dem Geschrei der Esel verglichen wurde.“ Lepp (I908), S. I35. Lepp nennt an dieser Stelle „Papstesel“, „Choresel“ und „Klosteresel“ als die prominentesten Schimpfwörter.

${ }_{564}$ Stuhlmann (2010), S. 32. 
der negativen Semantik aus den unterschiedlichen Bereichen dazu bei, eine aggressive Atmosphäre zu konstruieren, dessen dunkle Wirkung nicht Hoffman, sondern Amsdorf als Urheber zugerechnet wird.

Auf den letzten zwei Seiten von Nasen geist ergreift Hoffman abschließend auch das Wort gegen seinen zweiten Widersacher Marquard Schuldorp, mit dem er bereits seit ihrer gleichzeitigen Tätigkeit am Kieler Dom in einem mündlichen Streit stand. Mit dem Wechsel des polemischen Objekts, geht auch ein Umschwung der Beleidigungen einher. Das vorher nur einmalig verwendete Wort ,Blut ${ }^{\star}$ steht $\mathrm{ab}$ da $-\mathrm{z}$. T. kombiniert mit, Teufel ${ }^{1565}$ - im Mittelpunkt fast sämtlicher Beschimpfungen: Hoffman nennt seine Gegner in der Mehrzahl „blutteuffelische[...] geister“ und „blut teuffel[...] “ ( $\left.\mathrm{C}_{3} \mathrm{v}\right)$, die der „lose auffgeblasene blut teuffel hat [...] besessen / der treibt solche spil ynn [ihnen] / die [sie] nu gern das Euangelion widder schendeten / wenn nicht Gott so reichlich die erkentnis hett ausgeteilt" (C $3 \mathrm{v})$. Der direkt angesprochene Marquard Schuldorp wird zum „blůtling“ ( $\left.\mathrm{C}_{4} \mathrm{r}\right)$, der das Evangelium durch das eigene Blut geschändet habe. Hoffman stellt mit seiner Wortwahl und seiner Formulierung die kontextuelle Referenz auf die Geschehnisse um Schuldorps Heirat mit der Tochter seiner Schwester (vor Beendigung des Jahres I 525 ) her, die bei der Bevölkerung und innerhalb der Kirche auf große Proteste gestoßen waren. Schuldorp hatte mit der Eheschließung nicht nur gegen das Zölibat, sondern auch gegen die Inzestgesetze verstoßen. Vor dem Hintergrund des Tumults um diese Heirat sind Hoffmans Andeutungen für die Kieler Leserschaft, aber auch für Leser über die Grenzen Kiels hinaus leicht zu dekodieren gewesen. Aber Hoffman geht hier nicht nur ad personam vor, sondern auch ad hominem. Hoffman schreibt:

du hast einst das Evangelion geschendt durch dein eigen blut / das doch ym gantzen newen Testament nicht gehort ist / also wolstu ytzt auch gerne thun dem wort vnd Euangelio / das ich nu v. iar geprediget hab / Nein mein blůtling / es sol dir ab Gott wil an mir feilen“. ( $\left.\mathrm{C}_{4} \mathrm{a}\right)$

Hoffman stützt sich damit auf die Verteidigungsschrift Schuldorps, ${ }^{566}$ in der das Beispiel Abrahams von Luther und Amsdorf zur Rechtfertigung

${ }_{565}$ Zum Schimpfwort ,Blutteufel' siehe Anmerkung 467.

${ }_{566}$ Schuldorp hatte sich von Luther und Amsdorf die Rechtmäßigkeit seiner Ehe bestätigen lassen, die dann mit einer Stellungnahme seinerseits zusammen I 526 unter dem Titel Grundt und orsake worup Marquardus Schuldorp hefft syner suster dochter thor ehe genamen [...] gedruckt wurden. Vollständige Titelangabe und weitere Informationen bei Anmerkung 490. 
herangezogen wird. Schuldorp selbst bringt das I 8. Kapitel im 3. Buch Mose (Leviticus) als Beweis, in dem die verbotenen Eheverbindungen aufgezählt werden, in denen die Nichte nicht genannt wird. Vorausgesetzt, dass die Leserschaft auch diesen Hinweis interpretieren konnte, funktioniert Hoffmans Polemik hier auch ad hominem, da er sich auf Äußerungen Schuldorps bezieht, die als Indiz für die Disqualifizierung Schuldorps bezüglich der Kenntnis des Evangeliums gedeutet wird.

Neben einer Fülle von Schimpfnamen und -wörtern gebraucht Hoffman in seinen Schriften auch auf andere Weise Anschaulichkeit und Bildhaftigkeit für seine Polemik. Im Vergleich zu Amsdorfs Texten zeigt sich die verwendete Sprache bei Hoffman wesentlich gemeinsprachlicher und lebhafter. In Bezug auf die unterschiedliche Verwendung von Metaphern, Vergleichen, Wortwitz, Redewendungen und Sprüchen scheinen die Ergebnisse Tomothy Nelsons (für Johannes Nas' antilutherische Polemik) auch auf die Texte Amsdorfs und Hoffmans zuzutreffen:

Das Vorkommen der Verdichtung von Redewendungen und Sprüchen, als Glossen oder Einschübe in Texte kleineren Umfangs, ist eine Selbstverständlichkeit in der Polemik des I6. Jahrhunderts. Um den Gegner zu überrumpeln bzw. mit den Worten Wolfgang Pfeifers ,zu vernichten', zog man eine Fülle von Zitaten und alten Weisheiten für die Argumentation heran. [...] Je sachlicher die Diskussion, desto seltener begegnet man ihnen; je polemischer der Ton, desto häufiger treten sie in Erscheinung[. $]^{567}$

Hoffman inszeniert den Streit als einen, der im Höchstmaß persönlicher Natur ist, in dem er sich als einer der Hauptakteure für die göttliche Wahrheit mit der gesamten Kraft seiner Seele einsetzt. Amsdorf hingegen distanziert sich davon, emotional involviert zu sein, und inszeniert sich als überlegenen, sachlich agierenden Theologe. Auch bei Hoffman scheint die Polemik mit bildhafter Sprache zu korrelieren:

Der laruen geist sagt / er woll bey dem einfeltigen sinn bleiben / ist recht gesprochen / Einfeltig ist dein sinn gnug / narheit zu speyen gegen Gotis krafft vnd wort / aber Gótliche einfeltigkeit wird ynn diesem narrenfex nicht gespưrt / sondern es geht yhm eben nach der Fabel / die vom Fux laut / der gutte birnen auff einem baum sahe / vnd mit seinem stertz dran schlug / da sie nicht fielen / sprach er / ich wil yhr auch nicht / so sein die einfeltigen narren geister auch / die so nasen geistich von der einfalt reden / der sie nie

${ }_{567}$ Nelson, Tomothy C. (1990): „Oh du armer Luther... “ Sprichwörtliches in der antilutherischen Polemik des Johannes Nas (I534-I590). Diss. Uppsala: Uppsala universitet, S. 92. 
sein noch kommen $v \bar{n}$ kommen yhr auch nicht noch / Die rechten einfalt der Gơtlichen weisheit ist diesen laruen geistern ein nasen růmpffen / nach solt mancher meinen der es nicht besser verstůnd / wenn solche laruen geister yhr o̊des loses geschwetz aus scheumpten / es were Gottis einfalt / Mein lieber lůgen geist / da ist Gottis wort ein edler golt stein / darauff wir armen auch ytzt den schaum vor dem golt vnd silber kennen kónnen aus Gottis gnaden.“ (A $4 \mathrm{v}-\mathrm{B}$ Ir, Hervorhebungen K. L.)

Anhand dieser kurzen Textstelle lässt sich beispielhaft zeigen, wie die Polemik gegen Amsdorf sprachlich realisiert wird. Hoffman verdreht die Aussage seines Kontrahenten bezüglich des „einfeltigen verstandt[s] “, 568 und spielt mit der Polysemie des Wortes, einfältig' und den zwei Synonymen ,Verstand' und ,Sinn‘. Was bei Amsdorf zum einen noch positive, edle Einfalt im Sinne einer Absage an den Menschenverstand und zum anderen Lob des einfachen Schriftsinns war, wird in Hoffmans Text zur bloßen Dummheit und Naivität, die den Blick für die wahre Göttlichkeit verhindert. Der Vergleich Amsdorfs mit dem Fuchs aus der Fabel vom Fuchs und dem Birnenbaum, ${ }^{569}$ der das eigentlich Gute (die Birnen) als nicht erstrebenswert deklariert, nachdem er dieses Gute nicht erreichen konnte, mutet spöttisch an: Amsdorf wird dadurch nicht nur kritisiert, sondern auch - und weitaus stärker - verhöhnt und lächerlich gemacht. Durch die Zuhilfenahme des Sprichworts gelingt dies besonders gut, denn Sprichwörter „setzen ein kollektives Einverständnis voraus, das sie im Moment der Benutzung perpetuierend wieder herstellen. " 570 Das Sprichwort beinhaltet dementsprechend ein vorgefertigtes Urteil, dass die hämische Wirkung unterstützt.

${ }_{568} 68$,Bey diesem einfeltigen verstandt / welchen ewer Melchior ein vnuerstandt no̊met / den vns der einfeltige / vnuerstendige Christus ynn der einfeltigen schrifft gegeben hat / wöllen wir bleiben / vnd Melchior Hoffman mit seinem hohen verstandt / den yhm der hochuerstendige listige Satan eingegeben hat / faren lassen / Vns als sympeln genůget wol an der sympeln / einfeltigen leer Christi [...] Wir wöllen die klugen / scharpffsynnigen spitzlinge sich mit der scharpffsynnigen leer bekümmern lassen / aber wir wo̊llen vns fur yhn hůten als fur dem teuffel selbst“ (FP, BIr).

${ }_{569} \mathrm{Zu}$ der Fabel mit dem Fuchs siehe Burkard Waldis' Fabelsammlung, die I 536-40 geschrieben und I 548 gedruckt wurde. Titel: „Die lxxiij. Fabel / Vom Fuchß / vnd einem Byernbaum“. Waldis, Burkard (20II): Esopus. 400 Fabeln und Erzählungen nach der Erstausgabe von I 548. 2 Bde (I. Teil: Text, 2. Teil: Kommentar). Hg. von Ludger Lieb, Jan Mohr \& Herfried Vögel. Berlin \& New York: De Gruyter, Bd. I, S. 297 f.; Bd. 2, S. 224 f.

570 Lobenstein-Reichmann (2013), S. I 47. 
Solchen wirksamen Spott - wirksam, da er zumeist an (Sprach-)Witz gekoppelt ist ${ }^{57 \mathrm{I}}$ - trifft man in Nasen geist mehrfach an: An anderer Stelle schreibt Hoffman z. B., dass Amsdorf „einen schilt mo̊ch[]t erlangen / aber die esels oren ragen achter diesem schilt erfur / die werden aus Gottis gnaden recht troffen werden.“ (B2v) Er antwortet seinem Widersacher hämisch „Weine nicht lieber Amsdorff“ (CIr) auf den Vorwurf, er habe seinen Namen geschändet mit der Verbreitung falscher Gerüchte. ${ }^{572}$ Das semantische Wortfeld SAGEN in Nasen geist ebenso wie in Dat Nicolaus Amsdorff - stellt einen besonders reichen Fundus an bildhaften Ausdrücken dar. In Nasen geist lässt Hoffman Amsdorf quaken (A4r), „narheit [...] speyen“ (A4v), ausschäumen, "welch so ein öde stanck an tag stelt / damit man wol ratten vnd meusen vergeben kůnd“ ( $\left.\mathrm{B}_{I V}\right)$, „her als ein go̊ckler [gokeln]“ $\left(\mathrm{A}_{3} \mathrm{r}\right)$ und „lalle[n] / als einer der truncken / odder ynn die kindheit kommen ist“ (A2v). Indem Hoffman Amsdorfs Art zu sprechen mit Tierlauten oder dem Äußerungsvermögen eines Betrunkenen oder Kindes vergleicht, entstehen komische Bilder, die die Polemik lebhafter machen. Es ist anzunehmen, dass Hoffman mehr an eine mündliche als an eine schriftliche Lektüre gedacht hat, denn sein Stil ist einer mündlichen Sprechsituation durch die konzeptionelle Mündlichkeit näher. ${ }^{573}$ Zeitgenössische Vorbilder, wie z. B. Luther, mögen ebenfalls zu seiner scharfen und bildhaften Polemik beigetragen haben. Zudem mag Hoffman mit seiner anschaulichen Polemik das im I6. Jahrhundert sehr übliche laute Vorlesen vor einem vermutlich überwiegend städtischen

${ }^{571}$ Nelsons Untersuchungen bestätigen das polemische Potential von Fabeln, Redewendungen und Sprichwörtern, die auch bei Hoffman gelegentlich anzutreffen sind: „Einzelergebnisse können nicht angeführt werden; es soll genügen, mit Goedeke festzustellen, dass die Fabel (und das Sagwort) fast dafür erfunden schienen, ,um als polemische Waffe gehandhabt zu werden“ (S. I I 5).“ Nelson (I990), S. $293 \mathrm{a}-\mathrm{b}$.

572 „ob das die art des heiligen geists sey / das er seinen nechsten so leichtlich vmb eines stoltzen worts willen fur der gantzen welt schendt / lestert vnd dem teuffel gibt / Ein Christ hilfft seines nechsten sunde decken / aber Melchior lesset sich nicht daran genůgen / das er die sunde auffdeckt / offenbart / vnd seinen nechsten zu schanden macht / sondern schendt vnd lestert auch yhn mit offentlichen erdichten lugen / wenn das Gotes geist thut / so weis ich nicht was der teuffel thut“ (FP, B2v).

573 Vgl. Koch, Peter \& Wulf Oesterreicher (I994): „Schriftlichkeit und Sprache“. In: Günther, Hartmut \& Otto Ludwig (Hg.): Schrift und Schriftlichkeit. Writing and Its Use. Ein interdisziplinäres Handbuch internationaler Forschung. An Interdisciplinary Handbook of International Research. Bd. I. Berlin \& New York: De Gruyter, S. 587-604. 
(vorwiegend kaufmännischen und handwerklichen) Publikum im Kopf gehabt haben. ${ }^{574}$

Hoffmans zweite Schrift Nasen geist kann zusammenfassend als eine Steigerung der ersten polemischen Schrift gelten und löst Hoffmans Versprechen auf ein ordentliches „Valete“ ein. Quantitativ und qualitativ wird die Polemik in Dat Nicolaus Amsdorff weit überboten. Hoffman nutzt in seinem zweiten Schreiben mehr die Möglichkeiten, die ihm bei einer Replik in einem offen polemisierenden Schriftwechsel zur Verfügung stehen, wie z. B. die Verarbeitung von sowohl kontextuellen als auch intertextuellen Hinweisen. Er verwendet sämtliche Informationen, die ihm zur Verfügung stehen, zweckgerichtet für z. B. die Konstruktion des Eigen- und Fremdimages oder die Überprüfung und Widerlegung der gegnerischen Aussagen. Nicht etwa die Aufhebung des polemischen Antagonismus oder gar die Überredung des Gegners, die Differenzen fallen zu lassen, sondern die Umdeutung bzw. der Sieg im Kampf um die Deutungshoheit über den polemischen Antagonismus ist das Ziel der Inszenierung. Für die Umsetzung dessen macht Hoffman Gebrauch von der Bibel, von Schimpfnamen, Invektiven und bildhafter Sprache. Insbesondere die ironische Verzerrung oder angebliche Entlarvung Amsdorfs spielt dabei eine wichtige Rolle, die durch den gezielten Einsatz jeweils gewählter kontextueller oder intertextueller Referenzen auf die Bibel oder die gegnerische Schrift gelingt.

\section{Amsdorfs Reaktion auf Hoffmans „Valete“ Nasen geist}

Von dem polemischen Stil scheinbar unbeeindruckt, antwortet Amsdorf auf die Beschimpfungen Hoffmans mit bewusst gelassener Haltung und erklärt in seiner Replik, [d]as Melchior Hoffman / nicht ein wort auff

574 Es ist anzunehmen, dass sich Hoffmans Anhänger in Kiel ähnlich zusammensetzten. Die Quellenlage lässt jedoch lediglich Vermutungen zu. Vgl. dazu: „Die livländischen Hoffmanianer rekrutierten sich aus zwei heterogenen Schichten der Bevölkerung, die auch an allen Bilderstürmen führend beteiligt waren: aus den jüngeren deutschen Kaufgesellen, die in der Regel aus begüterten Familien stammten und in der angesehenen Schwarzhäuptergilde zusammengeschlossen waren, und aus den undeutschen städtischen Plebejern.“ Deppermann (I979), S. 77. In Stockholm wurde Hoffman „von den führenden deutschen Bürgern in der Stadt [unterstützt]: von dem Kaufherrn Gorius Holst, einem der reichsten Männer Schwedens, Hans Bökman, dem Kirchenvorsteher von St. Nikolai, Kort Piper, Lukas Bartscherer, Jürgen von Sotteren und Brand Schreiber." (Ebd., S. 80). 
[s]ein Büchlein geantwortet hat. ${ }^{575}$ Auf acht Textseiten konzentriert Amsdorf sich darauf, mit inszenierter Überheblichkeit zu zeigen, „wie der Sathan ynn diesem Melchar Hoffman an allen schein / so wüeten vnd toben kan" (NEW, A2r). Amsdorfs kleine Schrift bezieht sich sogar auf beide Schriften Hoffmans, kommentiert aber lediglich den polemischen Ton der Schriften, ohne auf konkrete Argumente oder Textstellen einzugehen. Inhaltlich werden keine neuen Akzente gegen die Prophetie Hoffmans gesetzt. Stattdessen werden bereits verwendete Argumente wiederholt, um Hoffmans Lehre der baldigen Apokalypse zu entkräften. Trotz des im Vergleich weniger emotionalen Tons, zielt die Schrift Amsdorfs ebenfalls deutlich auf die Imagezerstörung Hoffmans ab. Die Polemik ist bewusst entschärfter, gezähmter und emotionsloser, der Kontrast zu Hoffmans „schelden fluchen vn̄ vormaledeien " (NEW, BIv) bewusst in Szene gesetzt. Amsdorfs polemische Waffen sind vielmehr Ironie, rhetorische Fragen und herablassende, verhöhnende Kommentare, die Hoffmans Person und Argumente ins Lächerliche ziehen.

Wie bereits erläutert, sollte Amsdorf mit dieser Schrift das letzte Wort in dem Streit zwischen den beiden haben. Die zweite Hälfte des Jahres I 528 war bereits angebrochen und der Schriftwechsel hatte länger als ein halbes Jahr angedauert. Dass Hoffman keine Antwort mehr verfasste, kann u. a. darauf zurückgeführt werden, dass der Streit einen Punkt erreicht hatte, an dem eine weitere Schrift nichts Neues gebracht hätte. Beide Kontrahenten hatten erneut auf dieselben Argumente zurückgegriffen, ohne neue Akzente zu setzen. Ausgehend von Hoffmans enthusiastischer Gesinnung wäre eine Antwort von ihm zwar höchst wahrscheinlich gewesen, wurde dann aber vermutlich durch die Verlagerung des Streits auf die Abendmahlsfrage, die Hoffman parallel durch seine mündlichen Predigten in Kiel aufgeworfen haben muss, verhindert.

575 Vollständiger Titel: Amsdorf, Nikolaus von (I 528): Das Melchior Hoffman / nicht ein wort auff mein Büchlein geantwortet hat. [Magdeburg]: Hans Bart. Paginierung: AIr-BIv (Seite nach dem Titelblatt leer). Kurztitel: Nicht ein wort. Die Quellenangaben bei Zitaten werden mit den Initialen NEW und der Folienangabe der Übersichtlichkeit halber in Klammern gestellt. 